\title{
LOAD AND THERMAL RESISTANCE OF SANDWITCHED STEEL-WOOD COMPOSITE WALLING SYSTEMS INFILLED WITH INNOVATIVE COMMERCIAL FORM MATERIAL
}

\section{By}

\author{
Ashok Kumar Yadav \\ Bachelor of Civil Engineering, Tribhuvan University, Nepal 1998 \\ Master of Science in Structural Engineering, Tribhuvan University, Nepal 2001
}

\author{
A Project \\ presented to Ryerson University \\ in partial fulfillment of the \\ requirements for the degree of \\ Master of Engineering \\ in the program of \\ Civil Engineering
}

Toronto, Ontario, Canada, 2017

(C) Ashok Yadav 2017 


\begin{abstract}
AUTHOR'S DECLARATION
I hereby declare that I am the sole author of this thesis. This is a true copy of the thesis, including any required final revisions.

I authorize Ryerson University to lend this thesis to other institutions or individuals for the purpose of scholarly research.

I further authorize Ryerson University to reproduce this thesis by photocopying or by other means, in total or in part, at the request of other institutions or individuals for the purpose of scholarly research.

I understand that my thesis may be made electronically available to the public.
\end{abstract}




\title{
LOAD AND THERMAL RESISTANCE OF SANDWITCHED STEEL-WOOD COMPOSITE WALLING SYSTEMS INFILLED WITH INNOVATIVE COMMERCIAL FORM MATERIAL
}

\author{
Ashok Kumar Yadav \\ Master of Engineering, 2017 \\ Civil Engineering, Ryerson University
}

\begin{abstract}
This research investigated the behaviour of sandwich profiled steel sheet composite wall (PSSCW) and oriented strand board composite wall (OSBCW) with infill commercial form material (CFM). The axial load behaviour of PSSCWs and OSBCWs having different height to width ratio and PSS/OSB-CFM connector spacing was analysed based on experimental results of strength, load-deformation response, load-strain development and failure modes. In addition, flexural behaviour of OSBCW and the thermal conductivity tests on PSSCW and OSWCW specimens were carried-out. The axial load capacity of PSSCW/OSSCW was increased by $946 \%$ to $1714 \%$ compared to walls without in-fill and decreased with the increase of height to width and connector spacing to height ratio. The existing analytical equations were found to over predict the axial load capacity of both PSSCWs and OSBCWs. The recommendation of this research will understand the axial, flexural and thermal behaviour of PSSCW/OSBCW with CFM infill for practical building applications.
\end{abstract}




\section{ACKNOWLEDGEMENTS}

I would like to express my sincere appreciation to my supervisor Dr. Khandaker M. Anwar Hossain for his continuous support, encouragement and guidance in this project. He has set a high standard for the conduct of this study and his valuable suggestions and guidance have provided me the motivation needed to complete this research project.

I would like to thank Mr. Nidal Jaalouk, Mr. Khaleel Stoney and all other lab staff who assisted me in fabrication and performing physical testing in the structures laboratories. I also thank my family and friends for their support and encouragement. Their encouragement provided the often-needed motivation and inspiration for me to push through the hard times. I would also like to thank the M.Sc. students of Civil Engineering notably, Sandeep Parajuli for his great help in fabrication and casting.

Last but not least, I thank my dearest wife for her continued support throughout my study. I would also like to acknowledge the contributions of my classmates who have helped me in the experimental study of this project. 


\section{DEDICATION}

To my mother for her ongoing love and support and to my father who could not see this project completed. 


\section{TABLE OF CONTENTS}

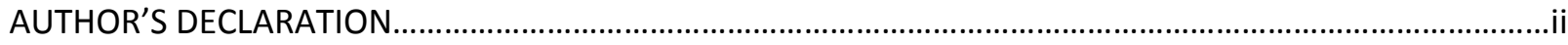

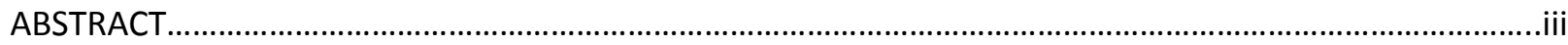

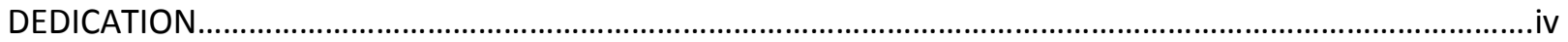

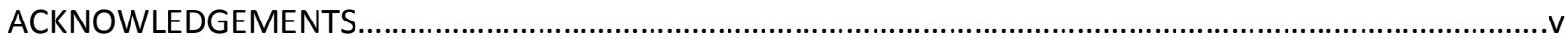

LIST OF TABLES

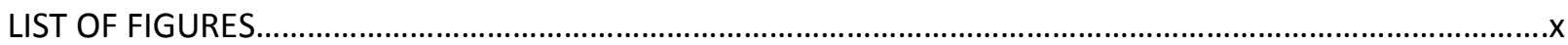

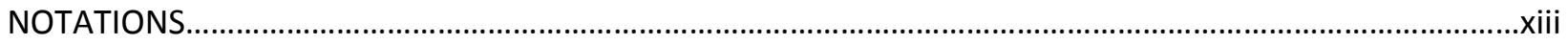

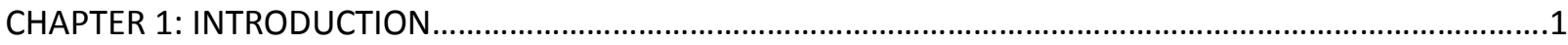

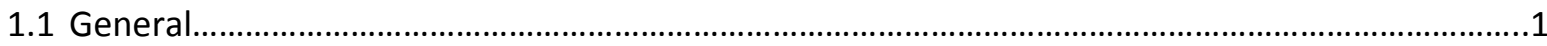

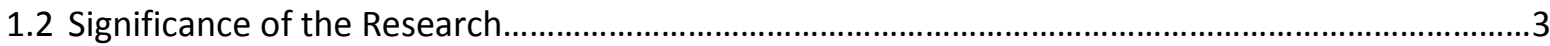

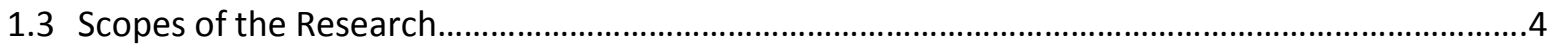

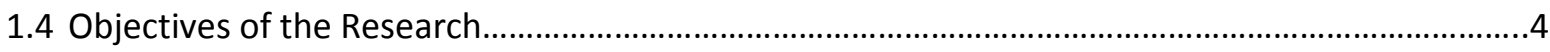

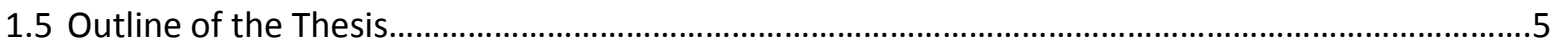

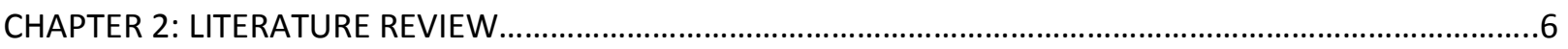

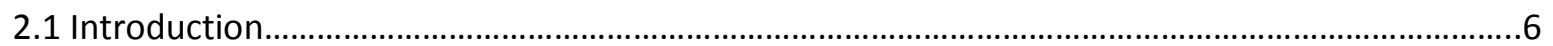

2.2 Research and Development of Composite Walling System.........................................................

2.3. Axial Load Resistance of DSCW System- Existing Analytical Equations..........................................12

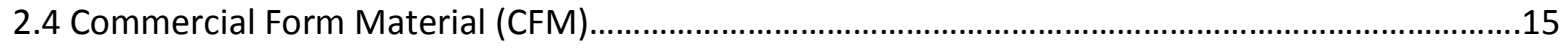

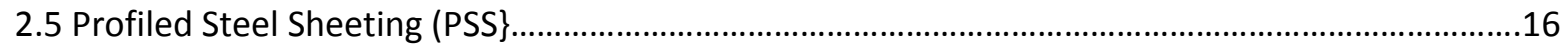

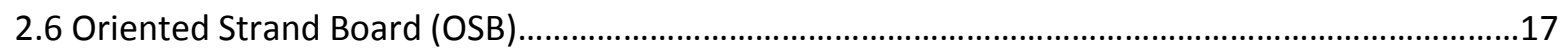

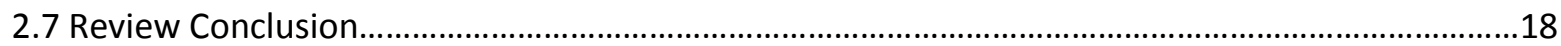




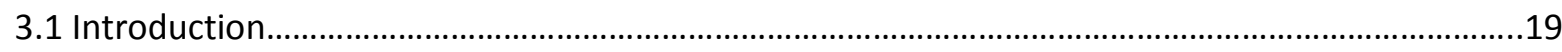

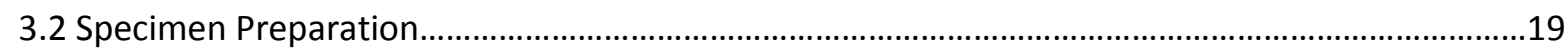

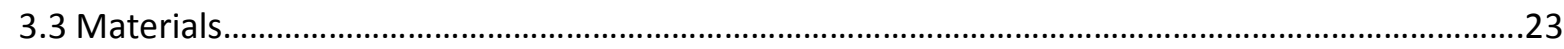

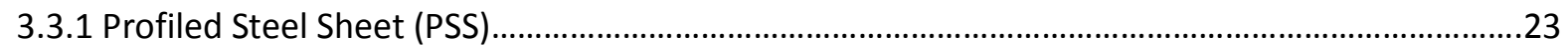

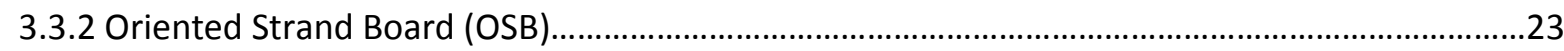

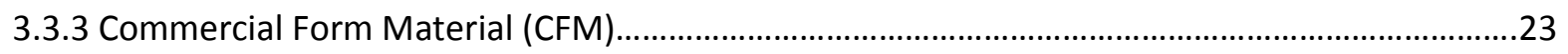

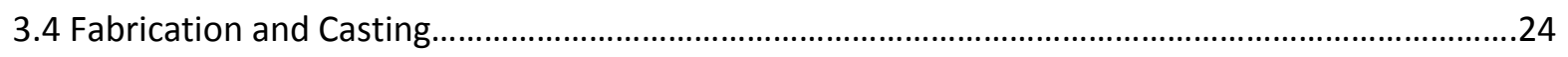

3.5 Compressive Strength and Modulus of Elasticity of Commercial Form Material...........................25

3.6 Flexural Strength of Commercial Form Material.............................................................................27

CHAPTER 4: EXPERIMENTAL INVESTIGATION ON COMPOSITE WALLING SYSTEM........................................29

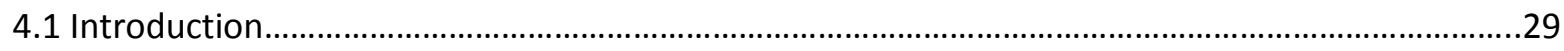

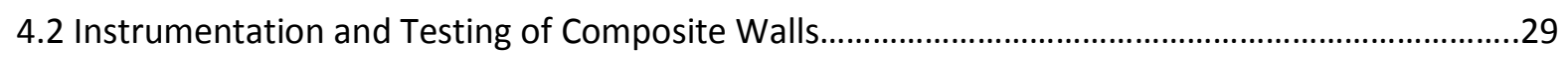

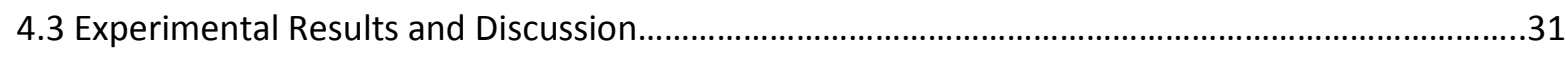

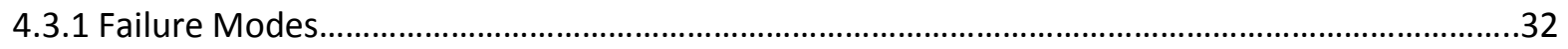

4.3.2 Axial Load-deformation Characteristics of Composite Walls.......................................................36

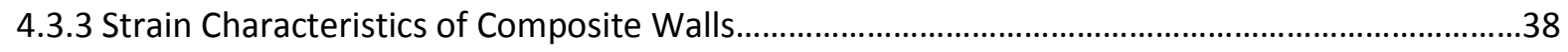

4.3.4 Load-transverse Displacement Response .................................................................................41

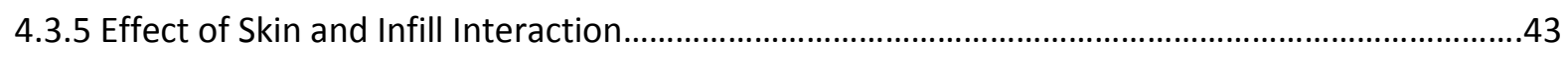

4.3.6 Effect of Height/Slenderness of Wall........................................................................................

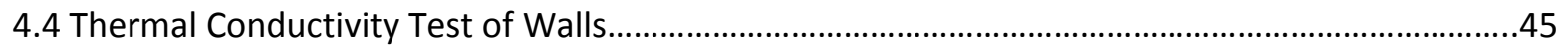

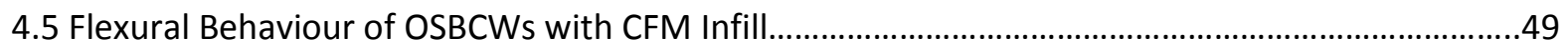




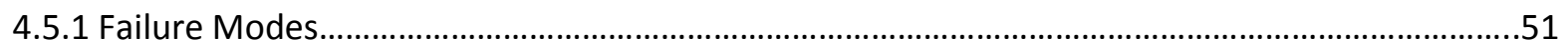

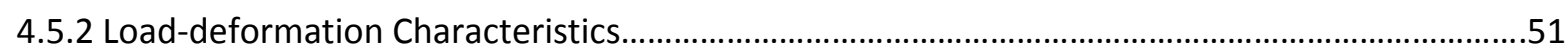

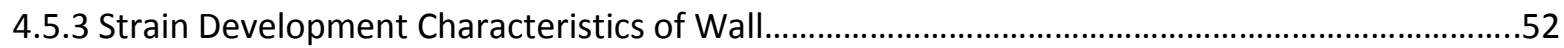

CHAPTER 5: THEORETICAL AXIAL LOAD CAPACITY OF COMPOSITE WALLS...............................................53

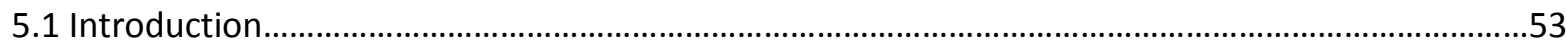

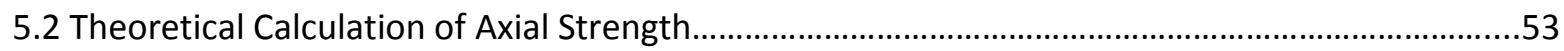

5.2.1 Profiled Steel Sheeting Composite Wall (PSSCW) with CFM Infill..............................................53

5.2.2 Oriented Strand Board Composite Wall (OSBCW) with CFM Infill..............................................54

5.3 Analysis of Theoretical and Experimental Axial Load Capacity of Composite Wall........................55

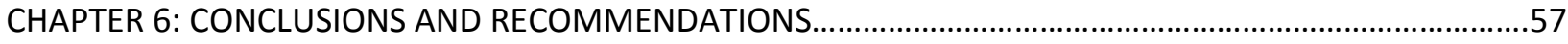

6.1 Conclusions

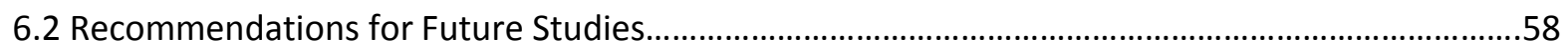

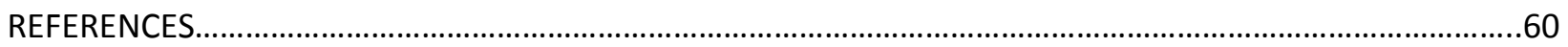




\section{LIST OF TABLES}

Table 2.1- Properties of typical oriented strand board................................................................................18

Table3.1- Geometric dimension and variables of specimen........................................................................20

Table 3.2- Compressive strength and modulus of elasticity of commercial form material........................27

Table 3.3- Flexural strength of commercial form material.......................................................................28

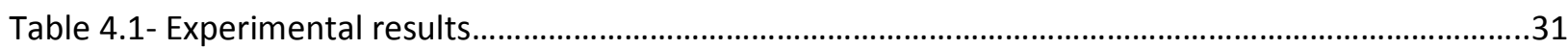

Table 5.1- Comparison of experimental value with analytical value of profiled steel sheet composite

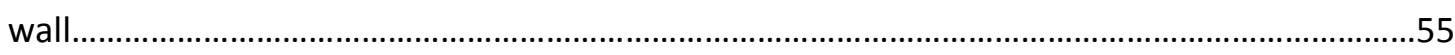

Table 5.2- Comparison of experimental value with analytical value oriented strand board composite

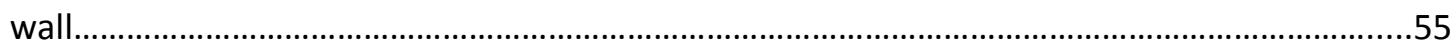




\section{LIST OF FIGURES}

Figure 1.1- Double skin composite walling systems..................................................................................

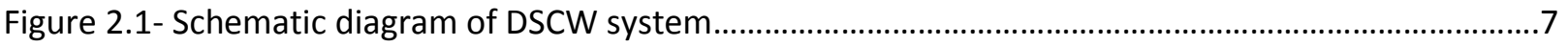

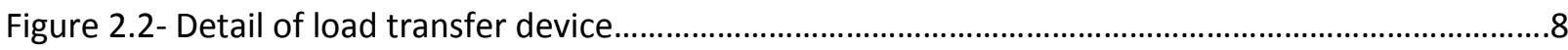

Figure 2.3- Axial load response of pierced and non-pierced wall............................................................

Figure 2.4- Effect of size parameters of hole on strength and deformation of walls.................................10

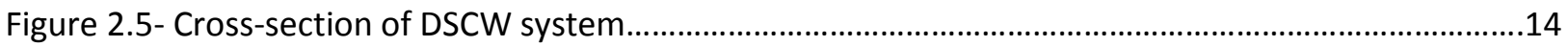

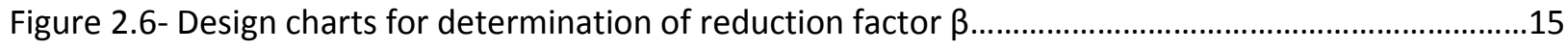

Figure 2.7- Profiled sheet of commercial name P-3615 and P-3606 .......................................................16

Figure 2.8- Profiled sheet of commercial name P-2436 and P-2404......................................................17

Figure 2.9- Profiled sheet of commercial name P-3615 composite and P-3606 composite........................17

Figure 3.1- Profiled steel sheet composite walls showing dimension, connectors and strain gauge

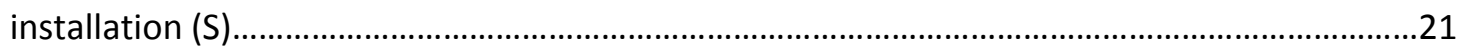

Figure 3.2- Oriented strand board composite walls showing dimension, connectors and strain gauge

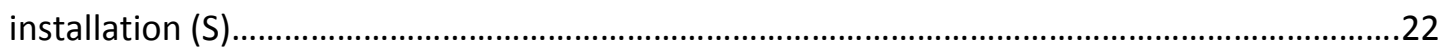

Figure 3.3- Geometry and dimension of steel profiled sheet...............................................................23

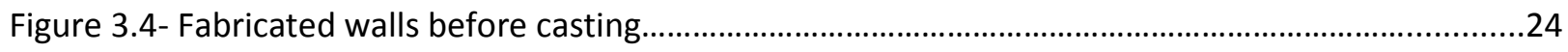

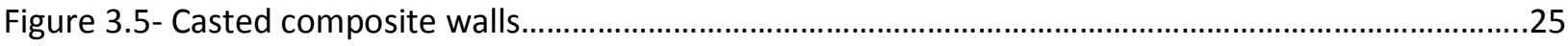

Figure 3.6- Typical stress-strain diagram of commercial form material....................................................26

Figure 3.7- Linear part of stress-strain diagram of commercial form material...........................................26

Figure 3.8- Four point loading test of commercial form material beam.....................................................27 
Figure 3.9- Load-mid span displacement response of sample 1.

Figure 4.1- Axial load test setup of wall on MTS machine. .30

Figure 4.2- Position of LBDT (L1, L2, L3 and L4) during testing of walls. .30

Figure 4.3- Failure modes of profiled steel sheeting composite wall. .33

Figure 4.4- Failure modes of oriented strand board composite wall 34

Figure 4.5- Failure modes of walls. .35

Figure 4.6- Load displacement behaviour of profiled steel sheet composite wall. .36

Figure 4.7- Load displacement behaviour of oriented strand board composite wall...... .37

Figure 4.8- Load strain behaviour of profiled steel sheet composite wall .39

Figure 4.9- Load strain behaviour of oriented strand board composite wall .40

Figure 4.10- Load-transverse displacement behaviour of composite wall..... 42

Figure 4.11- Load capacity enhancement due to interaction between OSB and infill form material.

Figure 4.12- Slenderness effect comparison of wall 1 with wall 2 and wall 6 with wall 7 .44

Figure 4.13- Effect of height to width ratio and connector spacing to width ratio on axial load of profiled sheet composite wall......

Figure 4.14- Effect of height to width ratio and connector spacing to width ratio on axial load of OSB composite wall.

Figure 4.15- Test set up for thermal conductivity test of wall .46

Figure 4.16- Wall dimensions and schematic of test set-up showing specimens showing thermocouples (TC1-TC3).

Figure 4.17- Thermocouple temperature data at larger thickness of PSSCW wall 1 . .47

Figure 4.18- Thermocouple temperature data at thinner thickness of PSSCW wall $1 .$. .48

Figure 4.19- Thermocouple temperature data of OSBCW wall 5 48 
Figure 4.20- Comparison of \% of temperature differences between two faces of OSBCW with PSSCW...49

Figure 4.21- Wall 11 showing geometry and dimension.......................................................................50

Figure 4.22- Four point flexural load test set-up for OSBSW wall................................................................50

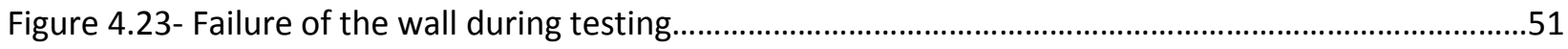

Figure 4.24- Flexural load displacement behaviour of composite wall.......................................................52

Figure 4.25- Load strain behaviour of composite wall................................................................52

Figure 5.1- Ratio of expt. to predicted load for profiled steel sheet wall with commercial form material

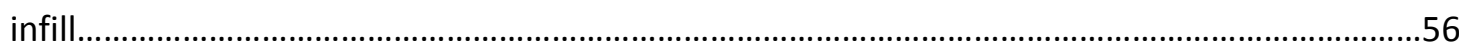

Figure 5.2- Ratio of expt. to predicted load for oriented strand board wall with commercial form material

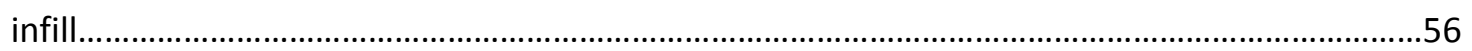




\section{NOTATIONS}

\begin{tabular}{|c|c|}
\hline PSSCW & Profiled steel sheet composite wall \\
\hline OSBCW & Oriented strand board composite wall \\
\hline DSCW & Double skin composite walling \\
\hline PSS & Profiled steel sheet \\
\hline OSB & Oriented strand board \\
\hline CFM & Commercial form material \\
\hline N & Axial load capacity of the composite wall \\
\hline$f_{c u}$ & Cube strength of concrete \\
\hline$A_{c}$ & Cross-sectional area of concrete core \\
\hline$f_{s y}$ & Yield strength of steel \\
\hline$A_{s}$ & Cross-sectional area of steel sheeting \\
\hline D & Overall thickness of wall \\
\hline$P$ & Pitch of profiles in wall \\
\hline$A_{c p}$ & Cross-sectional area of concrete in one pitch of wall \\
\hline b & Outer flange width \\
\hline $\mathrm{t}$ & Thickness of steel profiled sheet \\
\hline$\alpha$ & The reduction factor for the concrete capacity \\
\hline$\beta$ & The reduction factor for the steel capacity \\
\hline$A_{f}$ & Cross-sectional area of commercial form material core \\
\hline
\end{tabular}




\section{CHAPTER 1}

\section{INTRODUCTION}

\subsection{General}

Composite system is widely used as wall or slab in construction. Profiled steel sheet was first used in composite slab in America in early 1950 as a permanent formwork in the construction stage and as reinforcement in the service stage. Later on it was introduced in United Kingdom in 1970 and after that became popular form of composite floor system (Wright and Gallocher 1995). This system is called Fast rack construction and had grown rapidly since 1980 (Hossain and Wright 2004). Many researches on composite floor have been conducted over the last decades to determine its advantage (Wright and Gallocher 1995). After the success of composite floor system, composite walling system was introduced (Hossain and Wright 2004). It consists of vertically aligned profiled steel sheeting in fill with concrete as shown in Figure 1.1. Like composite flooring, the advantages of composite walling are related to speed and convenience of construction. It was originally developed to use as a shear wall or core wall to strengthen steel frame building structure. However it can also be used in concrete frame building, basement and blast structures. Steel plates with loose sand or stone infill composite system have also been used as wall in missile and blast resistant structure (Hossain 2000; Hossain et al 2015). Axial load capacity of composite wall is affected by the bond between steel sheeting and infill concrete particularly in the area near to the point of load application (Wright 1998).

Composite walling system has many advantages when used in building system. Steel sheeting stabilises the building frame immediately after it is fixed and acts as permanent formwork for infill material (Wright 1998; Hossain and Wright 2004; Hossain 2000; Hossain et al 2015). In the construction stage, it acts as a bracing to the building frame against wind destabilising forces. In the service stage, it acts as reinforcements (Hossain and Wright 2004). Confinement of concrete by steel sheeting increases its load caring capacity as well as fire durability (Taormina 2012; Akram 2014).

Axial, lateral and in-plane load are carried by both steel and concrete after the concrete gets hardened. The interconnection between profiled steel sheeting and concrete is the major factor in the composite action (Hossain 2000; Hossain et al 2015). The response of composite wall under axial loading is quite

different than composite slab. In composite wall, the problem is associated with the difficulty in transmitting the load between the still skins and the concrete core, buckling of the steel sheeting and 
reduction in concrete capacity due to profiling. The chemical bond between steel sheet and concrete is lost by axial loading at the interface due to lack of enough strain to develop force in the embossments which causes brittle failure at the interface (Hossain and Wright 2004; Hossain 2000; Hossain et al 2015). However the bond between concrete and steel sheeting can be improved by embossments or mechanical connector. Embossments contribute as longitudinal and transverse shear resistances at the interface of steel and concrete. The problem of load transfer is controlled by introducing extra shear connection devices at head and foot of the composite wall (Hossain and Wright 2004). The mechanical interconnection system at the interface of steel sheet and concrete may cause ductile or brittle failure of the composite system (Hossain 2000; Hossain et al 2015).

The interface of steel sheeting and concrete of composite wall behaves differently under in-plane shear than that under axial loading. Because geometry of profiling play vital role in providing mechanical bond if the chemical bond failed and steel tends to slide over the concrete. Hence transverse shear bond perpendicular to profiles is more effective than shear bond parallel to the profiles. Therefore shear resistance of composite wall depends on the transverse shear bond of profiles (Hossain and Wright 2004).

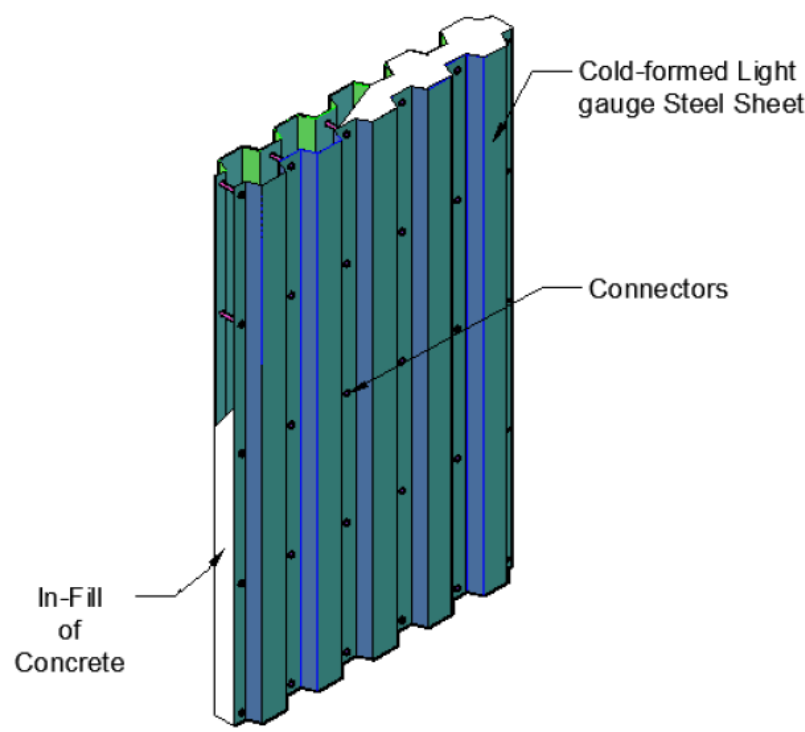

(a) Profiled steel sheet composite wall

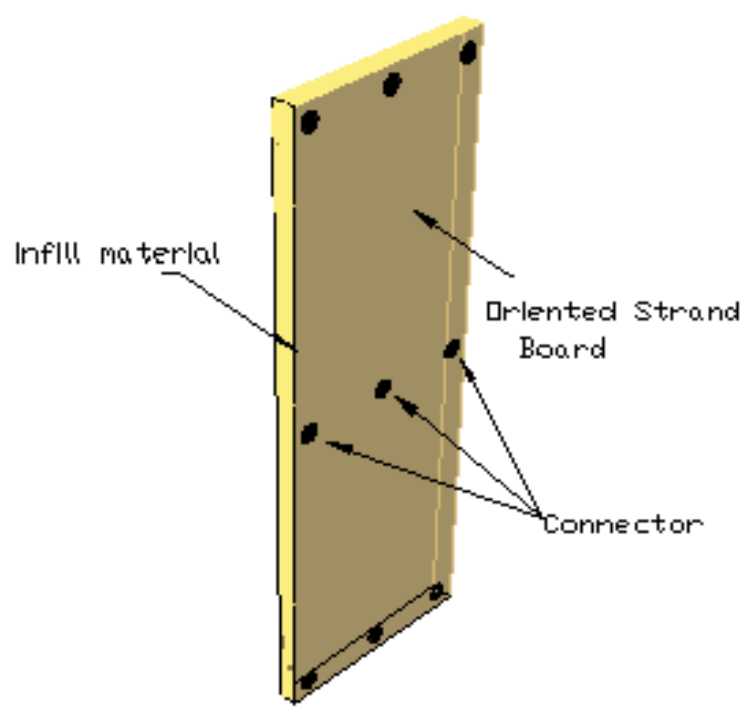

(b) OSB composite wall

Figure 1.1 - Double skin composite walling systems 
This experimental and theoretical research involved two sets of sandwich composite walling system made of two outer skin of profiled steel sheet or oriented strand board (OSB) with lightweight and fast setting commercial form material infill connected by mechanical connectors. This research investigated the axial load behaviour of profiled steel sheet composite wall (PSSCW) (Figure 1.1a) and oriented strand board composite wall (OSBCW) with CFM (Figure 1.1b) based on experimental and analytical investigations.

A new commercial form material (CFM) manufactured by Royal Adhesives and Sealants Canada, was used as infill material - as an alternative to concrete. CFM is a material with very high expansion capacity (requires very small quantity of material to produce required volume compared to conventional concrete), has much faster setting time (quick setting and ready for taken load within in an hour) and more convenient than concrete material (does not require water for its production). It can be used outside in summer and winter even when temperatures are as low as $-30^{\circ} \mathrm{C}$ or as high as $38^{\circ} \mathrm{C}$. However, it is recommended to keep form material bag at $22^{\circ} \mathrm{C}$ to $25^{\circ} \mathrm{C}$ for at least two hours before using it. The proposed PSSCW and OSBCW will provide much lighter and faster construction in addition lowering greenhouse gas emission due to the need of less transportation for moving lower volume of CFM material (with very high expansion capability) compared to huge volume of concrete materials needed for a specific project.

\subsection{Significance of the Research}

Many researches have been conducted to study the structural behaviour of profiled steel sheet composite wall (PSSCW) system in filled with concrete. Design guidelines and equations were developed based on experimental, analytical and numerical studies for strength and stiffness of the composite wall. However majority of previous study was based on the concrete as infill material. In this research, concrete is replaced by a new commercial form material (CFM). No research has been done on the structural behaviour of profiled steel sheet composite wall system in filled with that commercial form material and currently there are no design guide lines available. This research had focussed on the axial behaviour of PSSCWs and OSBCWs with CFM infill. In addition, flexural behaviour of OSBCWs and thermal behaviour of both OSBCWs and PSSCWSs with CFM had also been investigated. The outcome of this research will contribute to understand the structural and thermal behaviour of proposed composite walls with CFM infill. 


\subsection{Scopes of the Research}

This research was mainly focussed on the study of the axial behaviour of sandwich PSSCW and OSBCW with commercial form material infill. This study used different height of walls (to achieve different slenderness ratio) and different numbers of rows of connectors in experimental investigation. Walls without CFM infill were also tested. The axial response of composite walls was observed for different geometric dimensions and spacing of connectors. In addition, the failure modes, PSS or OSB skin-CFM infill interaction, axial-load displacement response and axial load-strain response of the composite walling system were investigated. Theoretical analyses were conducted to compares experimental axial strengths of composite walls to those obtained from existing analytical models. The flexural behaviour of OSBCWs was described based on experimental results of load-deflection response, load-strain response and failure modes. Thermal behaviour of OSBCWs and PSSCWSs were compared based on temperature development between heat exposed surfaces to unexposed surface based on temperature-time curves.

\subsection{Objectives of the Research}

The main objectives of this research were to:

- Perform experimental investigations on the mechanical properties (compressive strength, flexural strength, yield/ultimate strength and modulus of elasticity) of profiled steel sheet (PSS) and the commercial form material.

- Perform experimental tests on PSSCWs and OSBCWs with CFM infill under the axial loading to study the structural performance based on strength, deformation, strain development, PSS or OSB-CFM infill interaction and modes of failure.

- Conduct theoretical analyses on to compare axial strengths of composite walls derived from experiments with those obtained from existing analytical equations.

- Perform experimental test to study the thermal resistance behaviour of PSSCWs and OSBCWs with CFM infill.

- Perform experimental test to study the flexural behaviour of OSBCWs with CFM infill 


\subsection{Outline of the Thesis}

This research consists of six chapters which are outlined as follows.

Chapter 1 presents the brief introduction about new sandwich composite walling system with formed material infill compared to traditional concrete, research significance, scope and objectives of the research.

Chapter 2 presents a literature review of previous research work highlighting composite walling system emphasizing on performance and applications.

Chapter 3 presents the materials used for composite walling system, specimen fabrication, material testing to determine mechanical properties.

Chapter 4 presents the experimental investigation on composite walls, test results and analysis in terms of failure modes, load displacement, load strain, slenderness and infill skin interaction. It also includes thermal conductivity testing and flexural testing of composite walling system.

Chapter 5 presents the analytical method of calculation of load capacity of composite walling system and comparison with the experimental results.

Chapter 6 includes conclusions along with some recommendation for future research on composite walling system with commercial form material infill. 


\section{CHAPTER 2}

\section{LITERATURE REVIEW}

\subsection{Introduction}

This chapter includes the literature review on composite walling system and its behaviour. It describes the materials used, the research and development in this system. The behaviour of the system is reviewed based on strength, load deflection characteristics and failure modes.

\subsection{Research and Development of Composite Walling System}

Composite slabs with profile steel sheet were first introduced in America in early 1950 and later in United Kingdom in 1970. Following the success of composite floor system, composite walling system with was initially introduced as a shear wall or core wall in steel frame building structure (Hossain and Wright 2004). Many researches were conducted for the development of composite walling system under various loading conditions.

Wright and Gallocher (1995) studied the behaviour of double skin composite walling (DSCW) system (shown in Figure 2.1) in construction and service stage. DSCW consists of two skins of profiled steel sheeting with an infill of concrete. They proposed the construction methodology to reduce the lateral pressure of wet concrete on form work during construction stage and also conducted four pilot tests on wall element loaded axially. In the construction stage, lateral pressure on the wall was developed on the It was observed from the test that ultimate axial compression resistance of the wall was significantly less than the analytical fully composite failure load. The full axial compression resistance capacity of the composite wall was restricted by two major factors. The first factor was interface bond strength between concrete and commercially available profiled sheet and the second factor was the local buckling capacity of external profiled sheeting. 


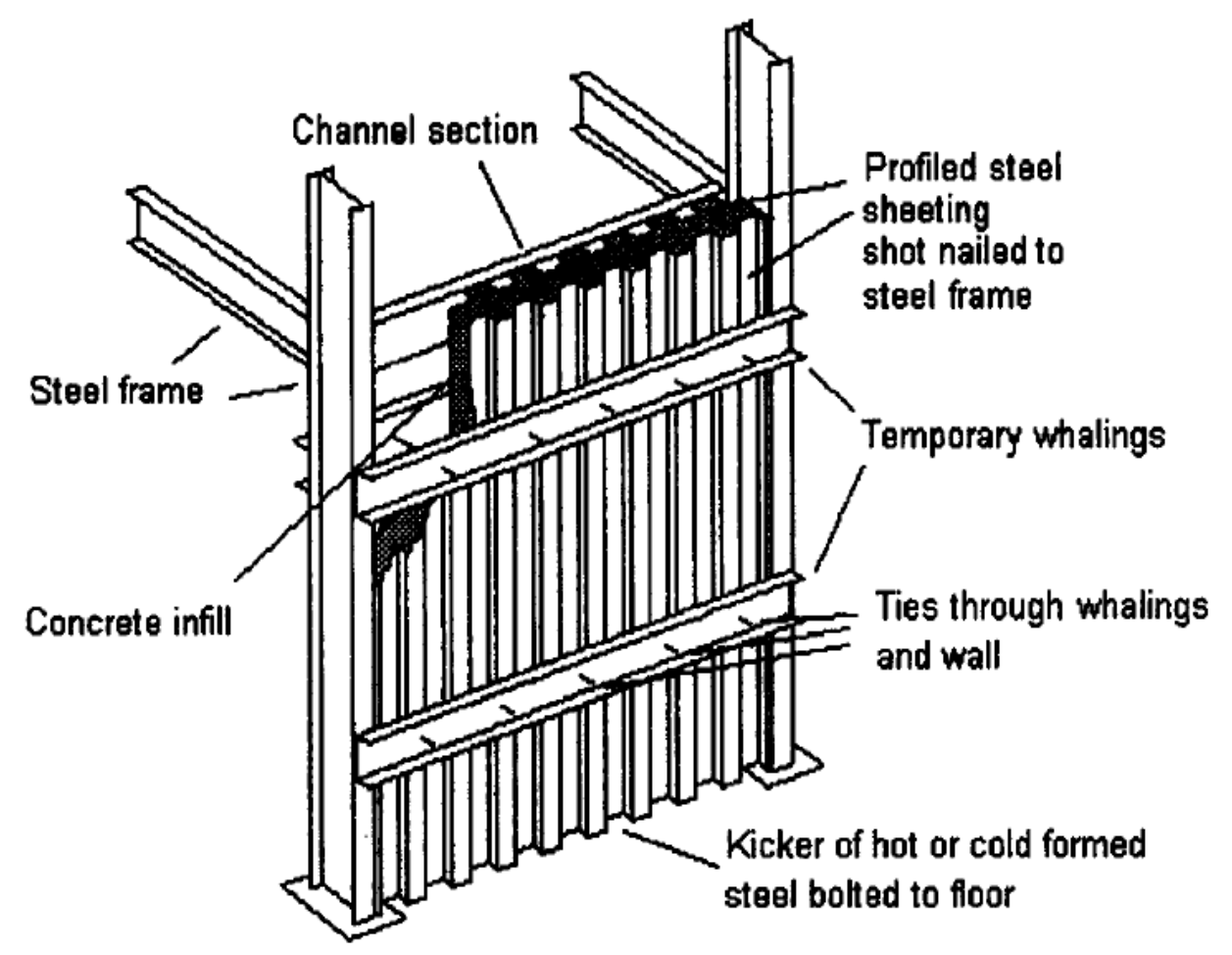

Figure 2.1- Schematic diagram of DSCW system (Hossain and Wright 2004)

The stiffness of the DSCW increases by infill concrete which acts as a bracing for metal sheets and prevents the buckling of metal sheeting. Metal sheeting provides confinement to the infill concrete which increases the load carrying capacity of the wall even after the concrete has cracked (Hossain et al 2013). Steel sheeting stabilise the building frame immediately after it is fixed and acts as permanent form work for infill material in construction stage. In the construction stage, the lateral pressure is developed on the metal sheet due to the wet concrete which is considerably greater in walling system than flooring system. Hence temporarily lateral supports are provided to resist this pressure. In the service stage, the wall acts as a composite unit and load is carried by both metal sheeting and concrete. Loading may be in the form of axial load, bending load and torsional load (Wright and Gallocher 1995). The strength and stiffness of the composite wall depend upon the material properties of metal sheet and concrete, geometry of the metal profile sheet, spacing between the metal sheets, bond between the metal sheet and concrete and the connection between wall and frames (Wright and Gallocher 1995; Hossain et al 2013).

Wright (1998) conducted the test of 13 full scale walls under axial load regime including 4 tests of his pilot study. It was observed from the test that the full yield stress in steel and concrete was not achieved. This was due to the buckling of component plate of the profiled sheeting and profiled shape of the 
concrete cross-section. Profiled shape of the concrete cross-section was unable to carry moments caused by eccentric loading and imperfections of the walls. Hence, he proposed reduction factor for concrete and steel in the theoretical calculation to make closer to the experimental result. It was also introduced load transfer device in some specimen to equally distribute load between steel and concrete along with the efficiency of embossments

Wright (1998) conducted test on twenty full scale wall specimen for the study of axial and bending behaviour composite wall. Fifteen wall specimens were tested under axial load pattern and five wall specimens were tested under combination of both axial and lateral loads. The test specimens were made by using different construction parameters and different modes of load application (through concrete, through steel and through both steel and concrete) was applied. Axial load capacity of the wall was found lesser than the squash load capacity. This was due to the early buckling of thin steel sheeting and difficulty in transferring load between steel and concrete. In some specimens different types of special load transfer device were used to check their performances however some transfer device had complex detailing. More practical and efficient load transferring device having less complex detail was developed. This was spot welded to sheeting and relatively simple to fabricate which is presented in Figure 2.2

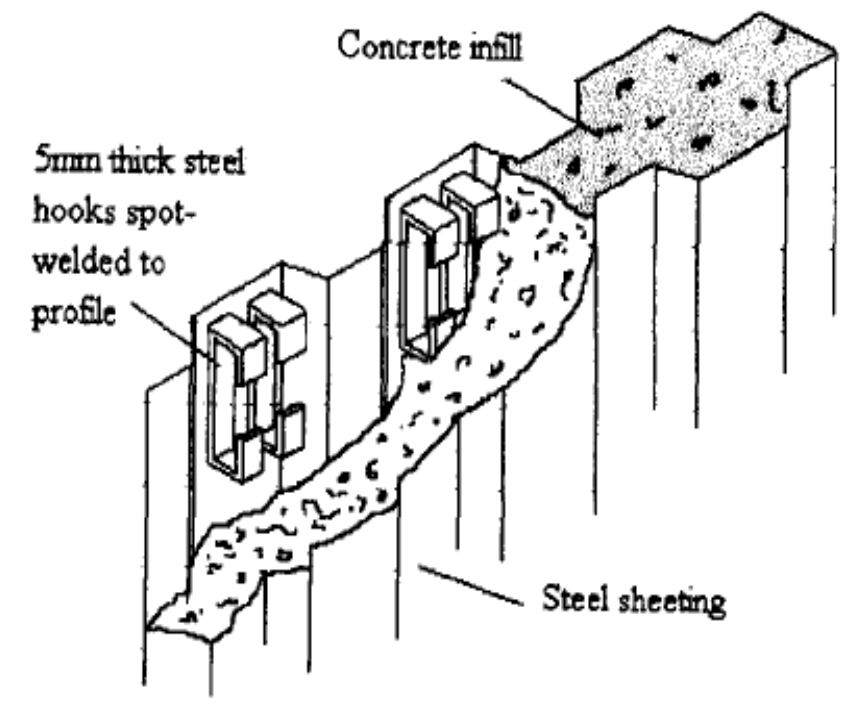

Figure 2.2- Detail of load transfer device (Wright 1998) 
Hossain (2000) investigated the axial load behaviour of a novel form of pierced and non-pierced composite wall. The wall specimens were made from two different types of profiled steel sheeting. Eight composite walls were tested to get information on the effect of holes on load deformation behaviour, strength, stiffness, stress-strain behaviour, buckling and failure modes. The behaviour of the walls was significantly affected by the presence of holes and their location (Figure 2.3). The test results were compared with theoretical calculation method. It was observed that composite wall has potential to use as shear or core walls with opening for doors or windows.
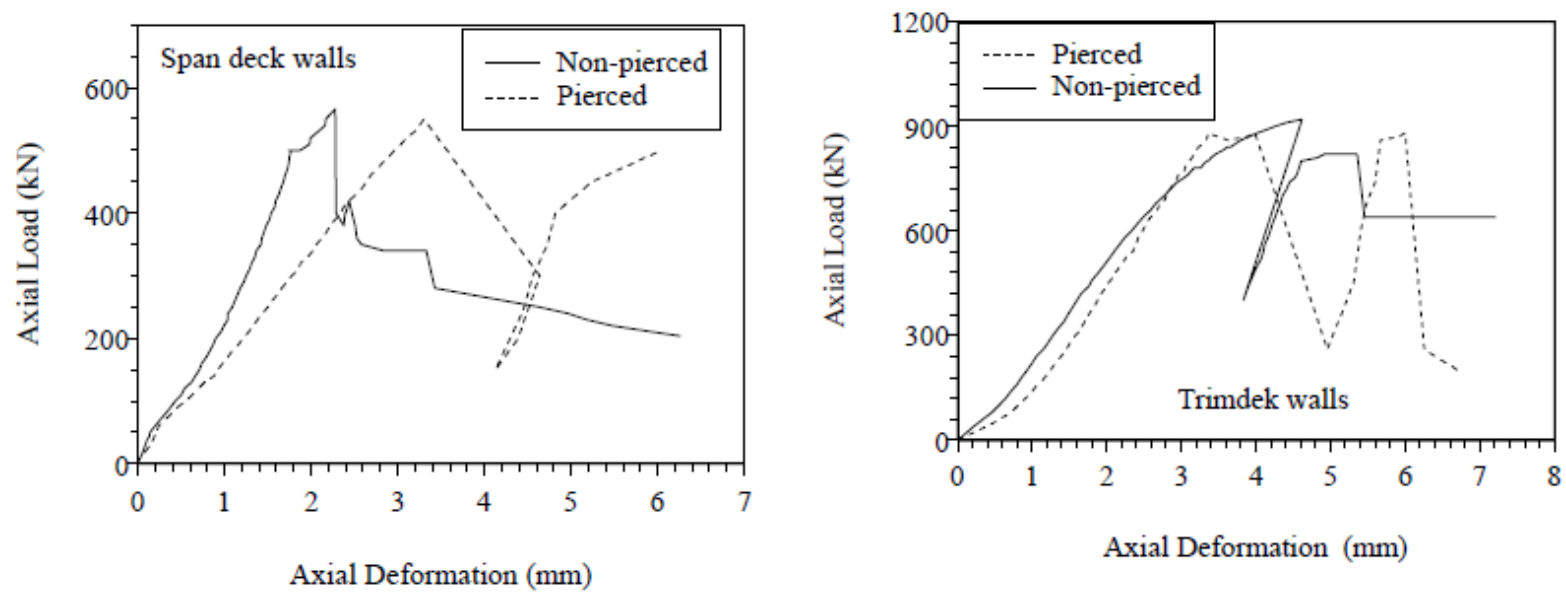

Figure 2.3- Axial load response of pierced and non-pierced wall (Hossain 2000)

The axial load and deformation behaviour of pierced and non-pierced walls are shown in Figure 2.3. It was found that axial load capacity of the non-pierced walls were greater than the pierced walls. However the deformation of the pierced walls was found greater than the non-pierced walls. The axial load capacity of the Trimdek wall was found greater than the Spandek wall in per unit length. But the Spandek wall was found of greater axial load capacity than the Trimdek wall when compared to net sectional area of concrete.

Hossain et al. (2015) conducted experimental and theoretical investigations for axial load behaviour of pierced DSCW system with strength enhancement devices. The wall specimens were made considering different variables which were types of profiled steel sheeting, types of load transfer device, size of opening, height of wall and types of strength enhancement devices around the opening. Experimental results of axial load deformation behaviour, axial strength, steel-concrete interaction, failure modes and stress-strain development were analyzed based on the effect of variables. The axial load capacity of the wall was increased by strengthening the boundaries of opening and by the use of load transfer device 
(Figure 2.4). From Figure 2.4(a-b), it is found that axial load and deformation capacity of wall decreased with the increase of hole size.

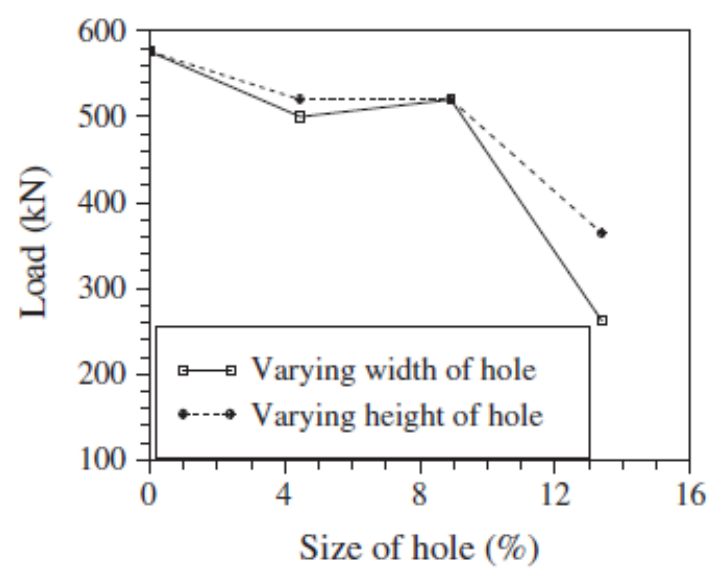

(a) Variation of strength

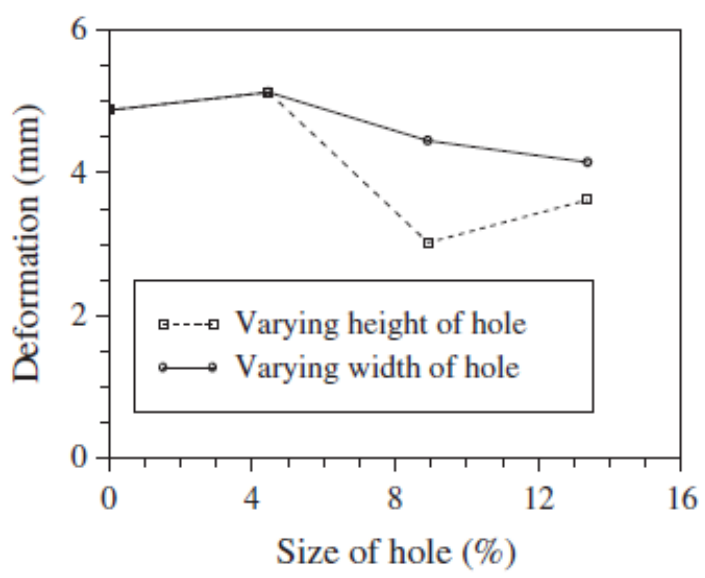

(b) Variation of ultimate deformation

Figure 2.4- Effect of size parameters of hole on strength and deformation of walls (Hossain 2015)

Mydin and Wang (2010) conducted analytical and experimental investigation on the performance of the thin profiled steel sheet in filled with lightweight foamed concrete composite walling system under compression. Twelve specimens of size $400 \mathrm{~mm} * 400 \mathrm{~mm} * 100 \mathrm{~mm}$ were made for testing. Six specimens were of profiled steel sheet of thickness $0.4 \mathrm{~mm}$ and other six specimens were of profiled sheet of thickness $0.8 \mathrm{~mm}$. Three edge conditions of profiled steel sheet (no stopping edge, with stopping edge and with welded stopping edge) were considered during the fabrication of wall sample. The density of LFC was $1000 \mathrm{~kg} / \mathrm{m}^{3}$. Experimental results of axial load deformation behaviour, axial strength, failure modes and stress-strain development were analyzed. In analysis, complete bond between steel and concrete were considered and the LFC was considered effective in preventing inward buckling of the steel sheets. The analytical load capacity of the specimens was calculated using the effective width method for the steel sheets and compared with the experimental value. Analytical calculation was based on combination of plate local buckling coefficient with effective width formulation. The analytical and experiment result were found in good agreement with each other.

Hossain and Wright (2004) studied the behaviour profiled steel sheet panel in plane shear and its application in building framing system. Small scale model of $560 \mathrm{~mm} * 560 \mathrm{~mm}$ were tested under pure shear forces along a diagonal of the specimen to study its behaviour. Analytical models were developed for shear strength and stiffness of the profiled steel sheeting which was justified by finite element 
analysis and experimental test of small scale model. The strength, stiffness, strain conditions and failure modes were observed to be highly affected by the boundary conditions. Due to unstable post buckling behaviour of panel, it was suggested to not consider post critical shear reserves in design. The values of several factors related to type of connection of the profiled steel sheeting to the building frame were studied to verify the appropriateness of design equations.

Hossain et al (2015) investigated the performance of profiled steel sheet composite with infill concrete under in plane cycling loading. Six specimens of size $1626 \mathrm{~mm}$ high and $720 \mathrm{~mm}$ wide were made for testing. The connection between steel and concrete were provided by intermediate fasteners along the height and width of the wall to achieve composite action. Two types of profiled sheets (same geometry but different yield strength) and two types of concrete (self-consolidating concrete SCC and highly ductile engineered cementitious composite ECC) were used for wall specimen preparation. Three walls were tested under in plane cyclic loading and three walls were tested under in plane monotonic shear loading. Mild steel profiled sheet wall was showing higher ductility and energy absorbing capacity than high strength profiled sheet wall. ECC wall was showing higher displacement ductility, less stiffness degradation and higher energy ductility than SCC wall.

Badaruzzaman (1996) investigated the structural behaviour of profiled steel sheet dry board panel composite system. It was investigated for variety of structural purposes. The panel was made by connecting dry boards to a core of profiled steel sheeting by mechanical connector. It was observed that profiled steel sheet dry board panel composite system has great potential to use as floors, walls and folded roof structures.

Benayoune et al. (2000) investigated the behaviour of profiled steel sheet dry board wall panels under axial and slightly eccentric load. Experimental investigation was done on three different heights of wall (1400, 1800 and $2000 \mathrm{~mm}$ ). The profiled steel sheet dry board system was made by using profiled steel sheet and cement board connected together by self-tapping and self-drilling screws. It was observed that the ultimate load based on theoretical calculations was $19 \%$ less than the experimental values. It was also observed that profiled steel sheet was the main structural element carrying major portion of load while dry board was carrying small portion of load.

Salma (2012) conducted test on eight small scale model for the study of axial load behaviour of profiled steel sheet dry board walling system. The test model was made based on different height to width ratio and connector spacing to height ratio which was in filled with engineered cementitious composite. 
Experimental results of axial load deformation behaviour, axial strength, failure modes and stress-strain development were analyzed. The test results were compared with theoretical calculation method. It was observed that this type of composite walling system has potential to meet the demand of modern industrialized building construction.

\subsection{Axial Load Resistance of DSCW system - Existing Analytical Equations}

Many researches have been conducted for the axial load response of DSCW system. It is evaluated based on the load caring capacity, load displacement response, load strain response, metal sheet-concrete interaction and failure modes. Studies have found that the ultimate strength of composite system was significantly less than the analytical failure load. It was due to the interface bond strength between steel sheeting and concrete and local buckling capacity of the steel sheeting. There was little mobilisation of ductile bond strength between steel and concrete produced by embossment. In the commercial available metal sheet, embossments are available of insufficient size which cannot produce large ductile transfer of load. Under axial compression, the transfer of load from concrete core to the steel sheeting should be rapid to prevent the brittle failure at loading point (Wright and Gallocher 1995; Hossain and Wright 2004).

The behaviour of composite wall is different in case of axial load than lateral load or moment. The moment due to lateral load produces maximum tensile stress at the centre of the span as moment is maximum there which gradually reduces to zero at support. Hence shear force produced are distributed over large area near the support and therefore it's easy to withstand the shear load in case of lateral loading (Wright and Gallocher 1995).

It was seen that the interface bond between concrete and steel sheeting was insufficient to rapidly transfer the load from concrete core to steel sheeting to avoid the brittle failure at wall head (Wright and Gallocher 1995; Hossain and Wright 2004). This problem can be eliminated by fixing wire mesh fabric and reinforcing bar on top and bottom face of the wall. Though, this is not cost effective and is unlikely to be used in construction. Later on interface bond were increased by introducing a hook of mild steel at head and foot of the wall which was welded to the sheeting as shown in Figure 2.2. That hook acted as an effective load transfer device from concrete to steel. Global buckling can be minimized by introducing intermediate fastener which increases the buckling strength of the wall as effective buckling length of wall decreases (Hossain and Wright 2004). 
Based on the previous research, It was seen the following outcomes of the axial behaviour of composite wall.

- Interface bond strength between steel and concrete was insufficient due to the lack of enough strain to develop force in embossment which resulted brittle failure at the interface of steel sheeting and concrete (Wright and Gallocher 1995; Hossain and Wright 2004).

- Local buckling was seen on the top of the wall which decreased the ultimate strength of the wall than its analytical strength (Wright and Gallocher 1995).

- In non-pierced profiled concrete core wall, concrete was crushed at top of the wall and the vertical crack was developed along the troughs which were extended from top to bottom of the wall (Hossain et al 2015).

- Buckling of edge steel was noticed.

- Tearing of the sheet was observed at the spacer.

- For pierced wall, local buckling was observed around the holes and diagonal buckles were found to be extended from top corner to loaded end.

The axial load capacity of the composite wall can be determined by BS8110:1985 simplified short wall method. The total axial capacity of the composite wall is the sum of individual axial capacity of steel sheeting and concrete. However total axial capacity (Eq. 2.1) is reduced by $10 \%$ considering the possibility of additional compressive bending stress caused by eccentric loading or the imperfection of wall.

$$
N=0.6 f_{c u} A_{C}+0.87 f_{s y} A_{s}
$$

where $N=$ axial load capacity of the composite wall, $\mathrm{f}_{c u}=$ cube strength of concrete, $A_{c}=$ cross-sectional area of concrete core, $\mathrm{f}_{\mathrm{sy}}=$ yield strength of steel and $A_{s}=$ cross-sectional area of steel sheeting.

If the bond between steel sheeting and concrete doesn't show full capacity, above equation is modified by introducing reduction factor for loss of bond. This reduction factor is applied in concrete term if load is applied in steel sheeting and in steel sheeting if the load is applied in concrete. If the load is applied through both steel sheeting and concrete in right proportions, bond between steel sheeting and concrete is not critical and full axial load capacity can be achieved. Ability of steel sheeting to resist compression buckling is the other constraint for the axial load resistance capacity of composite wall. Unlike the axially loaded concrete structures where the longitudinal bars are constrained until the 
crushing of surrounding concrete matrix occurs, local buckling of the steel sheeting occurs which reduce the axial load capacity of the composite wall (Wright and Gallocher 1995).

It was observed that the free outer flange of profiled steel sheeting at edges of wall buckled before the other surfaces of profiled steel sheeting. The extreme edge of the walls did not show the existing solid mass of concrete. The extra bending stress was resisted only by concrete in the ribs of the profile. Therefore, a profiled sheet wall of the same width as a solid wall was less able to resist bending moments developed by applications of eccentric load or imperfections of the wall. Therefore the empirical correction factor for both concrete and steel was derived (Hossain and Wright 2004; Hossain et al 2015).

An empirical correction factor for concrete is derived by considering the axial load capacity of concrete is directly proportional to the amount of void formed by the profiling on the compressed edge of the wall (Figure 2.5). Hence the reduction factor $\alpha$ is applied in the concrete capacity of Eq. 2.1. The reduction factor is determined by following Eq. 2.2 (Hossain et al 2015):

$$
\alpha=1-\frac{D * P-A_{c p}}{2 A_{c p}}
$$

where $D=$ overall thickness of wall, $P=$ pitch of profiles in wall and $A_{c p}=$ cross-sectional area of concrete in one pitch of wall.

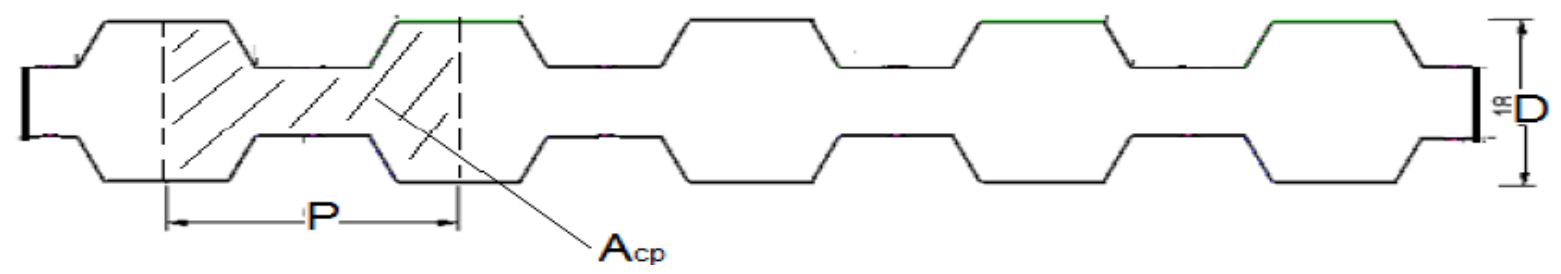

Figure 2.5- Cross-section of DSCW system

The sectional area is not necessary to calculate by great precision. Generally the strengthening materials are provided into the profiles less than $1 \%$ of concrete area and are ignored. Outer flange plate at edge of the wall was seen to be buckled before than other interior plates of the profile sheet. Hence reduction factor $\beta$ was applied to the yield strength of steel or steel capacity of equation 1 considering the buckling of plate in contact with concrete. The reduction factor $\beta$ is the ratio of buckling stress to the yield stress and can be related to the ratio of width $b$ to thickness $t$ of the outer flange plate. It can be determined 
from Figure 2.6 for different yield strength of steel and b/t ratio (Hossain 2000; Hossain et al 2015; Wright 1998).

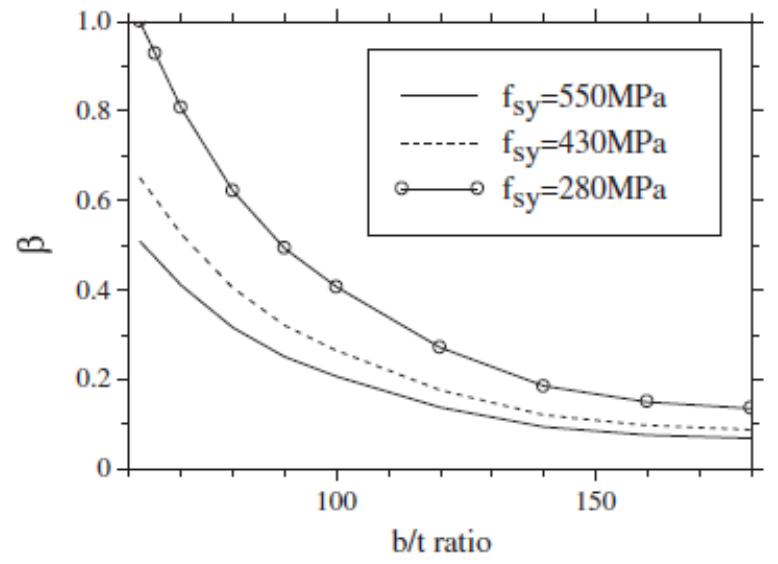

Figure 2.6- Design charts for determination of reduction factor $\beta$ (Hossain et al 2015)

Hence the Eq. 2.1 is modified by including reduction factor $\alpha$ and $\beta$. The modified equation (Eq. 2.3) for axial load calculation of composite wall is:

$$
N=0.4 f_{c u} A_{C} \alpha+0.75 f_{s y} A_{s} \beta
$$

The numerical parameter is reduced in Eq. 2.3 by considering the uncertainty in computing buckling capacity of steel sheeting and capacity of profiled concrete core.

\subsection{Commercial Form Material (CFM)}

Commercial form material (CFM) which is manufactured by Royal Adhesives and Sealants Canada, is a highly efficient expanding composite. It is used as an alternative of concrete for construction fence posts, mail boxes, signs, bollards, clotheslines, gate posts, garden light post, sport posts/poles such as basketball, soccer, volleyball and tennis etc. It is a composite material and does not need water for mixing and not block water in pore. It is waterproof and protects the metal posts from corroding and wooden post from rotting. It is very expandable and $26 \mathrm{fl} \mathrm{oz}(770 \mathrm{~mL})$ bags expand to a volume of $20 \mathrm{~L}$ or $0.70 \mathrm{ft}^{3}$. One 2 pound bag of this form material replaces $2 \times 50$ pound bags of concrete. Hence, its use as a replacement of concrete can eliminate the effort and the transportation cost of large volume of concrete. It also reduces the carbon dioxide emission by 96 percent due to vehicular pollution. It can be used outside in summer and winter even when temperatures are as low as $-30^{\circ} \mathrm{C}$ or as high as $38^{\circ} \mathrm{C}$. However the form material bag should be kept at $22^{\circ} \mathrm{C}$ to $25^{\circ} \mathrm{C}$ for at least two hours before using it. 
Concrete is very rigid and it does not resist lateral force. So, all the lateral force is resisted by post only. While form material absorbs some lateral force and hence post has to resist less lateral force. Hence, the post having form material as a foundation does not break easily in lateral force compared to the post having concrete as a foundation. The compressive strength of form material is 3 to 4 times higher than the tamped soil.

\subsection{Profiled Steel Sheeting (PSS)}

Profiled steel sheeting has been used in construction industry since early 1950. It was initially used in composite floor slab. Later on it was developed to use in a composite wall. Profiled steel sheeting is made from cold flat steel coil. It is coated with zinc/aluminum alloy and is more recognized as zincalume. Zincalume is an alloy coated steel which is corrosion resistant and is manufactured by a continuous hot dip process.

Steel profiled sheet used for composite wall and slab is available with yield strength from $350 \mathrm{MPa}$ to $550 \mathrm{MPa}$ and its stiffness is low even the strength is high. The thickness of steel sheeting is comparatively thin in composite wall and slab system. If the profiled steel sheeting is compared with flat steel plate of same thickness, it has significant out of plane stiffness in the direction of corrugations. Hence it can resist gravity loads as well as in plane shear loads.

Canam group is one of the leading manufacturers of profiled steel sheeting in North America for composite wall and slab system. They produce steel profiled sheet of different profile geometry, thickness and of different yield strength. Some of the profile sheets with their commercial name produced by Canam group are shown in Figures 2.7, 2.8 and 2.9.

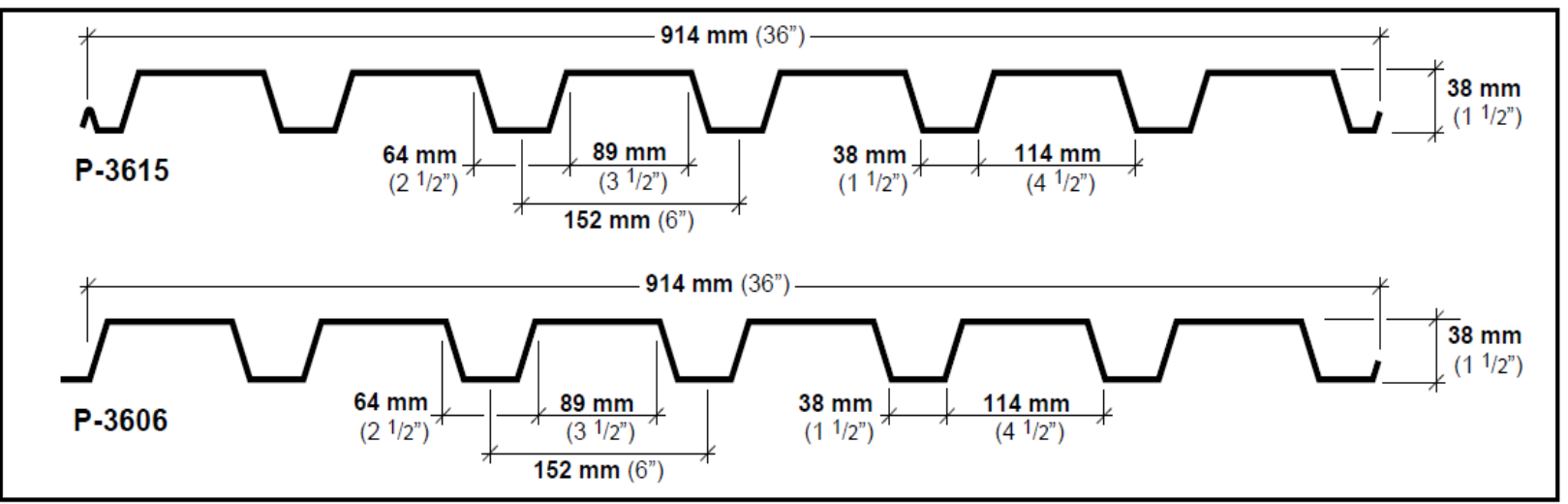

Figure 2.7 - Profiled sheet of commercial name P-3615 and P-3606 


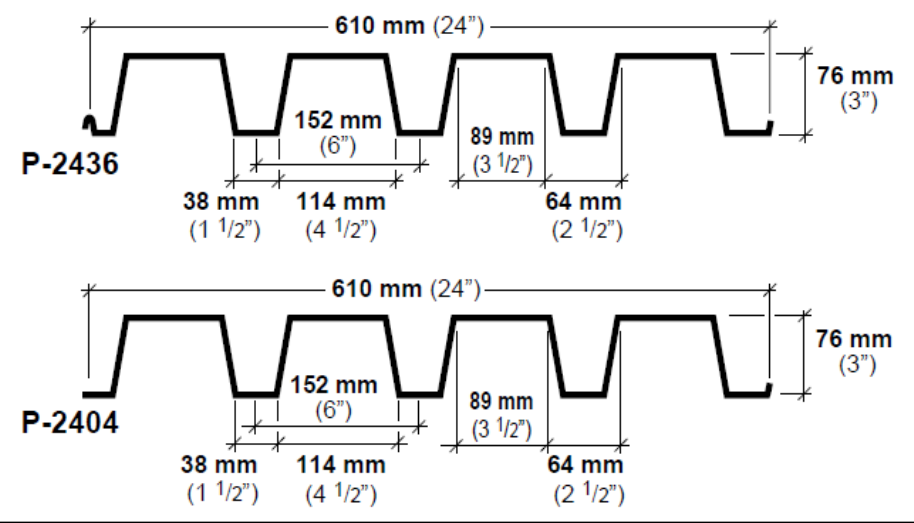

Figure 2.8 - Profiled sheet of commercial name P-2436 and P-2404

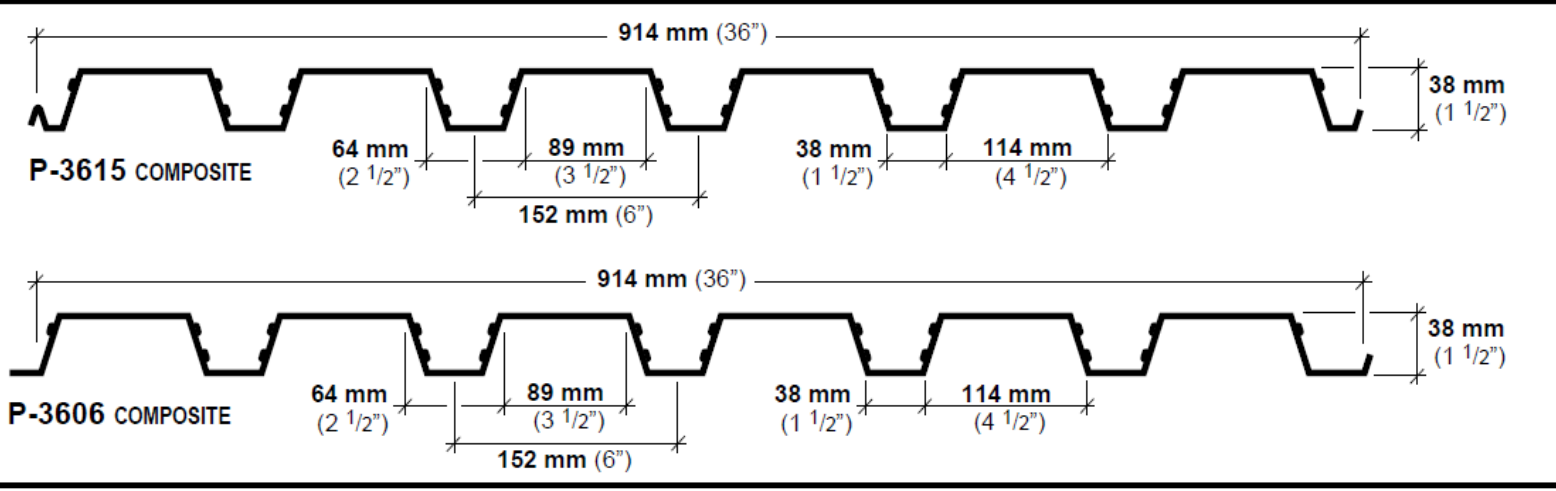

Figure 2.9 - Profiled sheet of commercial name P-3615 composite and P-3606 composite

\subsection{Oriented Strand Board (OSB)}

Oriented strand boards are panel product. They are manufactured by rectangular wood strands which are bonded together using a waterproof adhesive under heat and pressure. The stands are placed along longitudinal axis in outer layer while they are placed either perpendicular to the longitudinal axis or randomly in inner layer of OSB. Therefore OSB has greater strength along long axis than narrow axis like plywood. It is manufactured in large continuous mat and has uniform quality. It is also called sterling board. OSB has strength and performance similar to plywood, however it is more uniform and less expensive. It is widely used in construction industry and has already initiated to replace plywood in many applications. OSB is mostly used as roof, wall and floor and is also accepted to use for structural applications in diaphragm and shear wall. Strength and rigidity of OSB depends upon the species of wood strands used and manufacturing process. 
In Canada, OSB is manufactured according to requirement of Canadian Standards Association (CSA) standard CSA 0325, Construction Sheathing. The mechanical properties of typical OSB and Plywood are presented in Table 2.1.

Table 2.1 - Properties of typical oriented strand board

\begin{tabular}{|l|c|c|}
\hline PROPERTY & PLYWOOD & ORIENTED STRAND BOARD \\
\hline Modulus of Elasticity & 68948 to $131000 \mathrm{MPa}$ & 4826 to $82737 \mathrm{MPa}$ \\
\hline Modulus of rupture & 20.68 to $48.26 \mathrm{MPa}$ & 20.68 to $27.58 \mathrm{MPa}$ \\
\hline Tensile strength & 10.34 to $27.58 \mathrm{MPa}$ & 6.89 to $10.34 \mathrm{MPa}$ \\
\hline Compressive strength & 20.68 to $34.47 \mathrm{MPa}$ & 10.34 to $17.23 \mathrm{MPa}$ \\
\hline Shear strength & 4.14 to $6.89 \mathrm{MPa}$ & 6.89 to $10.34 \mathrm{MPa}$ \\
\hline
\end{tabular}

\subsection{Review Conclusion}

Research has been conducted on sandwich composite walls made of two skins of profiled steel sheet or wooden board and infill concrete. However, no research has been conducted on sandwich composite walls made of two skins of profiled steel sheet or wooden board with new lightweight commercial form material (CFM) with high expansion and fast setting characteristics with reduced transport costs leading to lower greenhouse gas (GHG) emissions.

This research is timely initiative to contribute to the development of high performance profiled steel sheet composite wall (PSSCW) and oriented strand board composite wall (OSBCW) using CFM infill leading to much lighter and faster construction in addition lower GHG emission. The proposed research on studying axial, flexural and thermal behaviour of such walls will help understanding the structural behaviour such walling system. 


\section{CHAPTER 3}

\section{COMPOSITE WALL FABRICATION AND MATERIAL TESTING}

\subsection{Introduction}

This chapter describes composite wall specimen fabrication, dimensions and material properties. The specimen fabrication was done in concrete and structural laboratory of Ryerson University. Profiled steel sheet (PSS), oriented strand board (OSB), commercial form material (CFM) and nut bolt were used for the fabrication of composite wall (CW). The strength of profiled steel sheet and oriented strand board were determined in mechanical department laboratory. Flexural strength and cylindrical compressive strength commercial form material were done in concrete and structural laboratory of Ryerson University.

\subsection{Specimen Preparation}

Four composite walls (wall 1, wall 2, wall 3 and wall 4) of profiled steel sheeting (PSSCW) with commercial form material infill and four composite walls (wall 5, wall 6, wall 7 and wall 8) of oriented strand board (OSBCW) with commercial form material (CFM) infill were fabricated. To compare the behaviour of composite wall with commercial form material infill, two walls of oriented strand board without commercial form material (wall 9 and wall 10) were also fabricated. The width of PSSCWs was $304 \mathrm{~mm}$ whereas width of OSBCW was $310 \mathrm{~mm}$. The height of PSSCWs was varied from $400 \mathrm{~mm}$ to 800 $\mathrm{mm}$ and that of OSBCWs from $400 \mathrm{~mm}$ to $890 \mathrm{~mm}$. The height to width ratio of PSSCWs was varied from 1.31 to 2.63 and that of OSBCWs from 1.29 to 2.87 . Three connectors were used in one row of each specimen. In PSSCWs, three rows of connector were used for wall of height $400 \mathrm{~mm}$ and $600 \mathrm{~mm}$ whereas five rows of connector were used for wall of height $800 \mathrm{~mm}$. In OSBCWs, two rows of connector were used for wall of height $400 \mathrm{~mm}$ and three rows of connector were used in of height $600 \mathrm{~mm}$ and $890 \mathrm{~mm}$. For each walls, edge distance were maintained $25 \mathrm{~mm}$. The inside spacing between two skin of oriented strand board wall was maintained $30 \mathrm{~mm}$ and that of profiled steel sheeting was maintained 25 $\mathrm{mm}$. One specimen (wall 11) was made similar to OSB composite wall with commercial form material infill of size $310 \mathrm{~mm}$ width and $890 \mathrm{~mm}$ height for flexure tests. The sketches of the walls showing their dimensions, connector spacing and cross-section are presented in Figures 3.1 and 3.2. The dimensions and other details of the wall specimens are summarized in Table 3.1. 
Table-3.1 Geometric dimension and variables of specimen

\begin{tabular}{|c|c|c|c|c|c|c|c|c|}
\hline $\begin{array}{l}\text { Wall } \\
\text { panels }\end{array}$ & $\begin{array}{l}\text { Width } \\
\text { b } \\
(\mathrm{mm})\end{array}$ & $\begin{array}{l}\text { Height } \\
\mathrm{h} \\
(\mathrm{mm})\end{array}$ & $\begin{array}{l}\text { Rows of } \\
\text { connectors }\end{array}$ & $\begin{array}{l}\text { Edge } \\
\text { distance }\end{array}$ & $\begin{array}{l}\text { Spacing of } \\
\text { connectors } \\
\mathrm{s}(\mathrm{mm})\end{array}$ & $\begin{array}{l}\text { Ratio } \\
\text { h/w }\end{array}$ & $\begin{array}{l}\text { Ratio } \\
\mathrm{s} / \mathrm{h}\end{array}$ & Remarks \\
\hline Wall 1 & 304 & 400 & 3 & 25 & 175 & 1.31 & 0.44 & $\begin{array}{l}\text { Double skins of profiled steel } \\
\text { sheet with CFM infill }\end{array}$ \\
\hline Wall 2 & 304 & 600 & 3 & 25 & 275 & 1.97 & 0.46 & $\begin{array}{l}\text { Double skins of profiled steel } \\
\text { sheet with CFM infill }\end{array}$ \\
\hline Wall 3 & 304 & 800 & 5 & 25 & 187.5 & 2.63 & 0.31 & $\begin{array}{l}\text { Double skins of profiled steel } \\
\text { sheet with CFM infill }\end{array}$ \\
\hline Wall 4 & 304 & 800 & 5 & 25 & 187.5 & 2.63 & 0.31 & $\begin{array}{l}\text { Double skins of profiled steel } \\
\text { sheet with CFM infill }\end{array}$ \\
\hline Wall 5 & 310 & 400 & 2 & 25 & 350 & 1.29 & 0.87 & $\begin{array}{l}\text { Double skins of oriented } \\
\text { strand board with CFM infill }\end{array}$ \\
\hline Wall 6 & 310 & 600 & 3 & 25 & 275 & 1.93 & 0.46 & $\begin{array}{l}\text { Double skins of oriented } \\
\text { strand board with CFM infill }\end{array}$ \\
\hline Wall 7 & 310 & 890 & 3 & 25 & 420 & 2.87 & 0.47 & $\begin{array}{l}\text { Double skins of oriented } \\
\text { strand board with CFM infill }\end{array}$ \\
\hline Wall 8 & 310 & 890 & 3 & 25 & 420 & 2.87 & 0.47 & $\begin{array}{l}\text { Double skins of oriented } \\
\text { strand board with CFM infill }\end{array}$ \\
\hline Wall 9 & 310 & 600 & 3 & 25 & 275 & 1.93 & 0.46 & $\begin{array}{l}\text { Double skins of oriented } \\
\text { strand board with no CFM } \\
\text { infill }\end{array}$ \\
\hline $\begin{array}{l}\text { Wall } \\
10\end{array}$ & 310 & 890 & 3 & 25 & 420 & 2.87 & 0.47 & $\begin{array}{l}\text { Double skins of oriented } \\
\text { strand board with no CFM } \\
\text { infill }\end{array}$ \\
\hline $\begin{array}{l}\text { Wall } \\
11\end{array}$ & 310 & 890 & 3 & 25 & 420 & 2.87 & 0.47 & $\begin{array}{l}\text { Double skins of oriented } \\
\text { strand board with CFM infill }\end{array}$ \\
\hline
\end{tabular}



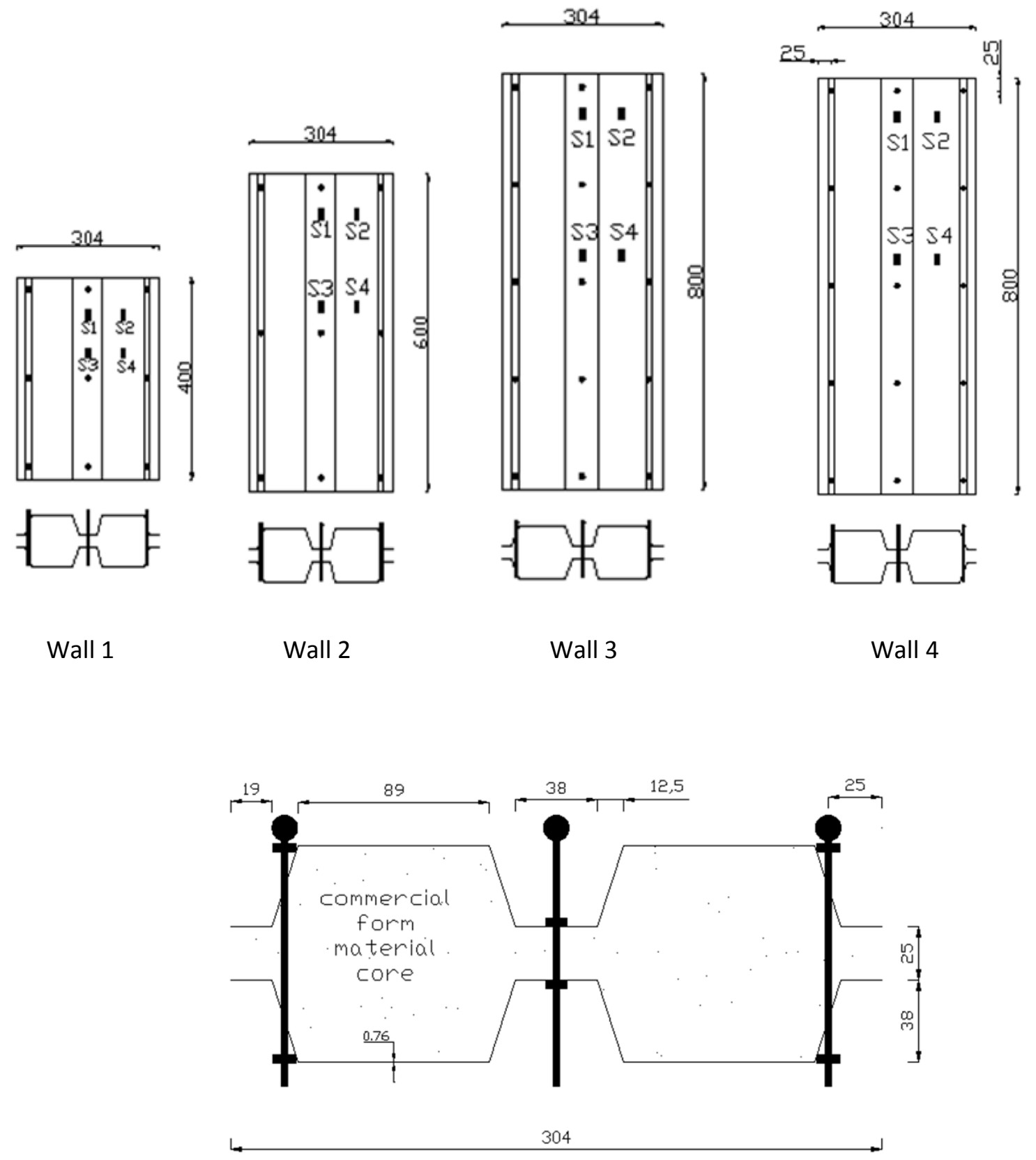

Cross-section of PSSCW

Figure 3.1- Profiled steel sheet composite walls showing dimension, connectors and strain gauge installation (S) 

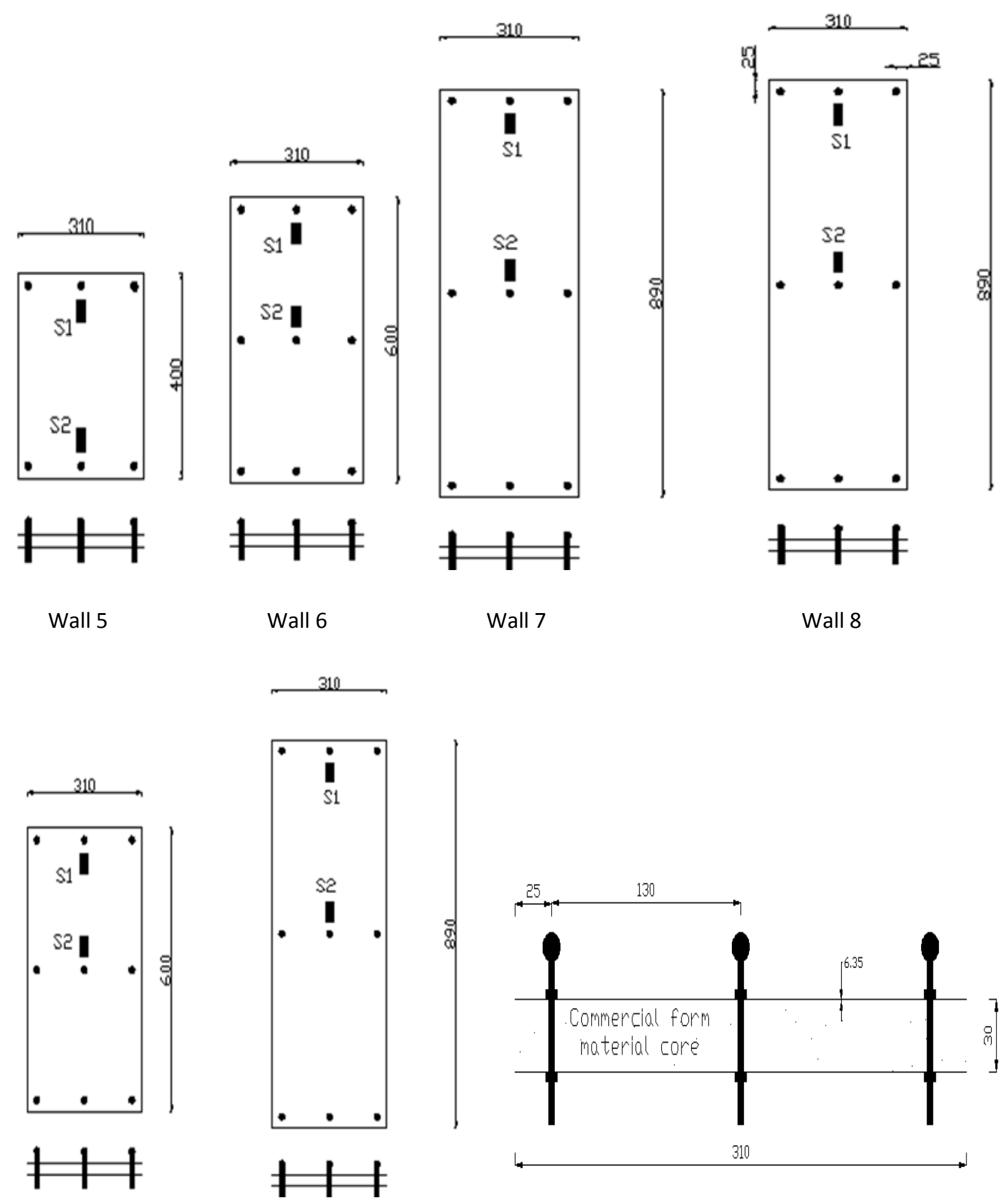

Wall 9 (No infill)

Wall 10 (No infill)

Cross-section of OSBCW

Figure 3.2- Oriented strand board composite walls showing dimension, connectors and strain gauge installation (S) 


\subsection{Materials}

\subsubsection{Profiled Steel Sheet (PSS)}

Profiled steel sheets of commercial name P-3606 manufactured by Canam Group were used for the two skins of composite wall. This commercial sheet has a galvanised coating according to the ASTM A 653M with zinc thickness corresponding to Z275 (G90) or ZF75 (A25). The thickness of sheet is $0.76 \mathrm{~mm}$. The flutes are $38 \mathrm{~mm}$ deep and are spaced at $152 \mathrm{~mm}$ centre to centre. The dimensions of this sheet are shown in Figure 3.3.

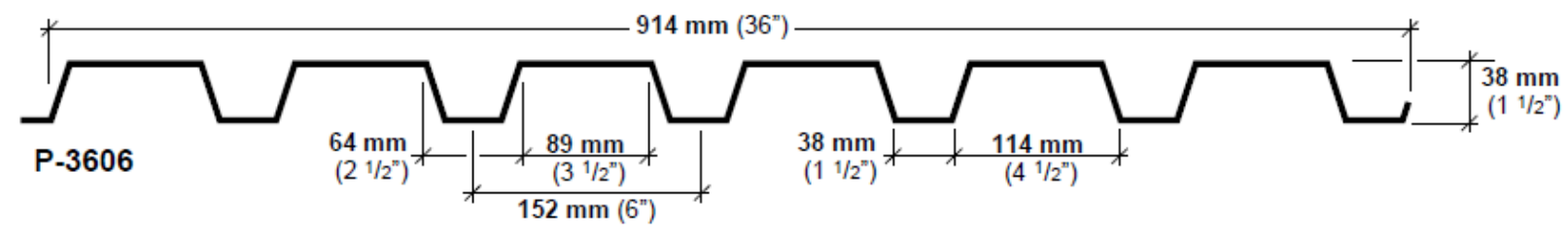

Figure 3.3- Geometry and dimension of steel profiled sheet

The strength and modulus of elasticity of profiled steel sheet P-3606 was determined in mechanical department laboratory of Ryerson University according to ASTM standard (ASTM E8 2011). It was seen from the test that yield strength, tensile strength and modulus of elasticity were $300 \mathrm{MPa}, 345 \mathrm{MPa}$ and $349345 \mathrm{MPa}$ respectively.

\subsubsection{Oriented Strand Board (OSB)}

Locally available oriented strand board of thickness $6.35 \mathrm{~mm}$ were used as two outer skin of composite wall. The strength and modulus of elasticity test of oriented strand board was performed in mechanical department laboratory of Ryerson University. It was seen from the test that tensile strength and modulus of elasticity were $9.38 \mathrm{MPa}$ and $5914 \mathrm{MPa}$ respectively.

\subsubsection{Commercial Form Material (CFM)}

Commercial form material (CFM) manufactured by Royal Adhesives and Sealants Canada Ltd. was used as infill material in composite wall replacing concrete. The compressive strength of CFM is 3 to 4 times higher than the tamped soil. However the specific mechanical properties are not mentioned by manufacturer. Therefore, cylindrical compressive strength and flexural strength test were done to find out the compressive strength and flexural strength as well as modulus of elasticity of this commercial form material which is presented in section 3.4 and section 3.5 . 


\subsection{Fabrication and Casting}

Steel profiled sheet and oriented strand board were cut in exact width and height needed for each wall given in Table 3.1. Pair of steel profiled sheets for each composite wall (wall 1 to wall 4) was connected with each other by nut bolt assembly as two skin of composite wall. Spacers were used to maintain uniform spacing throughout the wall. Similarly, pair of oriented strand board for each composite wall (wall 5 to wall 10) and wall 11 were connected with each other by nut bolt assembly as two skin of composite wall. Spacing between skins of oriented strand board wall was maintained $30 \mathrm{~mm}$ throughout the wall by using spacers where it was maintained $25 \mathrm{~mm}$ between skins of steel sheet wall at lower thickness of wall. The three sides of the wall were sealed by masking tape for casting liquid CFM material. Fabricated walls showing two skins of PSS ad OSB are shown in Figure 3.4.

The two constituents of commercial form material were mixed properly for 30 seconds in closed container and mixed material was poured between the skins of the wall. Hence commercial form material acted as the infill of the composite wall. Two form tubes of $150 \mathrm{~mm}$ were also casted with commercial form material for cylindrical compressive strength test and flexural strength test by beam test under four point loading method. The form tube was cut in to a length $300 \mathrm{~mm}$ to get cylindrical specimens of size $150 \mathrm{~mm} * 300 \mathrm{~mm}$. Beam specimens of dimension $50 * 70 * 360 \mathrm{~mm}$ was also cut from the block in the form tube. Masking tape around three sides of walls was removed after the commercial form material hardened. Walls after casting are shown in Figure 3.5.

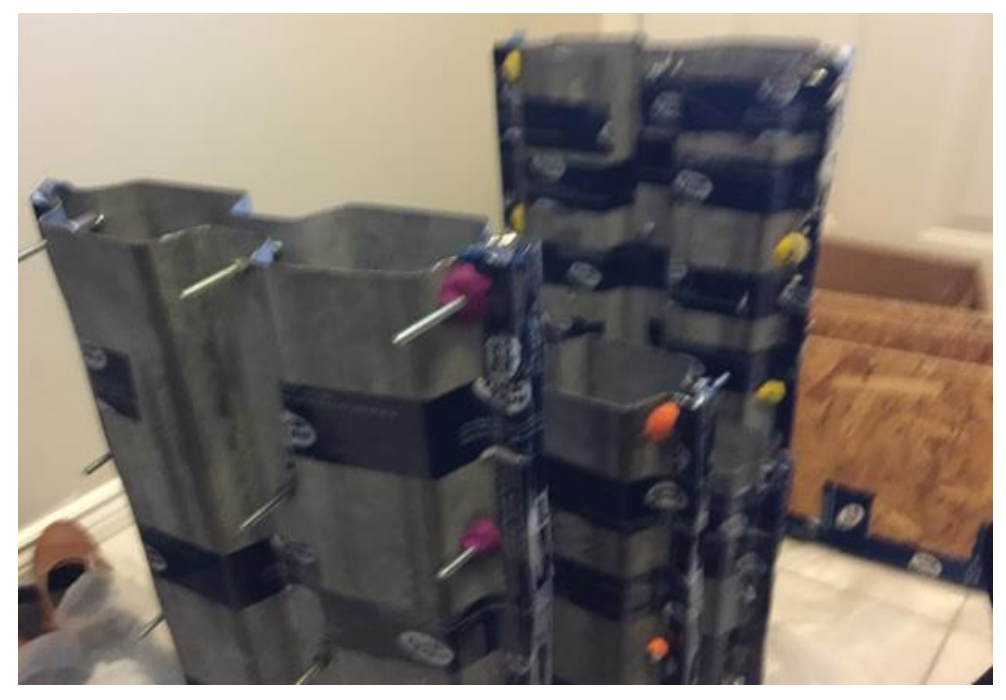

Figure 3.4 - Fabricated walls before casting 

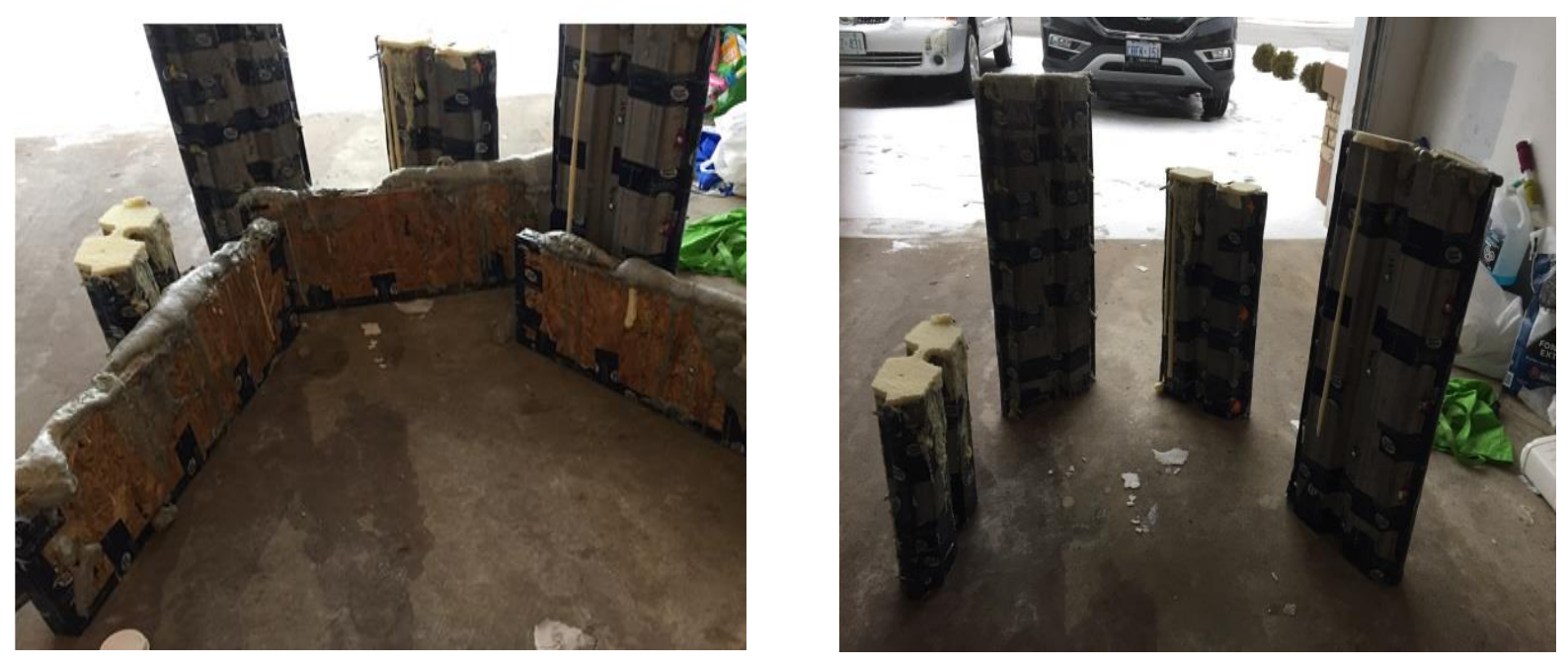

Figure 3.5- Casted composite walls

\subsection{Compressive Strength and Modulus of Elasticity of Commercial Form Material}

The two constituents of commercial form material were mixed in a closed container for 30 seconds as per instruction in a label. The mixed material was poured into a form tube of diameter $150 \mathrm{~mm}$ and length $2.44 \mathrm{~m}$ for expansion. Three standard cylindrical specimen of size $150 \mathrm{~mm} * 300 \mathrm{~mm}$ was made by cutting form tube.

Two strain gauges were fitted at the mid height of the each CFM cylindrical specimen. Then the cylindrical compression test of specimens was done in MTS machine according to ASTM standard (ASTM C39 2012) at a loading rate of $0.005 \mathrm{~mm}$ per second. During the test, load-deformation and load-strain were recorded by computer added data acquisition system. The failure modes of specimens were also observed. It was seen that failure occurred due to the bulging of the specimen. The stress strain response of the CFM cylinder is shown in the Figures 3.6 and 3.7. 


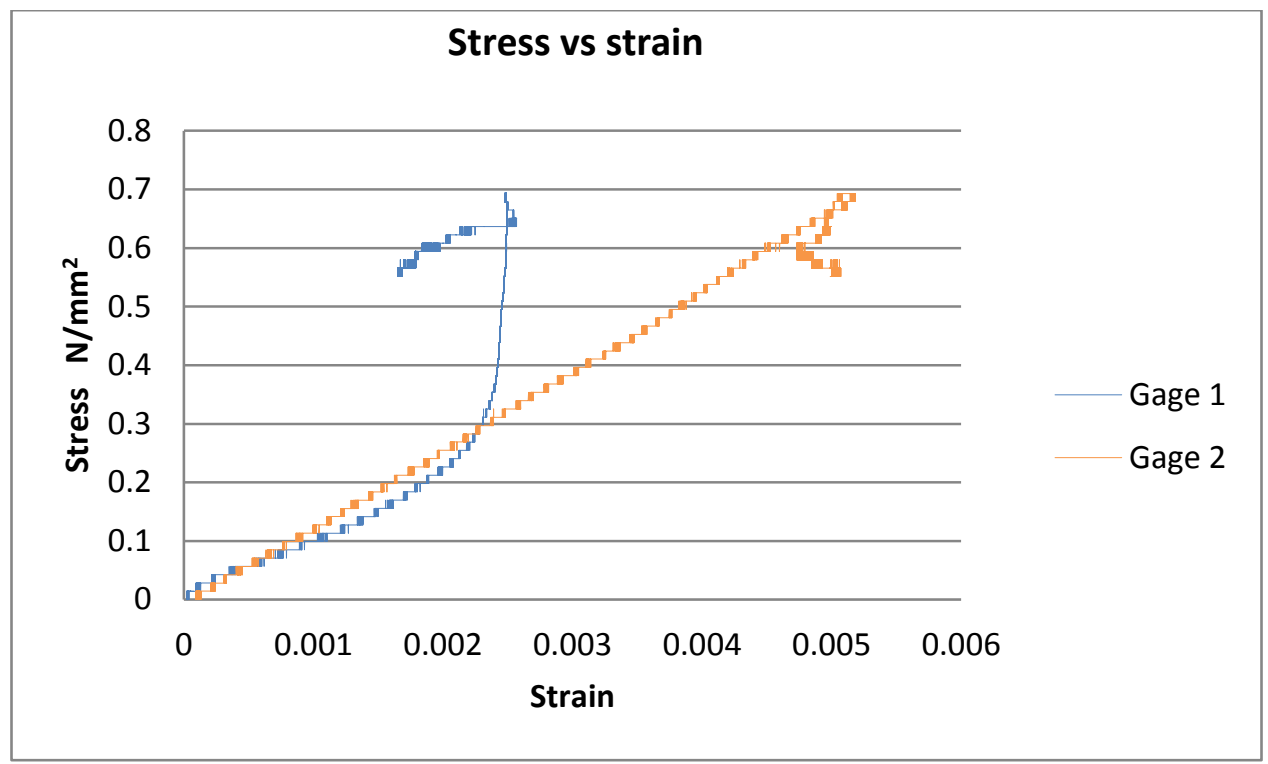

Figure 3.6- Typical stress-strain diagram of commercial form material

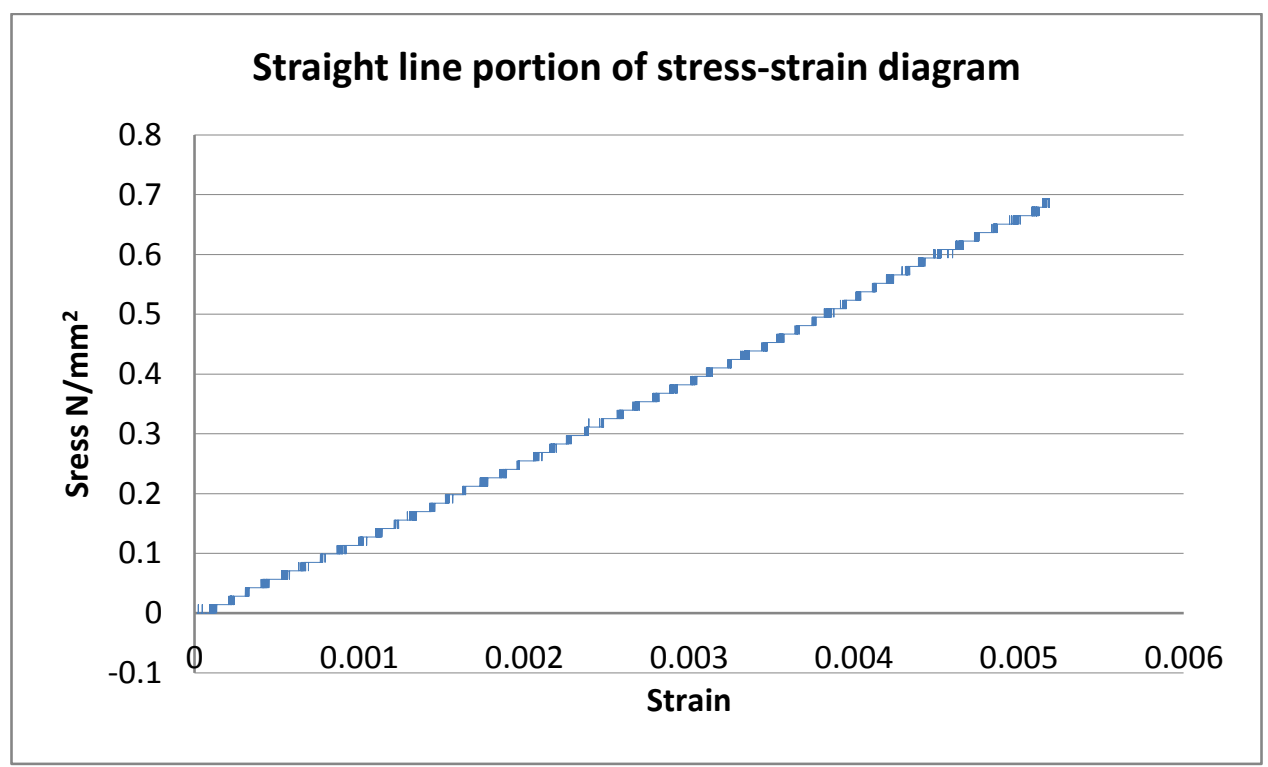

Figure 3.7- Linear part of stress-strain diagram of commercial form material

The linear part of the stress- strain diagram was used to calculate the modulus of elasticity of commercial form material. Modulus of elasticity is the slope of the linear part of stress-strain diagram. Table 3.2 summarizes material properties of CFM. 
Table 3.2- Compressive strength and modulus of elasticity of form material

\begin{tabular}{|c|c|c|c|c|c|}
\hline $\begin{array}{c}\text { Sample } \\
\text { No }\end{array}$ & $\begin{array}{c}\text { Maximum } \\
\text { load }\left(P_{\max }\right) \\
N\end{array}$ & $\begin{array}{c}\text { Compressive } \\
\text { strength }\left(\sigma_{\mathrm{cf}}\right) \\
\mathrm{MPa}\end{array}$ & $\begin{array}{c}\text { Mean compressive } \\
\text { strength }\left(\sigma_{\mathrm{cf}}\right) \\
\mathrm{MPa}\end{array}$ & $\begin{array}{c}\text { Modulus of } \\
\text { elasticity (E) } \\
\text { MPa }\end{array}$ & $\begin{array}{c}\text { Mean modulus } \\
\text { of elasticity (E) } \\
\mathrm{MPa}\end{array}$ \\
\hline 1 & 1225 & 0.69 & \multirow{3}{*}{0.61} & 180.78 & \multirow[t]{3}{*}{171.74} \\
\hline 2 & 1050 & 0.59 & & 162.70 & \\
\hline 3 & 975 & 0.55 & & & \\
\hline
\end{tabular}

\subsection{Flexural Strength of Commercial Form Material}

Flexural strength of commercial form material was found by beam test under four point loading method. Beam specimens of size $50 * 70 * 360 \mathrm{~mm}$ were made by cutting the block casted in form tube. The centre to centre span of the beam was $304.8 \mathrm{~mm}(\mathrm{~L})$ and load was applied at one third of the span. The maximum moment developed between two applied loads $(\mathrm{P})$ of constant value $\mathrm{PL} / 6$. The test set up of beam specimen is shown in Figure 3.8.

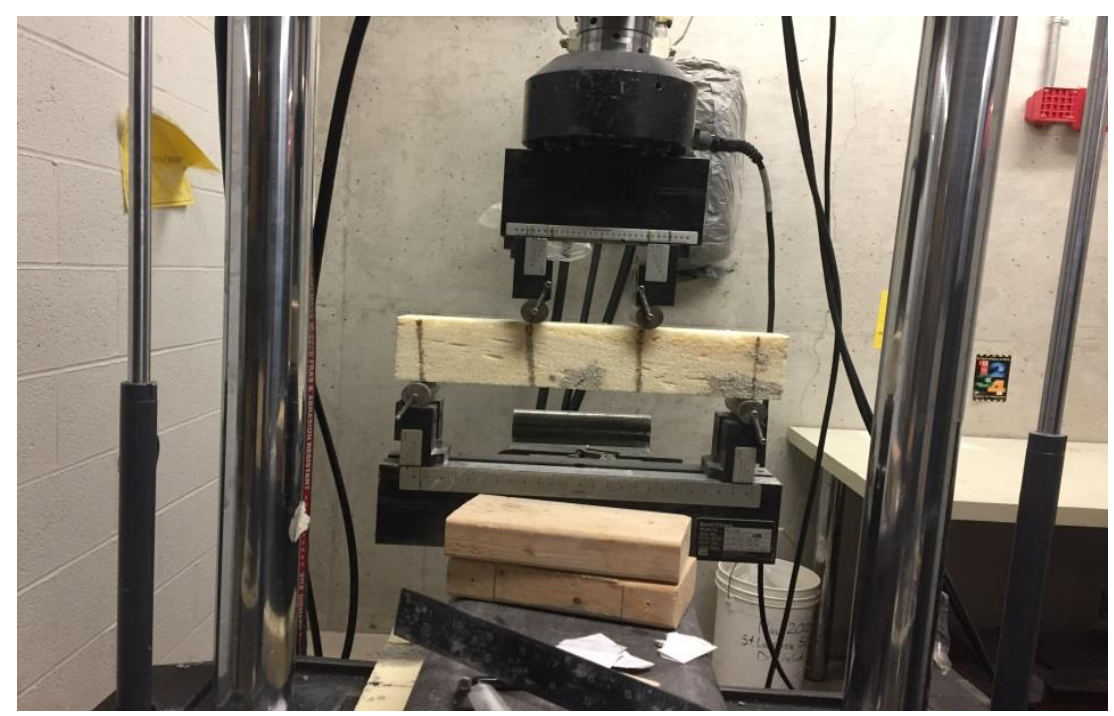

Figure 3.8- Four point loading test of commercial form material beam

During the test displacement at centre of the span of the beam were measured by computer data acquisition system. Typical load displacement response is shown in Figure 3.9. 


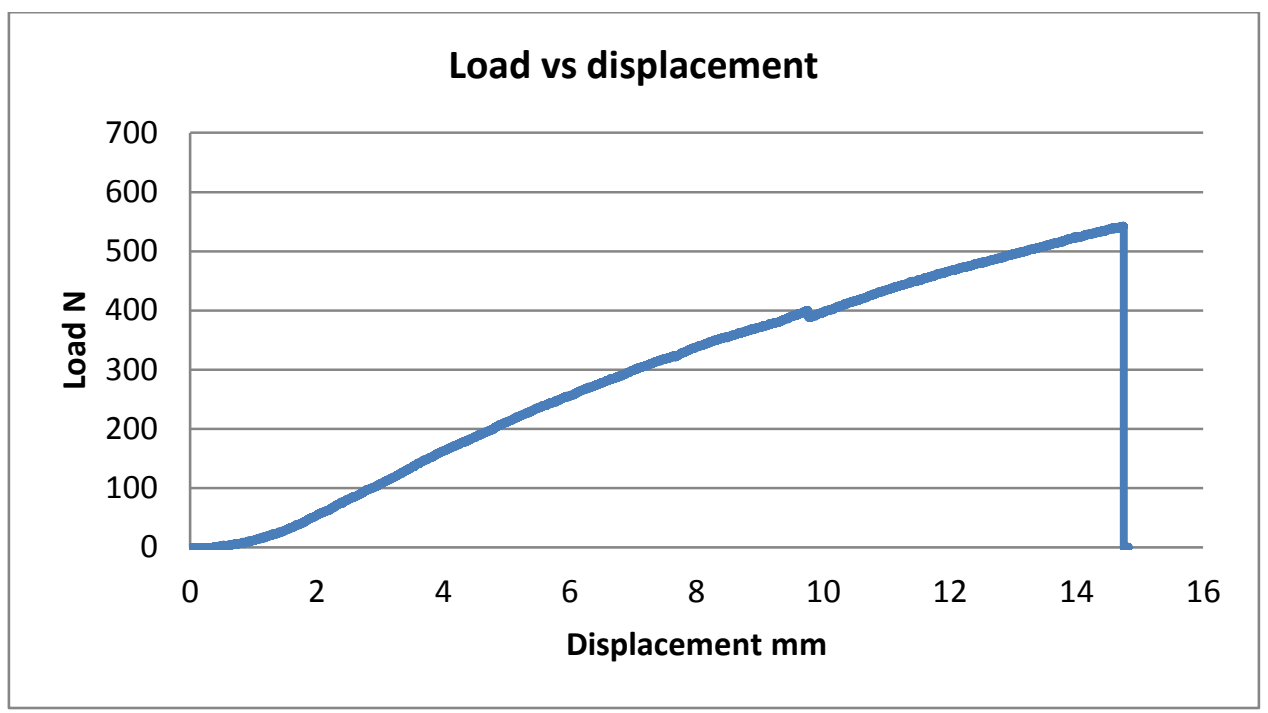

Figure 3.9- Load-mid span displacement response of sample 1

Calculation of flexural strength of specimen 1

$$
\begin{aligned}
& \text { Maximum load }(\mathrm{P})=543.32 \mathrm{~N} \\
& \text { Maximum moment }=\frac{(P * L)}{6}=\frac{543.2 * 304.8}{6}=27594.56 \mathrm{Nmm} \\
& \text { Moment of Inertia }=\frac{\left(b * h^{3}\right)}{12}=\frac{35 * 70^{3}}{12}=1429167 \mathrm{~mm}^{4} \\
& \text { Depth of neutral axis }(\mathrm{y})=35 \mathrm{~mm}
\end{aligned}
$$

$$
\text { Flexural stress }=\frac{M y}{I}=\frac{27594.56 * 35}{1429167}=0.67 M P a
$$

It is found from the calculation that the flexural stress of specimen $2=0.63 \mathrm{MPa}$. Table 3.3 summarizes the flexural strength properties of CFM.

Table 3.3- Flexural strength of commercial form material

\begin{tabular}{|c|c|c|}
\hline Sample no & Flexural strength (MPa) & Mean flexural strength ( MPa) \\
\hline 1 & 0.67 & 0.65 \\
\hline 2 & 0.63 & \\
\hline
\end{tabular}




\section{CHAPTER 4}

\section{EXPERIMENTAL INVESTIGATION ON COMPOSITE WALLING SYSTEM}

\subsection{Introduction}

This Chapter describes experimental testing of profiled sheet composite walls (PSSCWs) and oriented strand board composite walls (OSBCWs) conducted at in concrete and structural laboratory of Ryerson University. The axial behaviour of PSSCWs and OSBCWs with CFM infill in addition to flexural behaviour of OSBCWs is described based on load-deformation response, load-strain response and failure modes. Strain gauges were installed on the wall surface to record the strain response while linear voltage displacement transducers (LVDTs) were installed on the wall surface during the test to record the transverse displacement at various points along the height of the walls. The thermal behaviour of both OSBCWs and PSSCWSs with CFM had is described temperature-time development curves on heated and un-heated surface of the specimens.

\subsection{Instrumentation and Testing of Composite Walls}

Two strain gauges ( $\mathrm{S} 1$ and $\mathrm{S} 2$ ) were installed in OSBCWs. One strain gauge was installed at $50 \mathrm{~mm}$ below the midpoint of upper row of connection and other strain gauge was installed at $50 \mathrm{~mm}$ above the midpoint of the middle row of connection. Four strain gauges (S1-S4) were installed in PSSCWs. Two strain gauges were installed at $50 \mathrm{~mm}$ below the upper row of connection (one in thinner part of the wall and other in thicker part of the wall). Other two strain gauges were installed at $50 \mathrm{~mm}$ above the middle row of connection (One in thinner part of the wall and other in thicker part of the wall). The installation of strain gauges is presented in Figures 3.1 and 3.2.

The composite walls were tested in MTS machine under uniformly distributed axial loading. Linear voltage displacement transducers (LVDT) were fitted during the test. The LVDTs (L1-L4) were fitted at middle row of connection and middle between each two consecutive rows of connection on thinner thickness of the wall to record transverse or lateral displacements. During the test, load-displacement and load-strain response were recorded by computer data acquisition system. The composite wall axial test set up with instrumentation is shown in Figure 4.1 and schematic diagrams indicating locations of LVDTs are shown in Figure 4.2. 


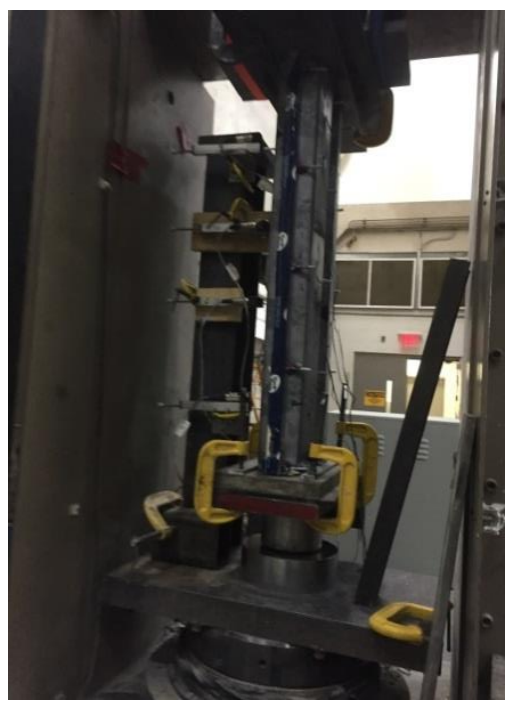

PSSCW

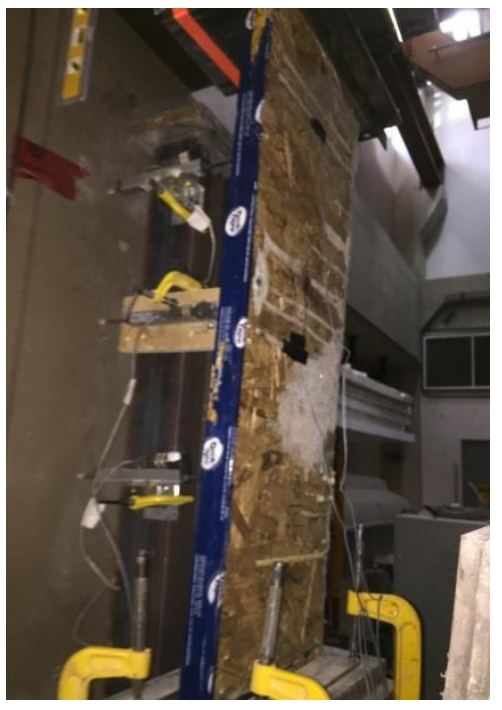

OSCW

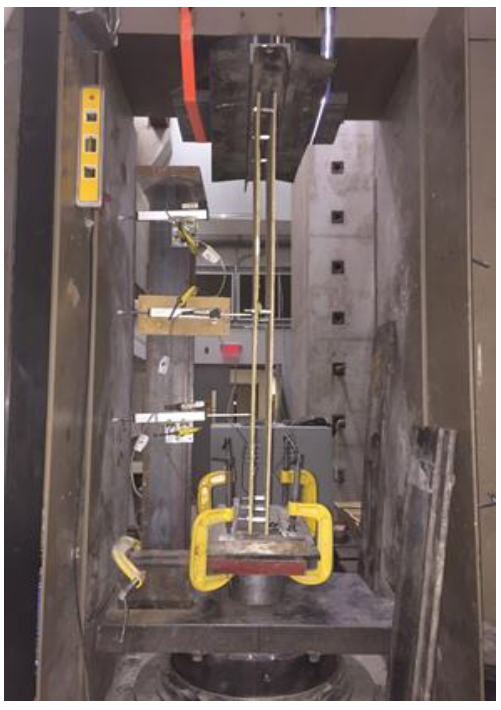

OSBCW without CFM infill

Figure 4.1- Axial load test setup of wall on MTS machine

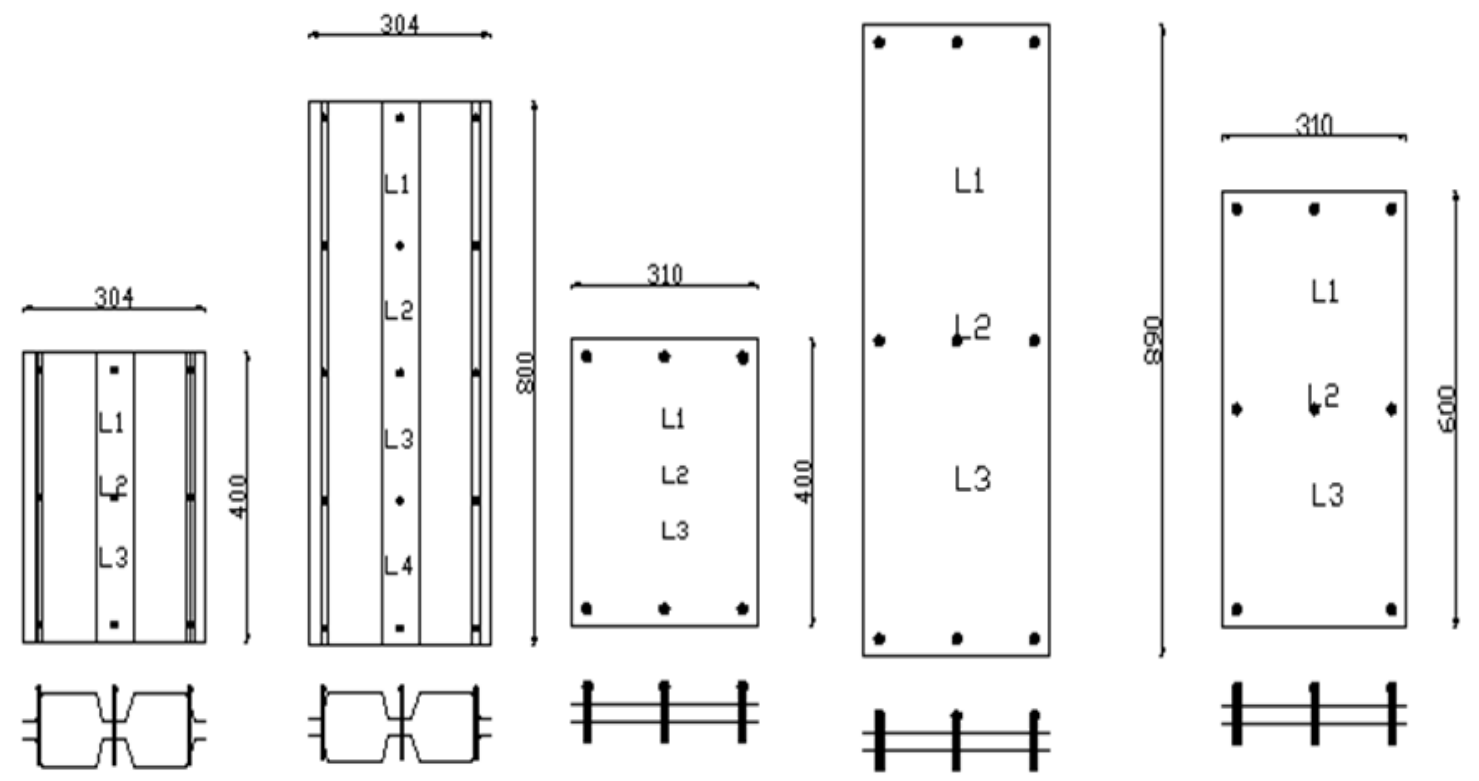

Figure 4.2- Position of LVDTs (L1, L2, L3 and L4) during testing of walls 


\subsection{Experimental Results and Discussion}

Experimental results are explained based on load displacement response, load-strain response and failure modes. Experimental results are summarized in table 4.1 which includes first buckling load, ultimate load, failure modes and maximum deformation at ultimate load.

Table 4.1- Experimental results

\begin{tabular}{|c|c|c|c|c|}
\hline $\begin{array}{l}\text { Specimen } \\
\text { no. }\end{array}$ & $\begin{array}{l}\text { First buckling } \\
\text { load (KN) }\end{array}$ & $\begin{array}{l}\text { Ultimate } \\
\text { Load (KN) }\end{array}$ & $\begin{array}{l}\text { Maximum deformation } \\
\text { at ultimate load (mm) }\end{array}$ & Failure modes \\
\hline Wall 1 & 44 & 95 & 7.15 & $\begin{array}{l}\text { Interface bond between PSS and } \\
\text { CFM, local buckling at bottom of } \\
\text { wall and edge plate buckling }\end{array}$ \\
\hline Wall 2 & 26 & 78.67 & 5.83 & $\begin{array}{l}\text { Interface bond between PSS and } \\
\text { CFM, local buckling at top of wall } \\
\text { and edge plate buckling }\end{array}$ \\
\hline Wall 3 & 22 & 72.12 & 4.73 & $\begin{array}{l}\text { Interface bond between PSS and } \\
\text { CFM, local buckling at top of wall } \\
\text { and edge plate buckling }\end{array}$ \\
\hline Wall 4 & 23.5 & 71.25 & 8.52 & $\begin{array}{l}\text { Interface bond between PSS and } \\
\text { CFM, local buckling at top of wall } \\
\text { and edge plate buckling }\end{array}$ \\
\hline Wall 5 & 22 & 58.5 & 9.01 & $\begin{array}{l}\text { Overall buckling and inter bond } \\
\text { between OSB and CFM }\end{array}$ \\
\hline Wall 6 & 20.5 & 40.17 & 7.59 & $\begin{array}{l}\text { Overall buckling and interface } \\
\text { bond between OSB and CFM }\end{array}$ \\
\hline Wall 7 & 16 & 33.84 & 7.69 & $\begin{array}{l}\text { Overall buckling and interface } \\
\text { bond between OSB and CFM }\end{array}$ \\
\hline Wall 8 & 15.28 & 31.75 & 6.12 & $\begin{array}{l}\text { Overall buckling and interface } \\
\text { bond between OSB and CFM }\end{array}$ \\
\hline Wall 9 & 2.8 & 3.84 & 2.05 & Overall buckling \\
\hline Wall 10 & 2.4 & 3.01 & 1.66 & Overall buckling \\
\hline
\end{tabular}




\subsubsection{Failure Modes}

Failure modes were closely observed during the test in both steel sheet and oriented strand board composite walls. In steel sheet composite walls, it was observed that the failure was due to interface bond between steel and commercial form material, buckling at the edge of steel sheeting, local buckling at top and bottom of steel sheeting. There was no global buckling observed at the middle of wall with global lateral deflection of profiled steel sheet in the same direction. But local buckling was observed where profiled sheet buckled outward from the commercial form material in different directions. This is the sign of additional stiffness provided by the infill of commercial form material which prevented the profiled steel sheeting to buckle globally. In wall 1, the local buckling was observed at bottom face of the wall while it was observed at the top face in wall 2, wall 3 and wall 4 (Figure 4.3).

In oriented strand board composite wall, each wall had different failure response however the interface bond between board and commercial form material was common failure problem. The failure of wall 5 was observed due to overall buckling failure at $40 \mathrm{~mm}$ above the bottom row of connectors. The failure of wall 6 was observed due to overall buckling failure at $100 \mathrm{~mm}$ below the central row of connectors. In wall 7 and wall 8 , the failure was observed due to overall buckling failure at $50 \mathrm{~mm}$ below the top row of connectors. The failure of wall 5 and wall 6 at the bottom level of wall was the indication of full load transfer from top to bottom of the wall. While there was inadequate load transfer in wall 7 and wall 8 from top to bottom of the wall and was failed at top level of wall.

The wall 9 and wall 10 had no infill material. It was observed that these walls were failed due to large buckling at centre of span at lower load. No failure was observed to the connector between the skins of the composite wall. The failures of the walls are presented in Figures 4.3 and 4.4 and 4.5 . 


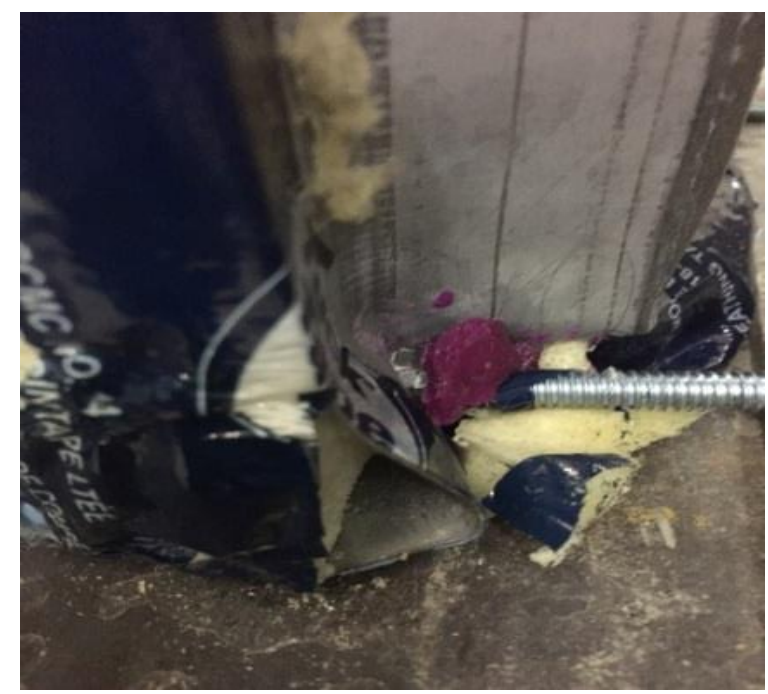

Wall 1

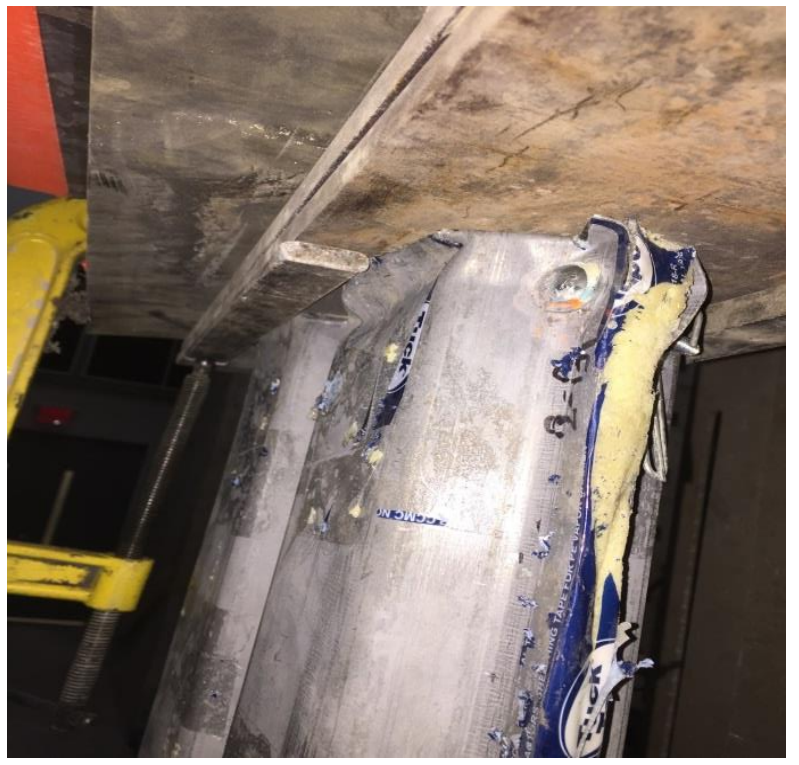

Wall 3

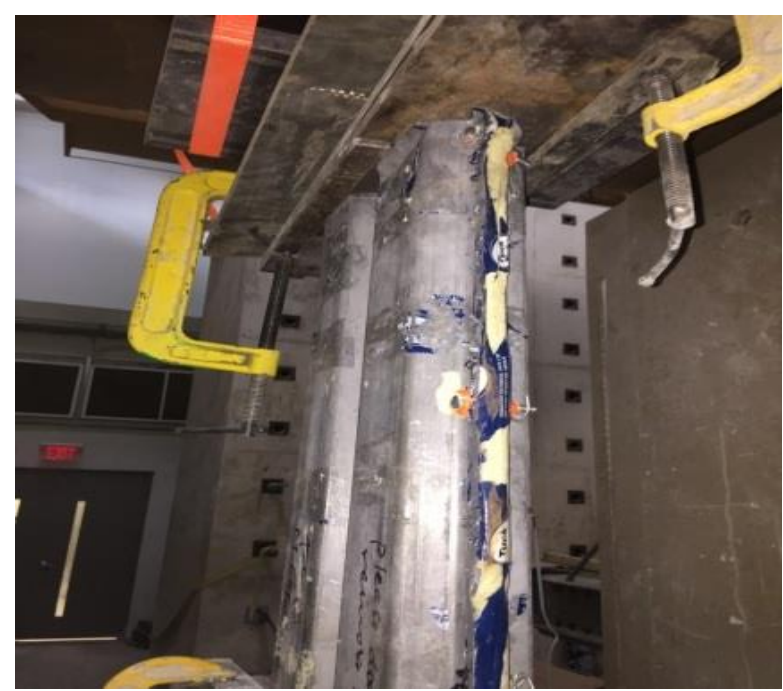

Wall 2

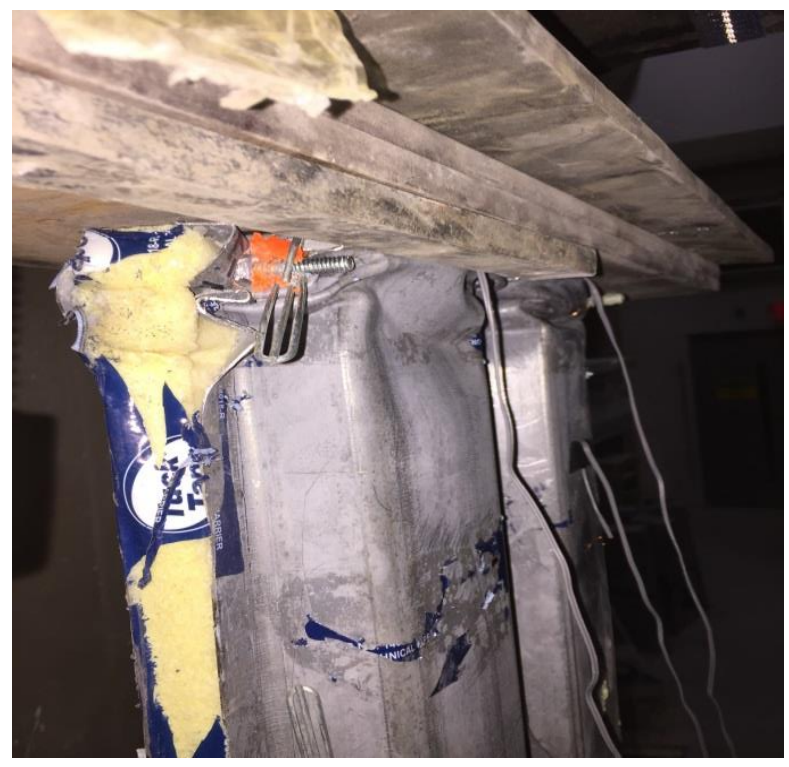

Wall 4

Figure 4.3- Failure modes profiled steel sheeting composite wall 


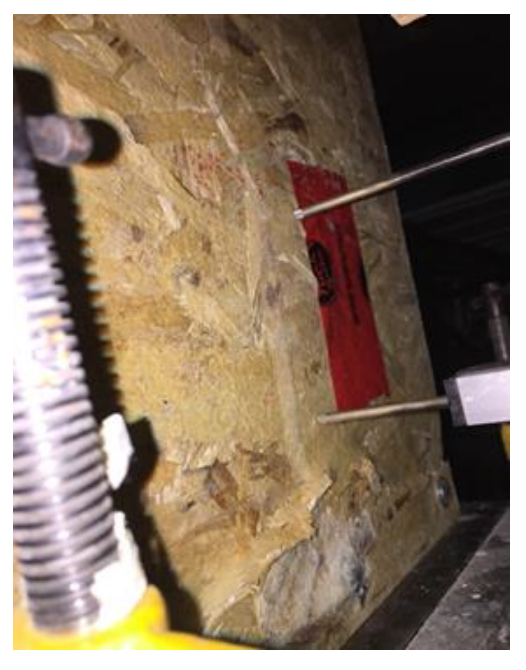

Wall 5

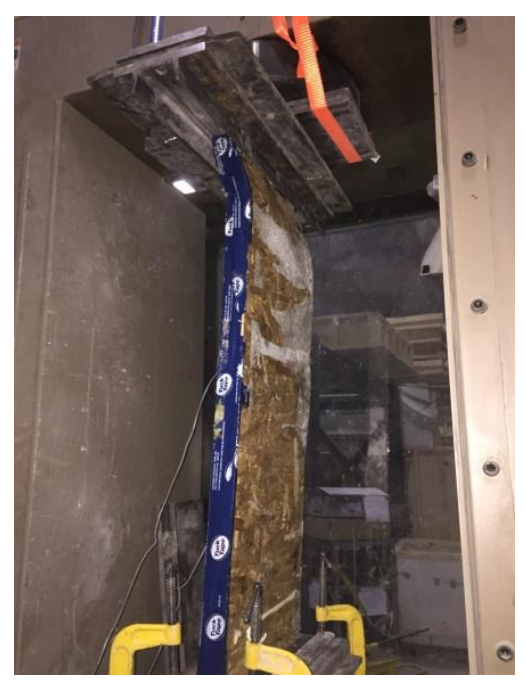

Wall 8

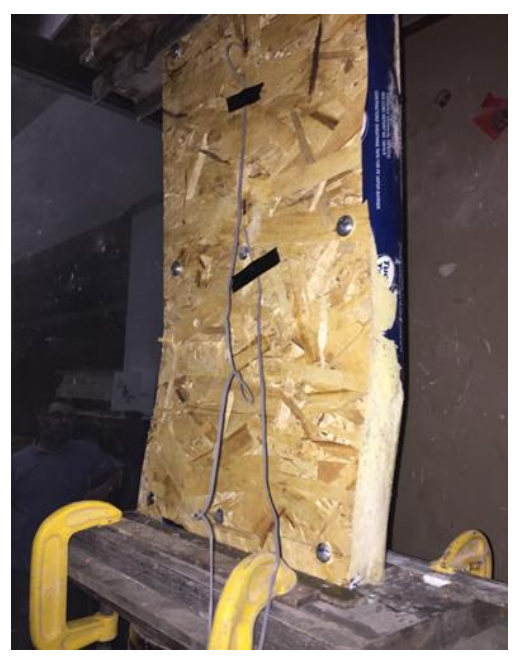

Wall 6

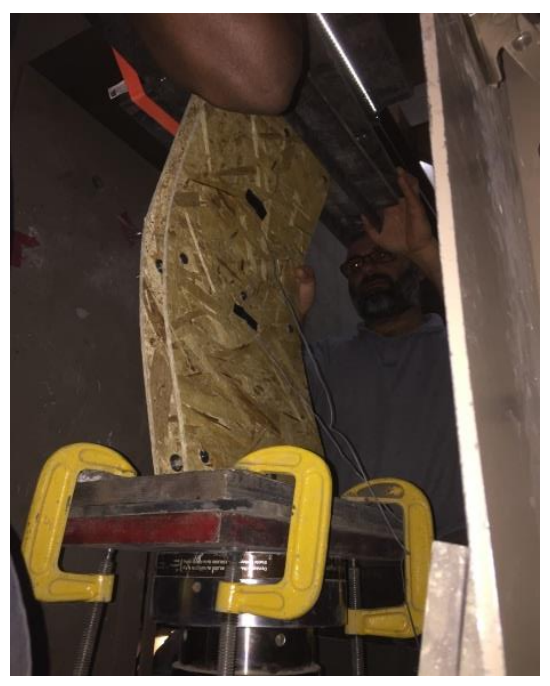

Wall 9

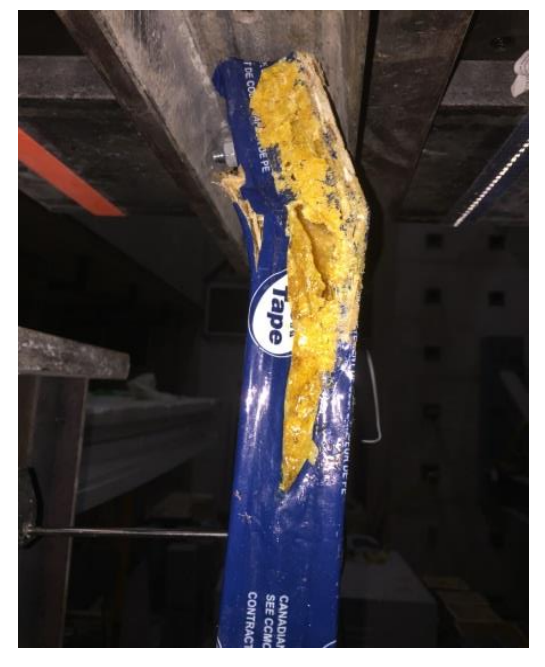

Wall 7

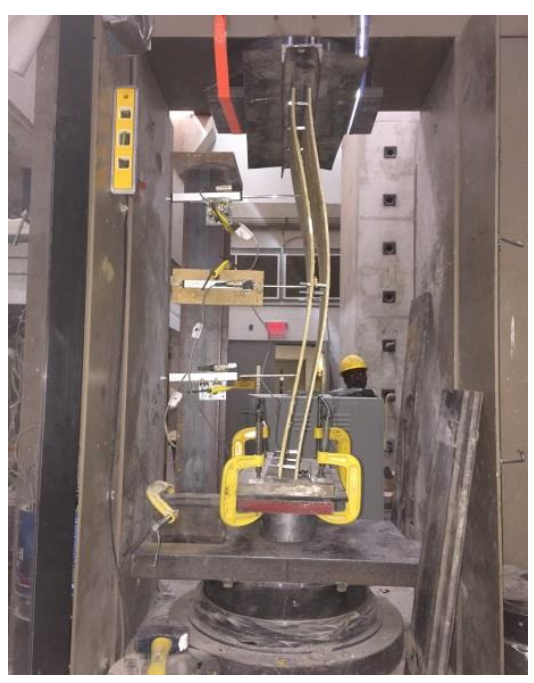

Wall 10

Figure 4.4- Failure modes of oriented strand board composite wall 


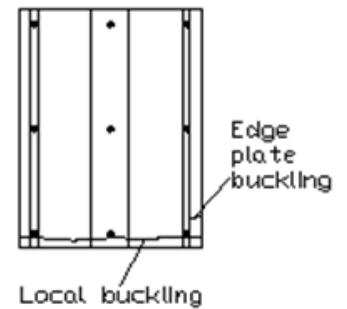

Wall 1

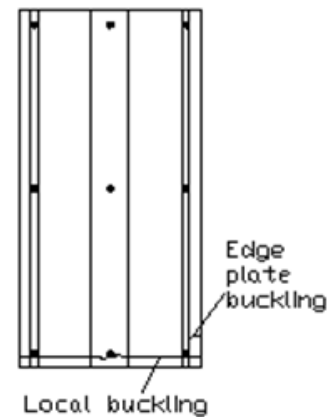

Wall 2

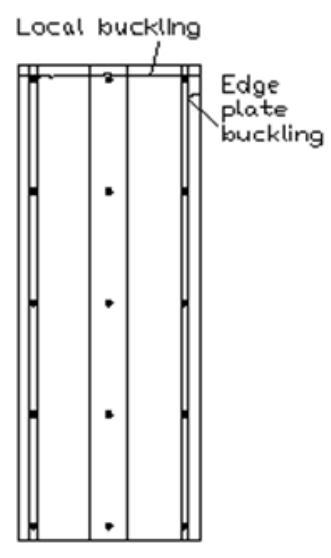

Wall 3

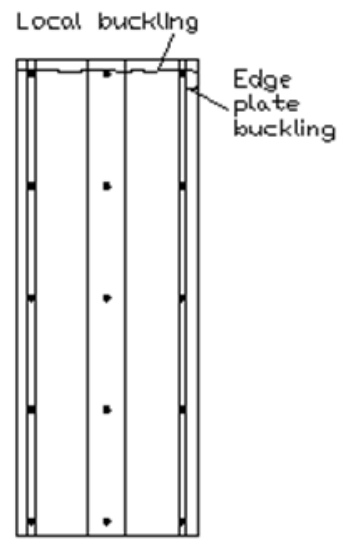

Wall 4

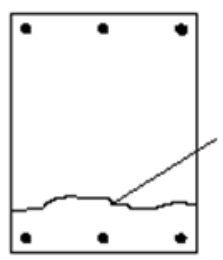

Wall 5

Wall 6

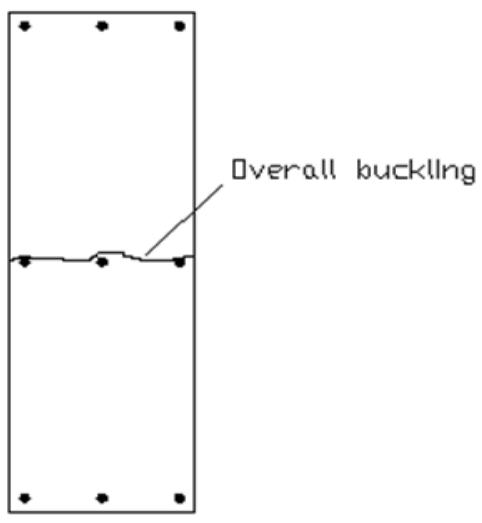

Wall 9

Wall 10

Figure 4.5- Failure modes of walls 


\subsubsection{Axial Load-deformation Characteristics of Composite Walls}

Axial load-deformation responses of the profiled sheet composite walls and oriented strand board composite walls are presented in Figure 4.6 and 4.7, respectively. It was observed from the loaddeformation responses of composite walls that there was slow rate of load increment in the early stage of the test. This was due to the localized deformation of profiled steel sheet and oriented strand board at top and bottom of the walls. After localized deformation, there was steady increase of deformation with the increase of load up to the peak value which was showing constant initial stifness. Whereas there was sharp drop in load immediately after the peak value of load showing high negative slope of the descending branch. This was due to unstable post peak performance with low ductility. This low ductility may cause the initiation of buckling before yielding.
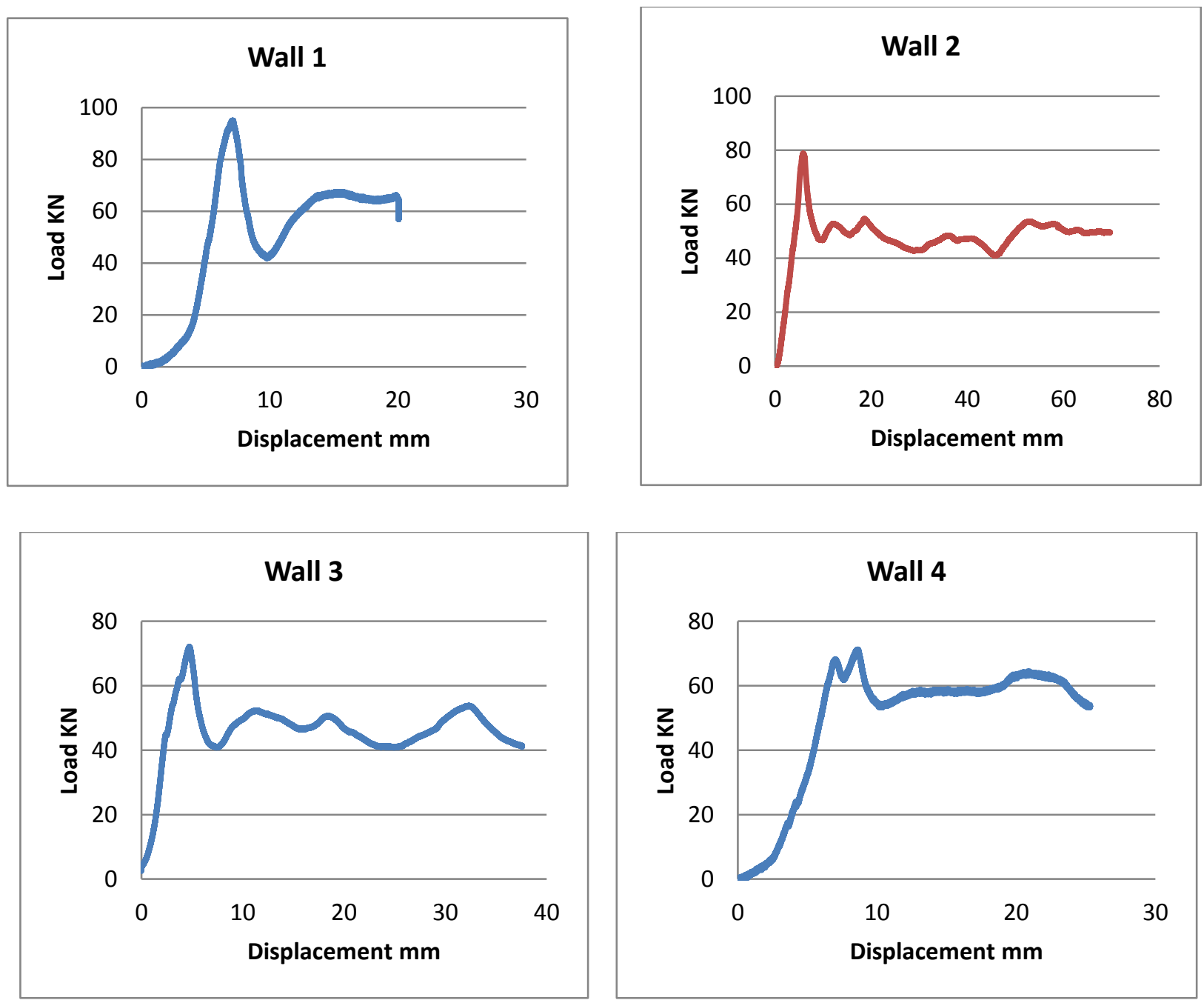

Figure 4.6- Load displacement behaviour of profiled steel sheet composite walls 

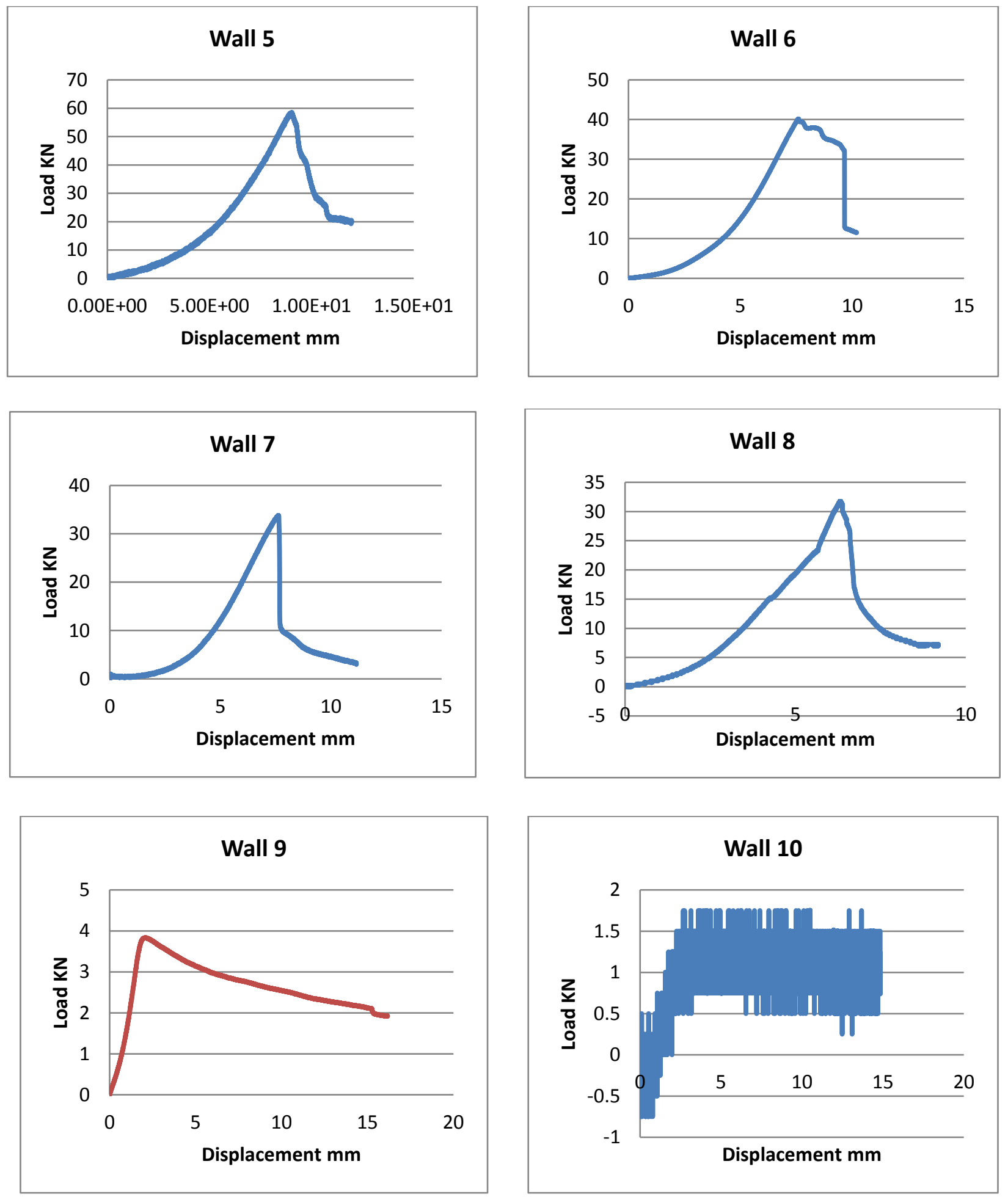

Figure 4.7- Load displacement behaviour of oriented strand board composite walls 


\subsubsection{Strain Characteristics of Composite Walls}

The load-strain responses of PSS and OSB walls are presented in Figures 4.8 and 4.9. It was observed from the tests that all four strain gauges were displaying compressive strain in each profiled steel sheet composite walls. In wall 1 and wall 2, the compressive strains were increasing from top to bottom of the wall which was indication of adequate load distribution from top to bottom of the wall. While the compressive strain were decreasing from top to bottom of wall 3 and wall 4 which was indication of insufficient load distribution from top to bottom of wall. Due to inadequate load transfer from top to bottom in wall 3 and wall 4 , it was observed the failure in these walls at loaded end. The strains in all walls did not reach yield strain of PSS at failure. The load-strain responses for strain gauge positions at S1, S2, S3 and S4 for PSSCWs are presented in Figure 4.8.

It was also observed that both strain gauges were showing Compressive strain in each oriented strand board composite walls. In wall 5 and wall 6 , it was observed that strain was increasing from top to bottom of the wall which was indicating sufficient load distribution along the height of the wall. While the strain in wall 7 and wall 8 were observed decreasing from top to bottom of the wall which was indicating inadequate load transfer from top to bottom of wall.

There was no infill material in oriented strand board wall 9 and wall 10 and it was seen extremely high buckling during test of these walls. In wall 9 and wall 10, it was seen strain decreasing from top to bottom of the wall. The load-strain responses for strain gauge positions at S1 and S2 for OSBCWs are presented in Figure 4.9. 

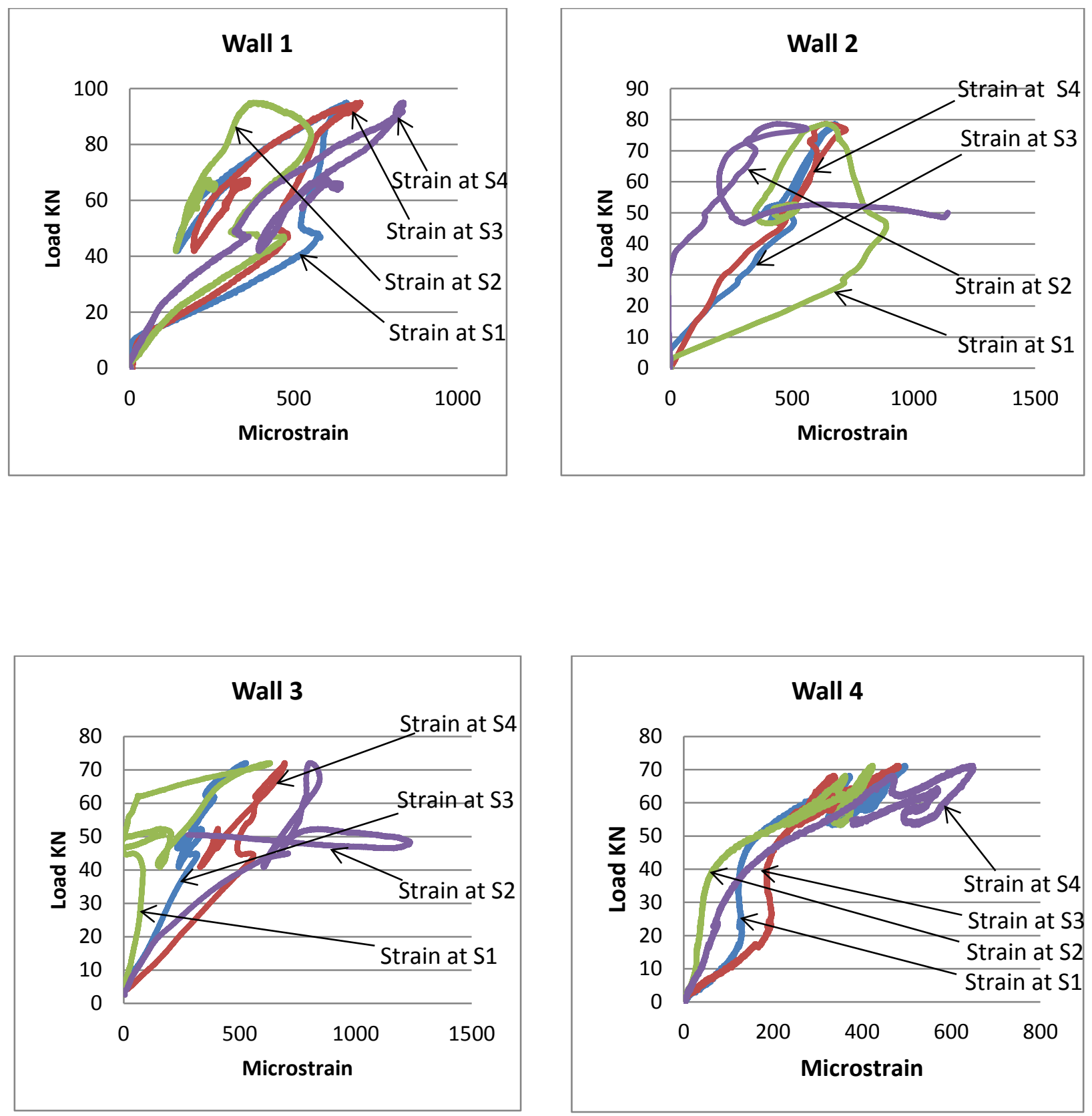

Figure 4.8- Load strain behaviour of profiled steel sheet composite wall 

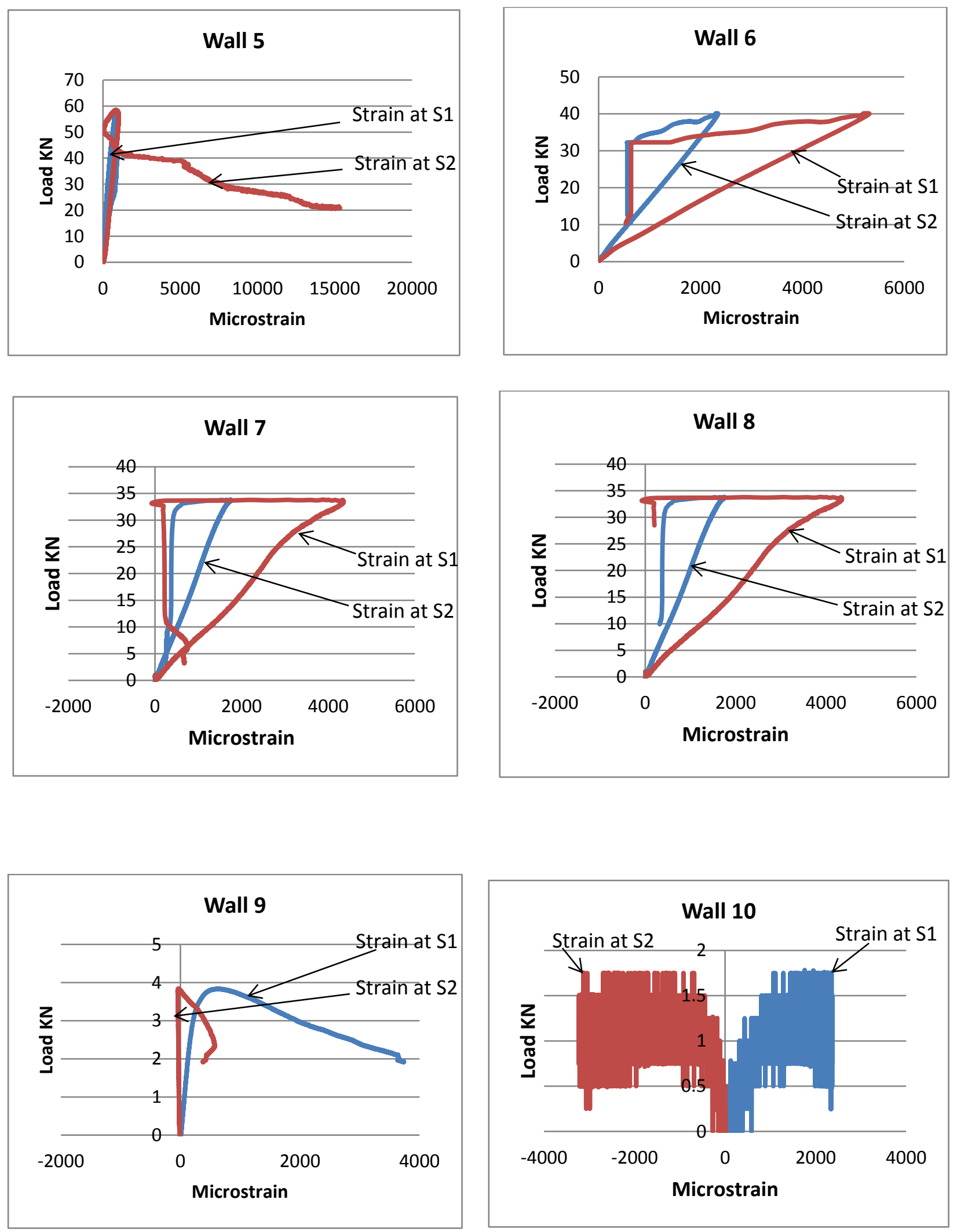

Figure 4.9- Load strain behaviour of oriented strand board composite wall 


\subsubsection{Load-transverse Displacement Response}

Axial load-transverse displacement responses of the walls were measured from the readings provided by LVDTs installed on the wall surface at various heights as shown in Figure 4.2 which was connected to the computer data acquisition system. Load-transverse displacement responses of the steel profiled sheet composite walls (wall 1 and wall 4) and oriented strand board composite walls (wall 5, wall 8 and wall 10) are presented in Figure 4.10. It is observed that all LVDTs recorded transverse (lateral) displacement in the same direction (outward) at ultimate load in the steel profiled sheet composite walls and the magnitude of the transverse displacements was comparatively low. On the other hand, oriented strand board composite wall 5 and wall 8 showed different load-transverse displacement behaviour from each other. Wall 5 showed low magnitude of transverse displacement in the same (outward) direction at ultimate load while wall 8 showed double curvature with magnitude of transverse displacement more than wall 5. Wall 10 had no infill material and it showed large transverse displacement in the same direction. 

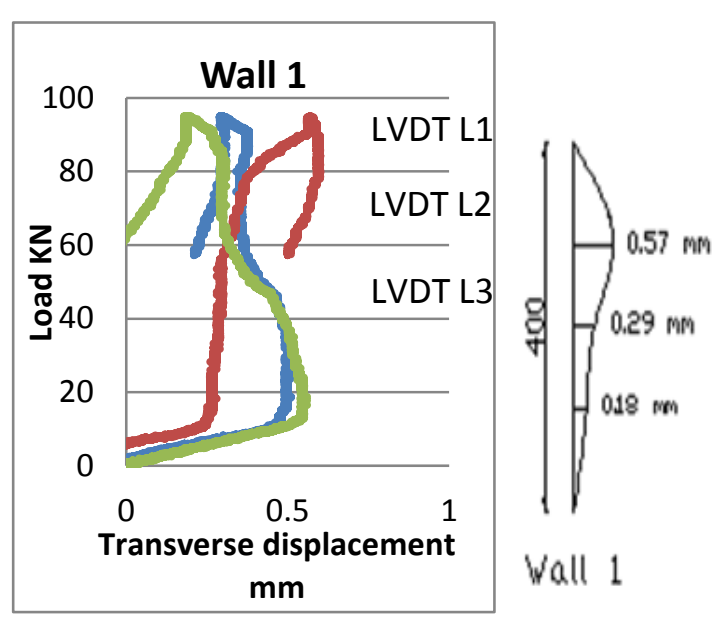

Wall 1

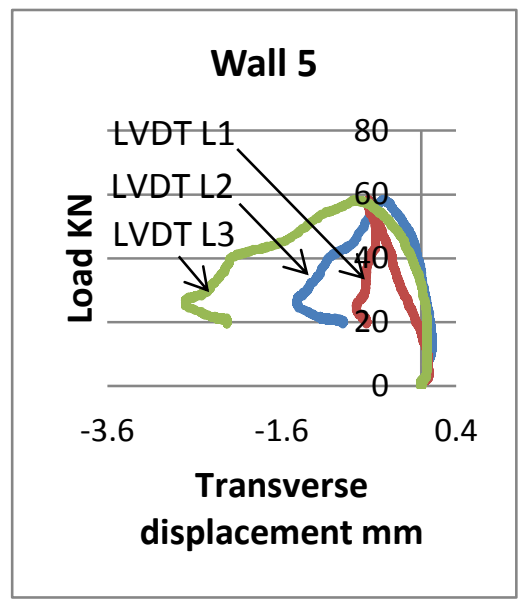

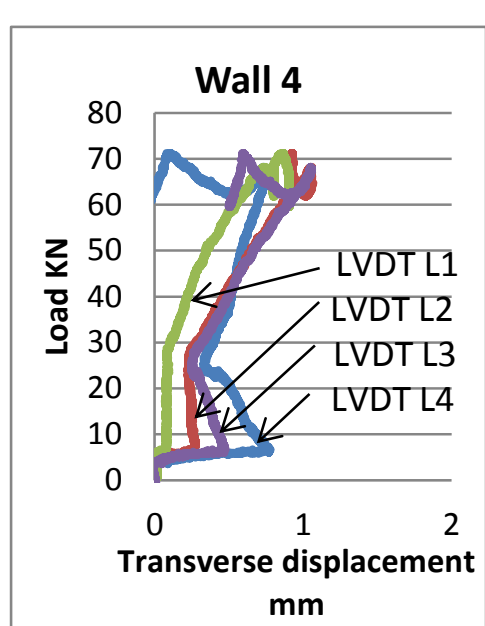
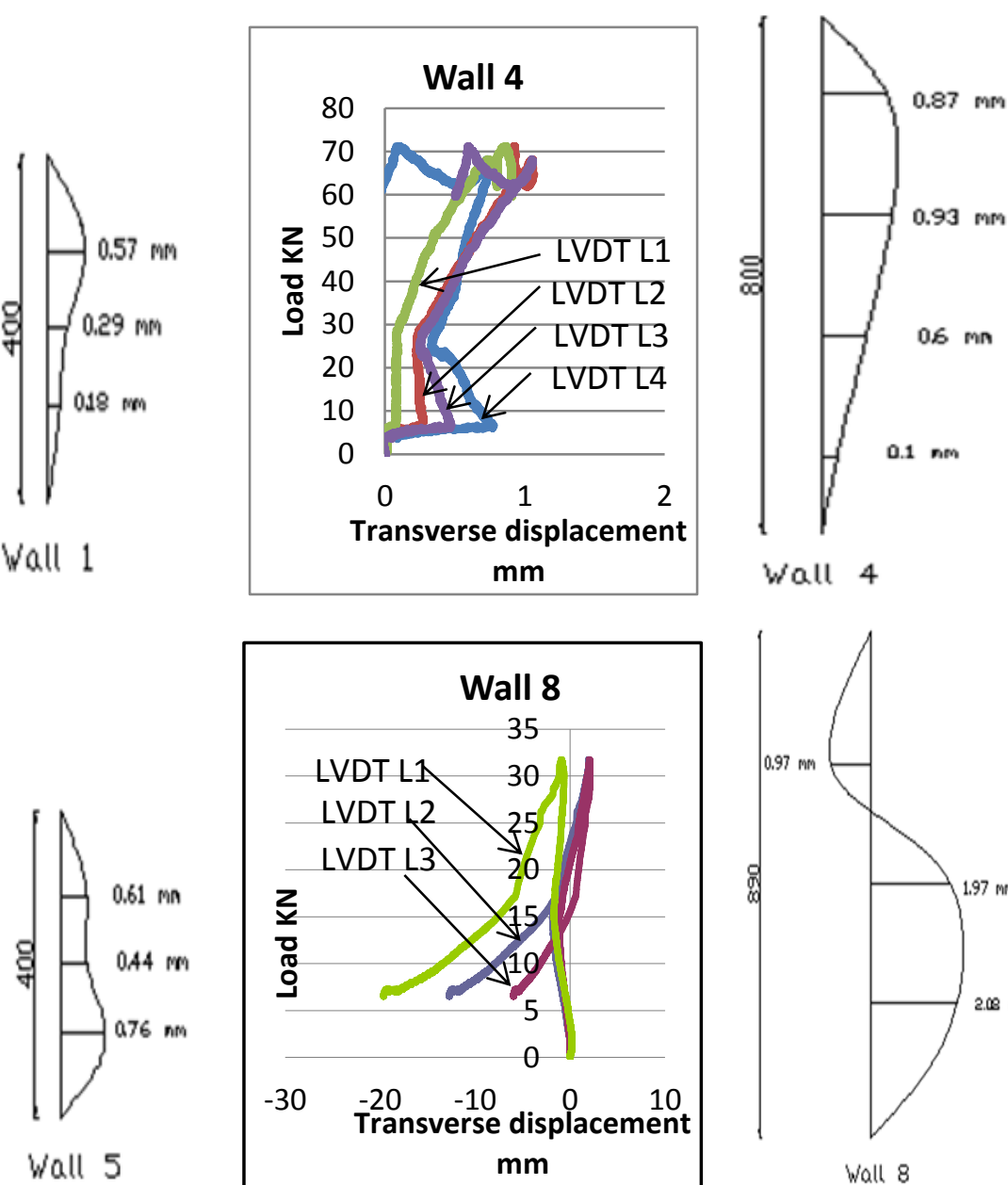

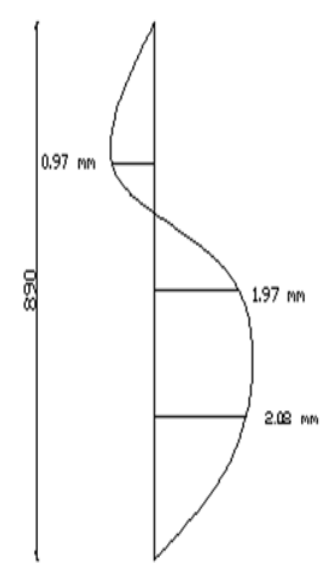

Wall 8
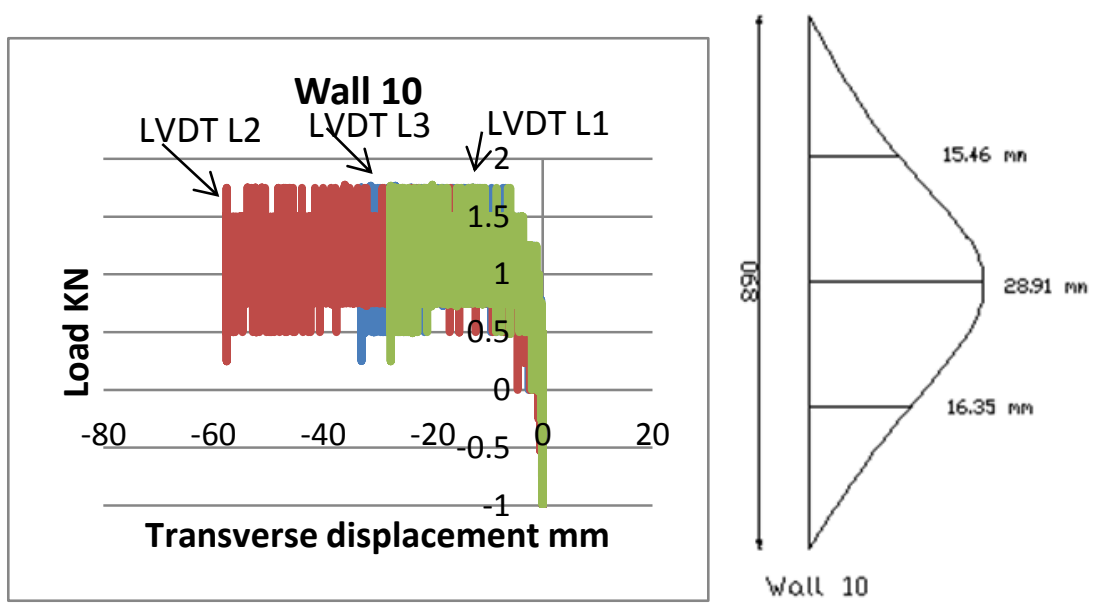

Figure 4.10- Load-transverse displacement behaviour of composite wall 


\subsubsection{Effect of Skin and Infill Interaction}

Four walls (wall 6, wall 7, wall 9 and wall 10) were made to study the effect of oriented strand board and commercial form material interaction. Wall 6 and wall 9 were fabricated with identical geometric dimensions and rows of connectors. Similarly wall 7 and wall 10 were fabricated with identical geometric dimension and rows of connectors. Wall 6 and wall 7 had double skins of oriented strand board with commercial form material infill where as wall 9 and wall 10 had double skins of oriented strand board without infill. Axial load displacement responses of walls with infill and without infill are presented in Figure 4.11. It was observed from the test that wall 9 and wall 10 (without CFM infill) buckled too much at the centre and were unable to carry enough loads. However, the load carrying capacity of wall 6 and wall 7 was increased significantly compared to wall 9 and wall 10, respectively. The increase in load carrying capacity of wall 6 and wall 7 was attributed to the increase of stiffness of the wall due to commercial form material infill. It was seen from the test that the load caring capacity of wall 6 was increased by $946 \%$ compared to wall 9 and the load caring capacity of wall 7 was increased by $1714 \%$ compared to wall 10.
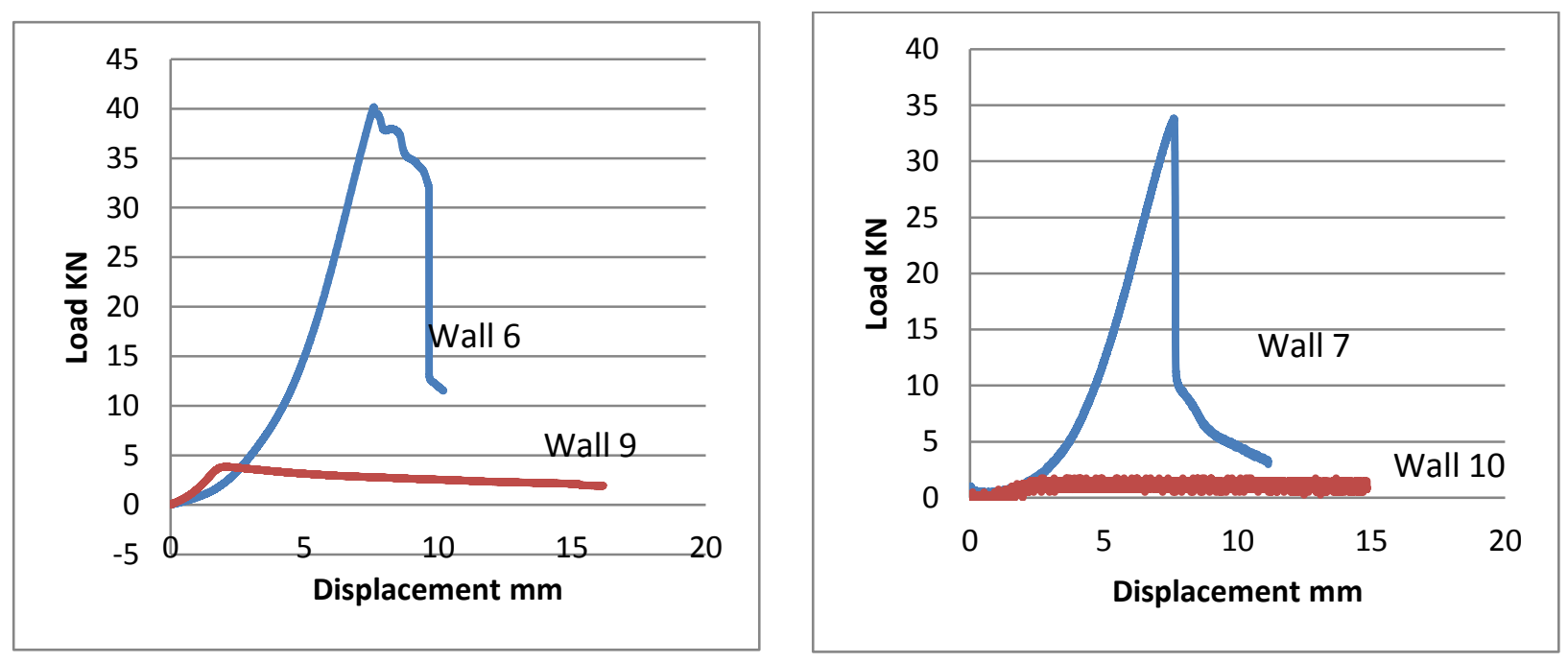

Figure 4.11- Load capacity enhancement due to interaction between OSB and infill form material

\subsubsection{Effect of Height/Slenderness of Wall}

The height of profiled steel sheet composite wall was increased from 400 (wall 1) to 600 (wall 2) and height of oriented strand board composite wall was increased from 600 (wall 6) to 890 (wall 7) while other geometric dimensions and number of rows of connectors were kept constant to study the slenderness effect. It was seen from the test that the ultimate load capacity of the wall was decreased by 
$17.2 \%$ in profiled steel sheeting composite wall and $15.76 \%$ in oriented strand board composite wall. In steel sheeting composite wall, the decrease in strength might be caused by lowering of edge plate buckling capacity and inadequate transfer of load from top to bottom of the wall. In oriented strand board composite wall, the decrease in strength may be caused by lowering of overall buckling capacity of the wall. The comparison of load displacement curve of wall 1 with wall 2 and wall 6 with wall 7 showed slenderness effect are presented in Figure 4.12. The effect of height to width ratio and connector spacing to height ratio on axial load capacity of composite walls are presented in Figures 4.13 and 4.14. In both PSS and OSB walls ultimate load decreased with the increase of height to width ratio (h/w) and connector spacing to width ratio (s/h) of walls as expected.
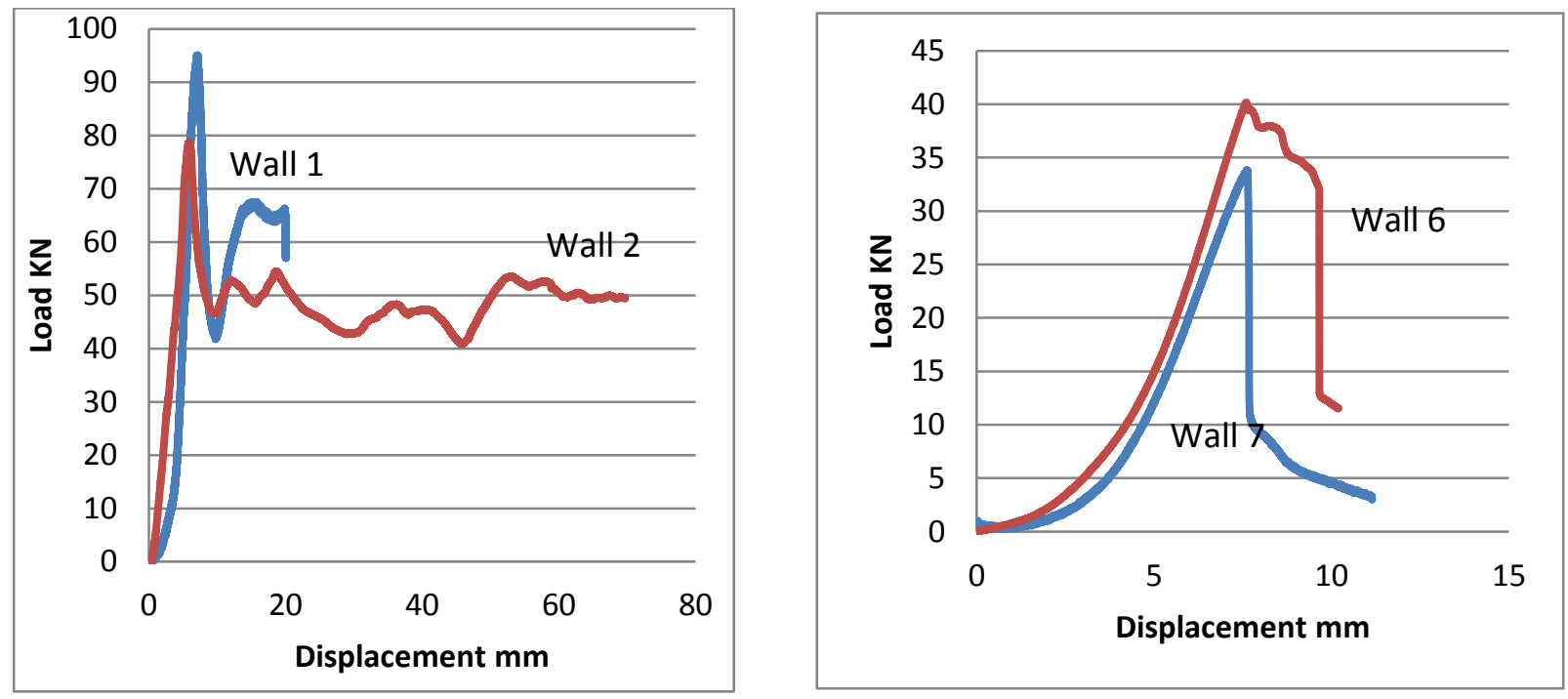

Figure 4.12- Slenderness effect comparison of wall 1 with wall 2 and wall 6 with wall 7 


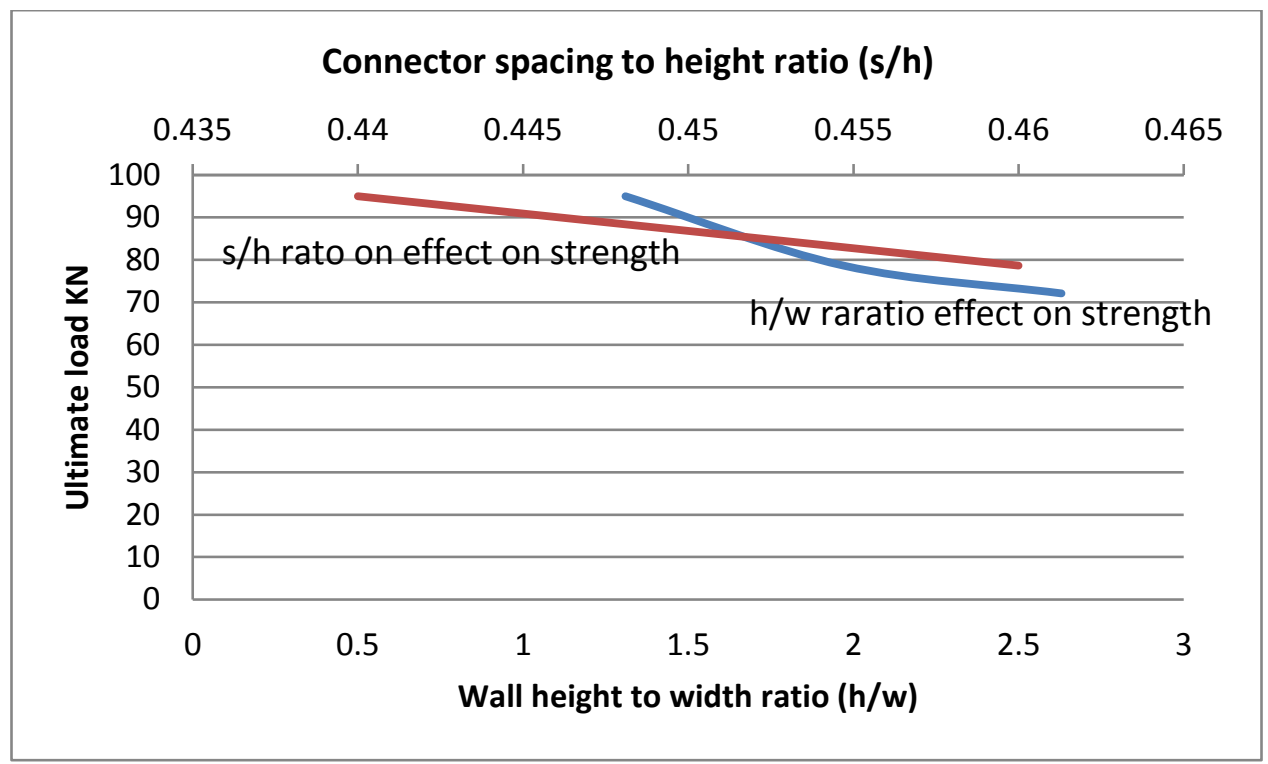

Figure 4.13- Effect of height to width ratio and connector spacing to width ratio on axial load of profiled sheet composite wall

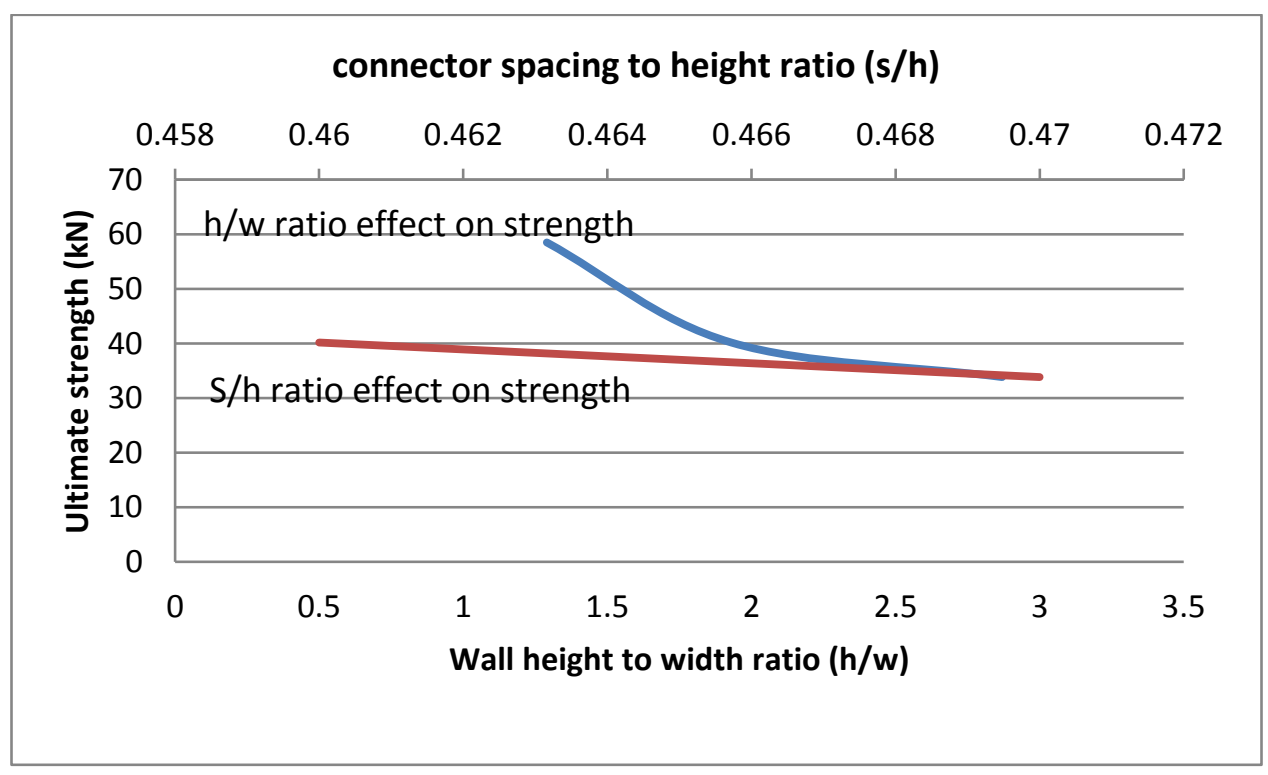

Figure 4.14- Effect of height to width ratio and connector spacing to width ratio on axial load of OSB composite wall

\subsection{Thermal Conductivity Test of Walls}

Thermal conductivity test was performed on wall 1 and wall 5 . A ply wood box was made with one side open. Open side of the box was mounted on wall 1 (PSSCW) and wall 5 (OSBCW). In wall 1, two thermocouples (one on the thicker part of the wall and other on the thinner part of the wall) were 
installed on upper face and two thermocouples were installed on the opposing face at the same location as on upper face. Similarly in wall 2, two thermocouples were installed, one in each face at opposite side. Two cylindrical pipes were fitted on the top of the box. The wooden box was fully insulated with upper face of the wall by insulating material while lower face of the wall was separately fully insulated. Hair drier was installed in each pipe for providing heat on upper face of the wall. All thermocouples were connected to the computer and temperature development with time in each thermocouple was recorded by computer data acquisition system. The experimental test set up for thermal resistance test is presented in Figure 4.15. Wall dimension and cross-section with experimental test set up are shown in Figure 4.16.

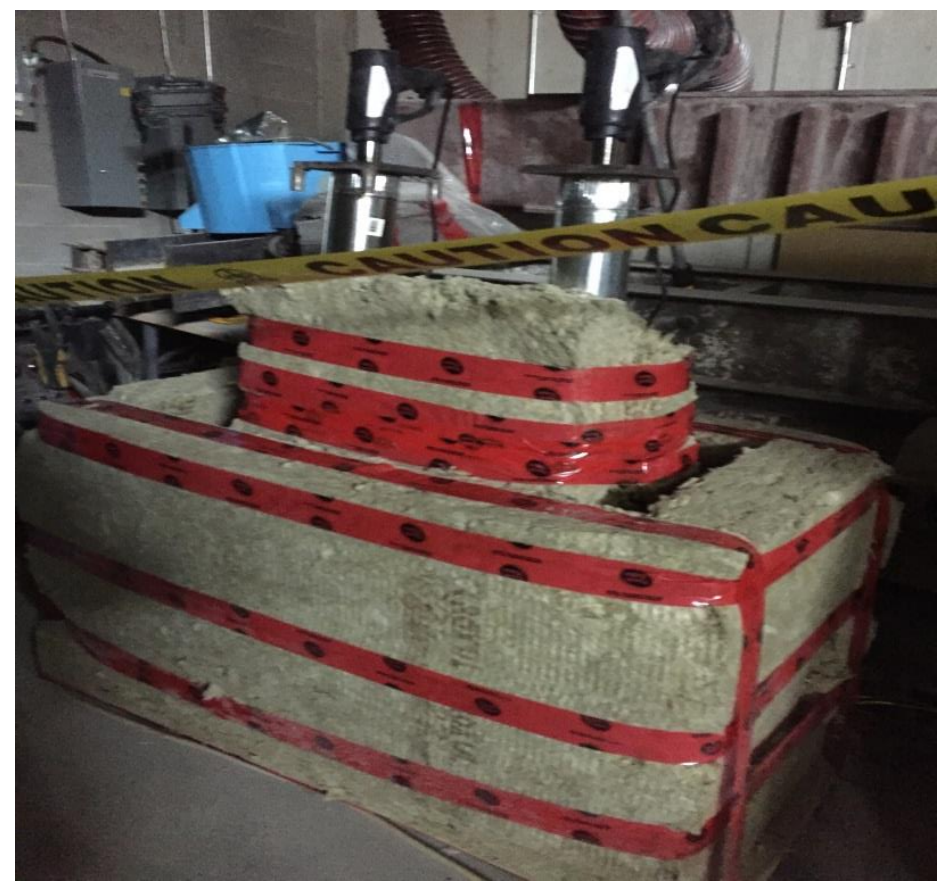

Figure 4.15- Test set up for thermal conductivity test of wall 

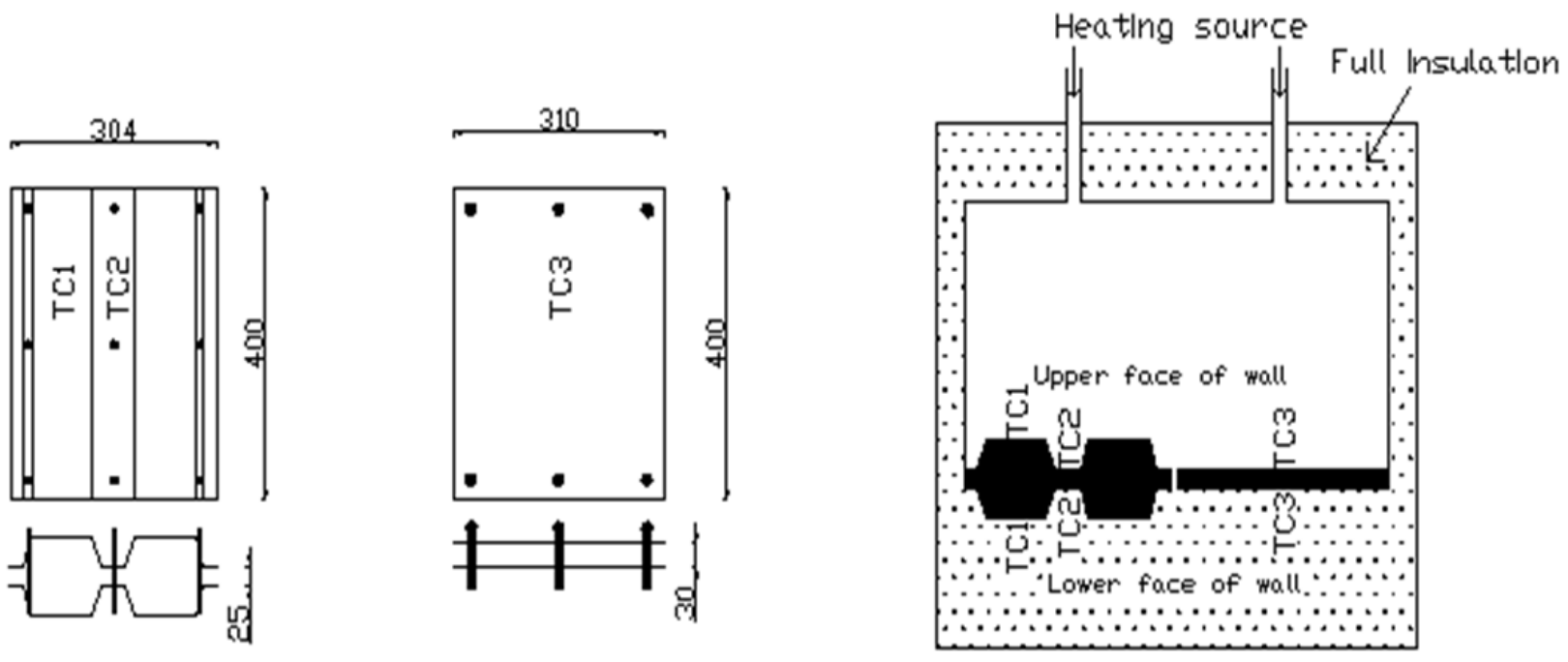

Figure 4.16- Wall dimensions and schematic of test set-up showing specimens showing thermocouples

(TC1-TC3)

Temp in input face of the wall was maintained up to 57 degree centigrade. The input face and output face temperature was measured every single second up to 46 hour. The plot between input face temperature and output face temperature with time is presented in Figure 4.17, 4.18 and 4.19.The temperature difference between two faces is found to be higher in OSB wall than PSS wall (as shown in Figure 4.20) - confirming that tested OSB wall was less thermal conductive than PSSB wall. More detailed investigations are necessary on this aspect to study thermal conductivity of OSSB and PSSCW walls with CFM compared to other infill materials such as concrete.

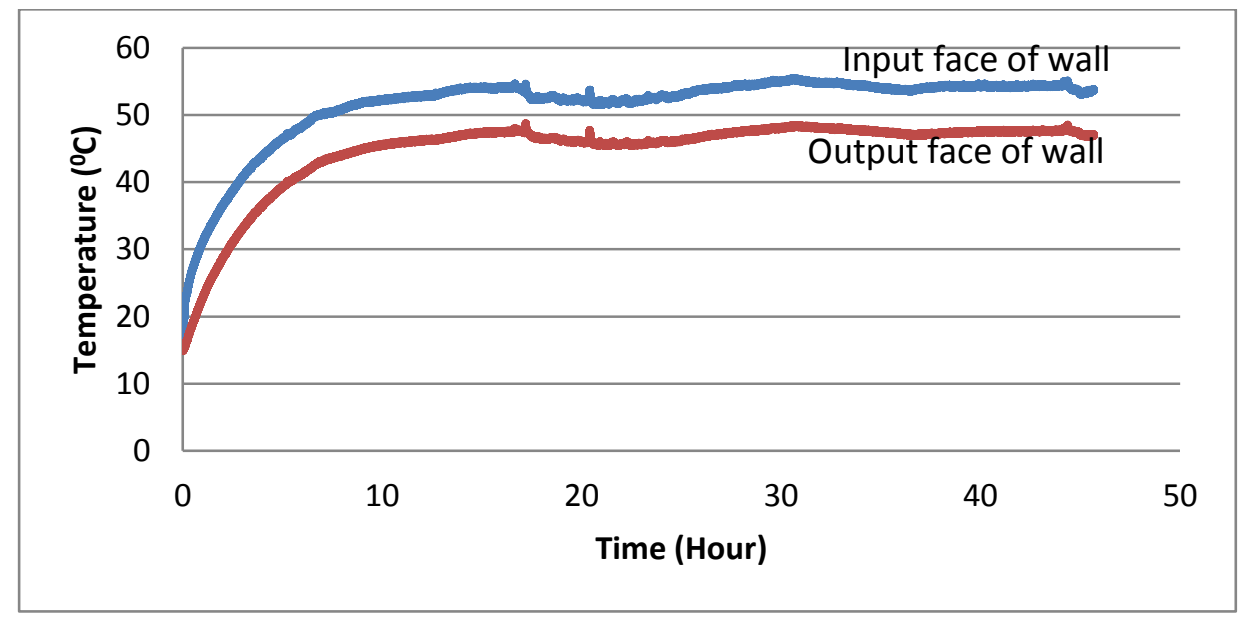

Figure 4.17- Thermocouple temperature data at larger thickness of PSSCW wall 1 


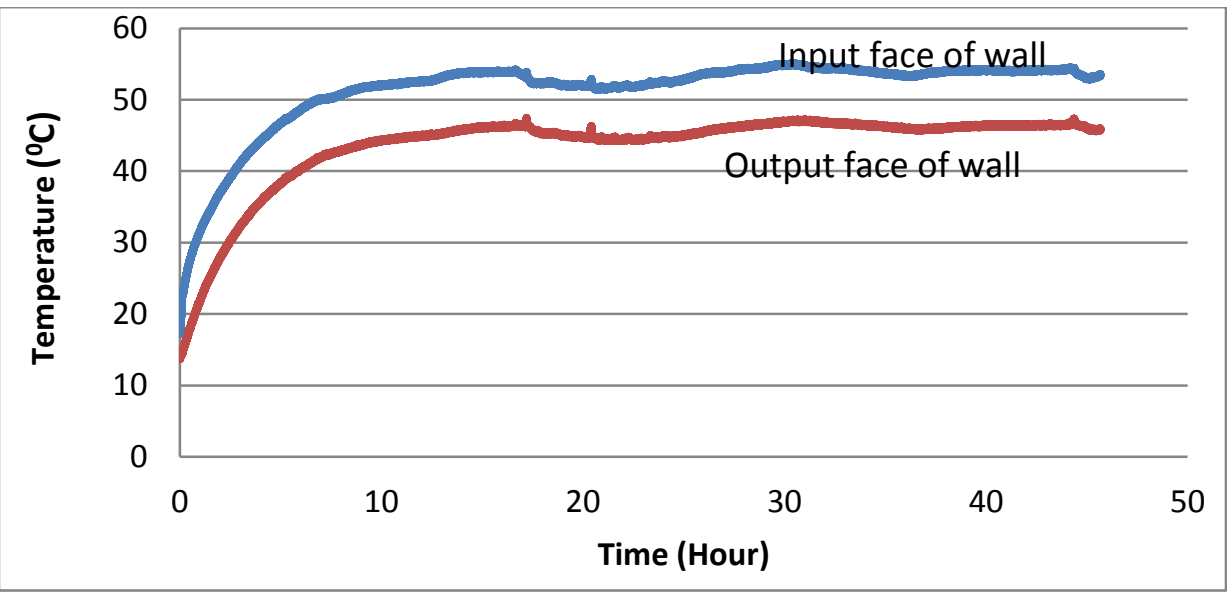

Figure 4.18- Thermocouple temperature data at thinner thickness of PSSCW wall 1

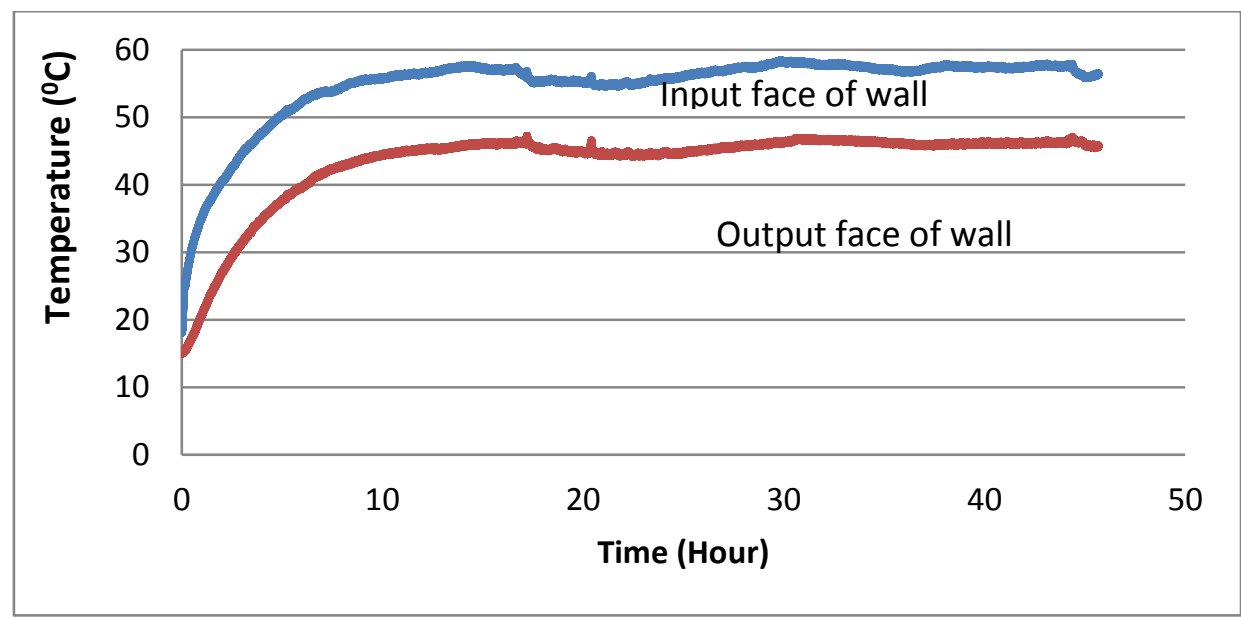

Figure 4.19- Thermocouple temperature data of OSBCW wall 5 


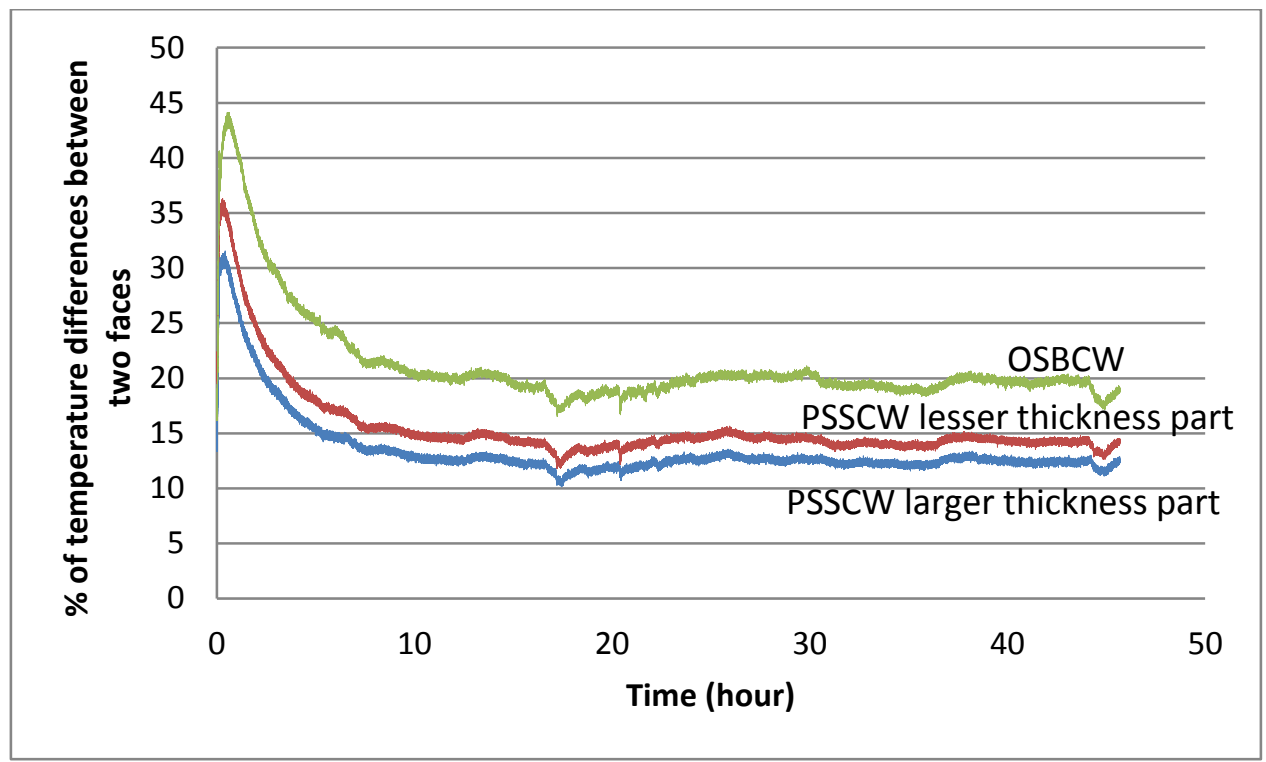

Figure 4.20- Comparison of $\%$ of temperature differences between two faces of OSBCW with PSSCW

\subsection{Flexural Behaviour of OSBCWs with CFM Infill}

An OSB composite wall (wall 11) specimen was made of two skin of oriented strand board with commercial form material infill of width $310 \mathrm{~mm}$ and height $890 \mathrm{~mm}$. The geometry and dimension of wall 11 is shown in Figure 4.21. The wall was tested as simply supported beam having a span of $800 \mathrm{~mm}$ under four point (two load and two reaction points) loading. Statically determinate system was made by providing hinge and roller supports at the two ends. The wall was instrumented with two strain gauges and one LVDT. One of the strain gauges was installed at the lower face of the wall at the mid span while other one at the upper face at mid span. LVDT was installed at lower face of the wall at mid span. Strain gauges and LVDT were connected to a computer data acquisition system to store the data during testing. The test set up is presented in Figure 4.22. 


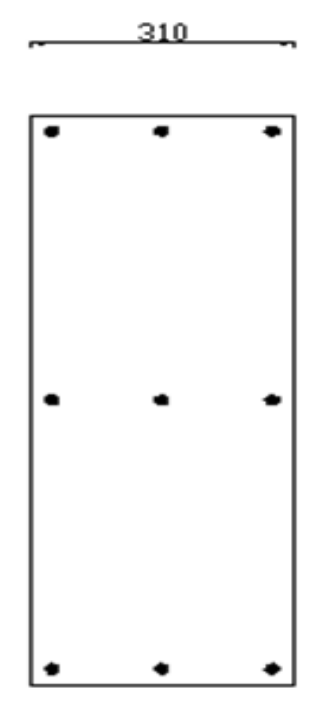

Wall elevation

$$
\text { 명 }
$$

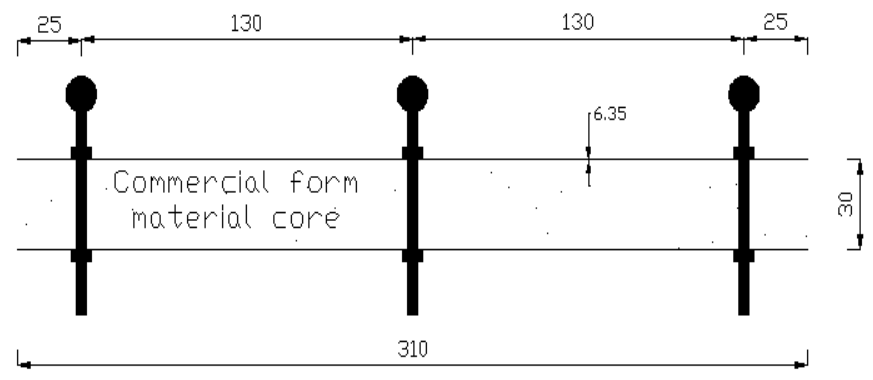

Wall cross-section

Figure 4.21- Wall 11 showing geometry and dimension

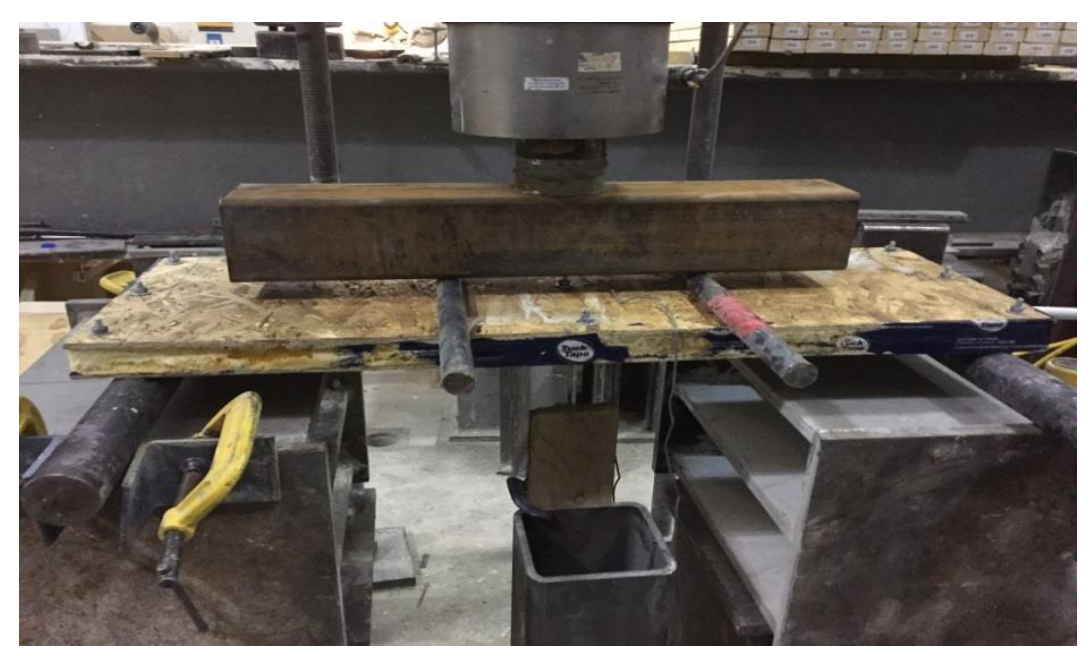

Figure 4.22- Four point flexural load test set-up for OSBSW wall

The ultimate load capacity of the OSSB wall with CFM infill was $4.37 \mathrm{KN}$ and mid span displacement at ultimate load was $19 \mathrm{~mm}$. Maximum tensile and compressive strains were 4587 and 2747 microstrain respectively. 


\subsubsection{Failure Modes}

Vertical mid-span flexural deflection of the wall was increased with the increase of load and the separation between lower layer of oriented strand board and commercial form material began to appear with continuous increase of load. With further increase of load, the cracking of lower level of oriented strand board was started at loading point and extended through commercial form material up to the upper level of oriented strand board. There was no evidence of shear failure found near the supports. Failure of slab during test is presented in Figure 4.23.

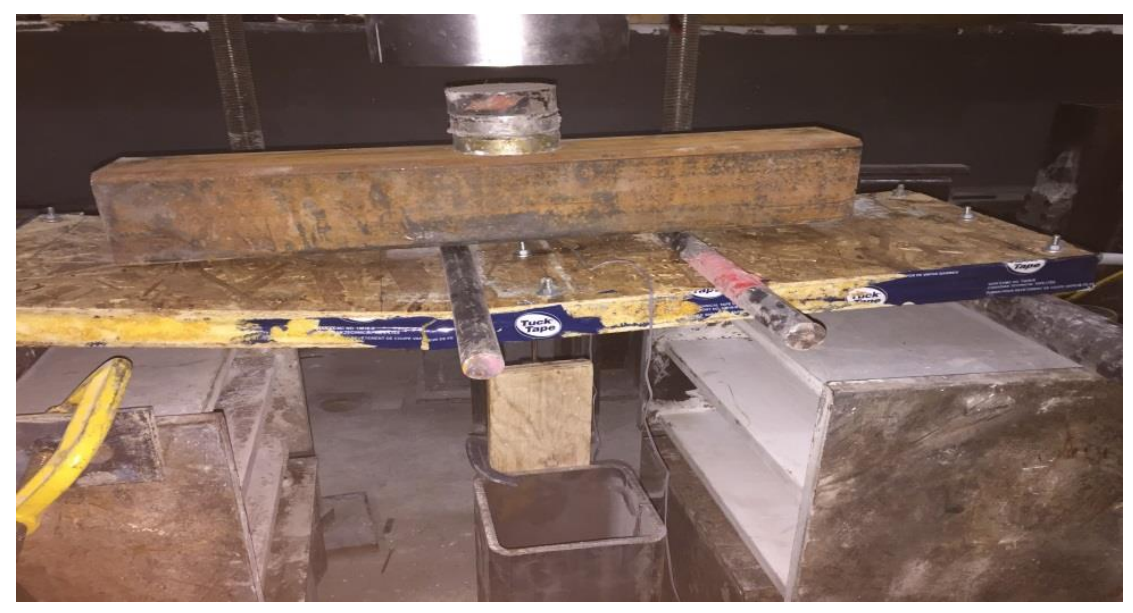

Figure 4.23- Failure of the wall during testing

\subsubsection{Load-deformation Characteristics}

Load-deformation response at mid span of the wall subjected to four point loading is presented in Figure 4.24. It was observed from the load-deformation response that load increased with the increase of load showing linear load deformation behaviour up to peak load. It was also observed that there was sudden drop of load after the peak load and then dropping gradually. 


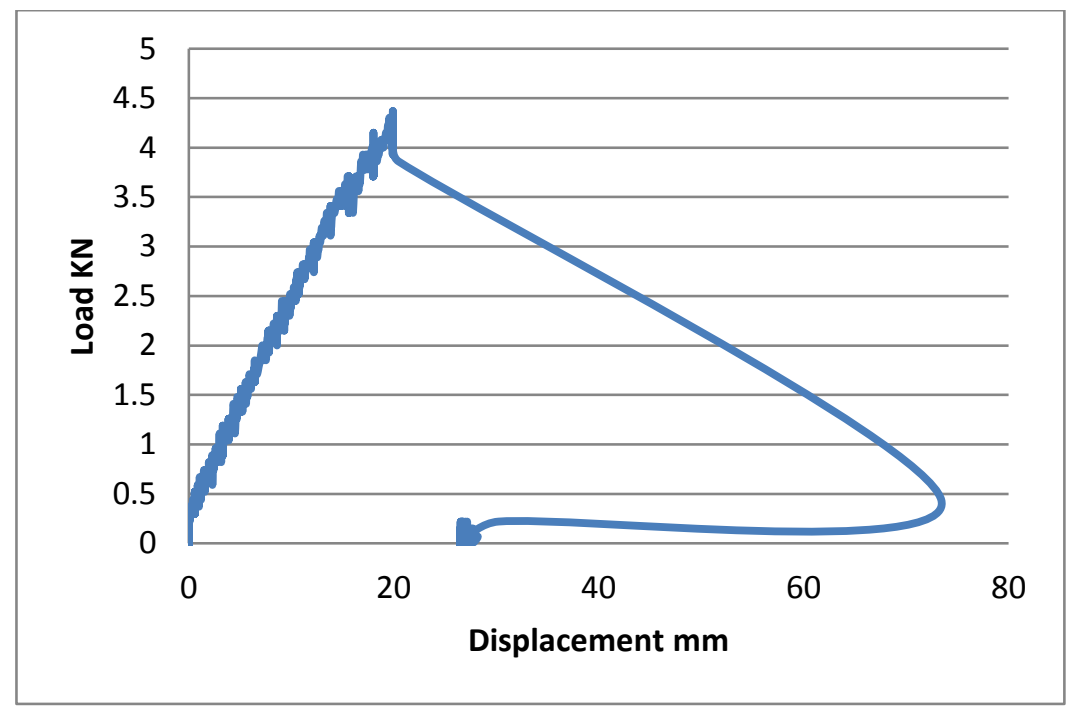

Figure 4.24- Flexural load displacement behaviour of wall

\subsubsection{Strain Development Characteristics of Wall}

Load-strain responses at mid span of wall are presented in Figure 4.25. There was large increment of strain at early stage on the tension face of the wall with little increase in load. After that, there was steady increase of strain with the increase of load showing linear increment up to the peak load. In the compression face of the wall, load strain diagram was varying linearly up to the peak load. After failure, the load and strain suddenly drop down to zero from peak value in compression face and tension face.
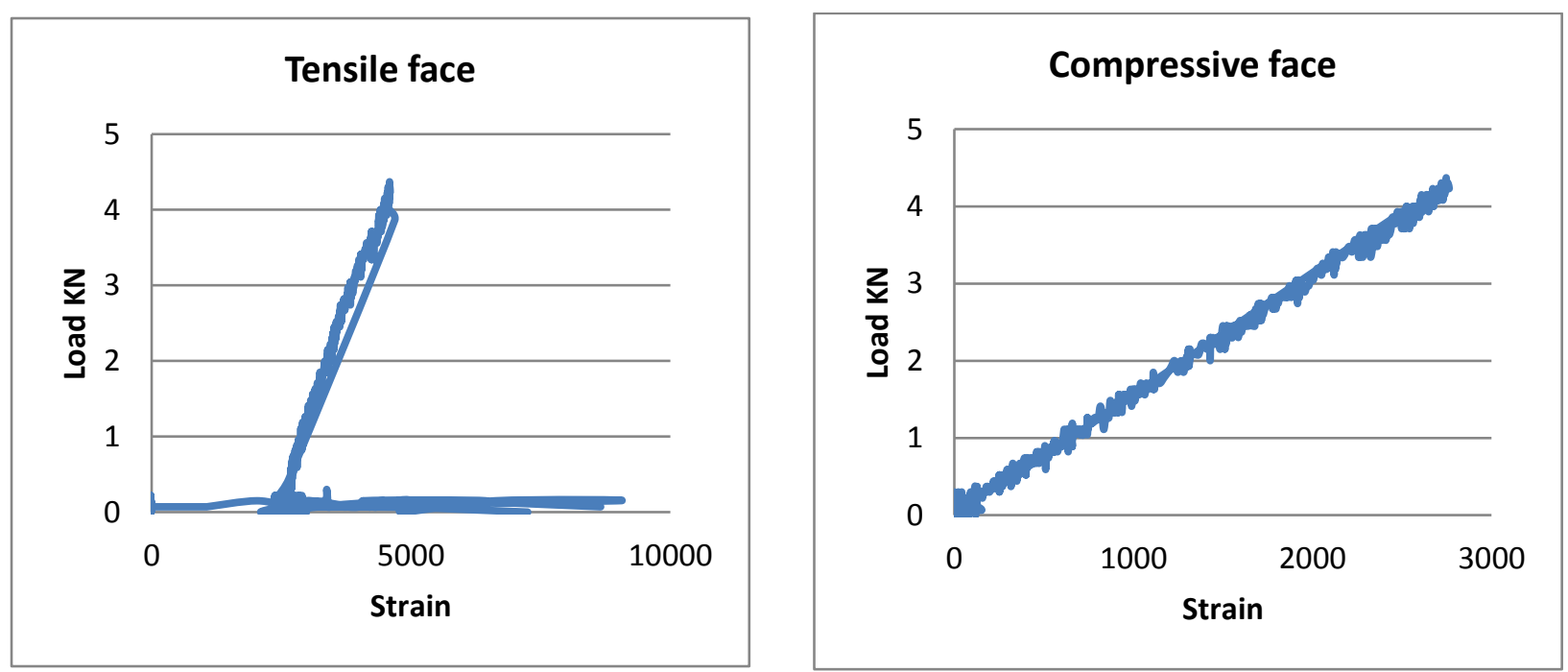

Figure 4.25 - Load strain behaviour of composite wall 


\section{CHAPTER 5}

\section{THEORETICAL AXIAL LOAD CAPACITY OF COMPOSITE WALLS}

\subsection{Introduction}

Chapter 5 presents the analytical methods for the calculation of load capacity of composite walling system and compare axial strengths of composite walls derived from experiments with those obtained from existing analytical equations presented in Chapter 2.

\subsection{Theoretical Calculation of Axial Strength}

The simplified and modified method of BS8110 for Profiled steel sheet composite wall (PSSCW) with concrete infill was used to find the axial load capacity of PSSCW and oriented strand board composite wall (OSSBCW) with commercial form material (CFM) infill.

\subsubsection{Profiled Steel Sheeting Composite Wall (PSSCW) with CFM Infill}

Maximum spacing between rows of connector $=275 \mathrm{~mm}$; Minimum thickness of wall $=25+2 * 0.76=$ $26.52 \mathrm{~mm}$; The height to thickness ratio of the wall $=(275 / 26.52)=10.36$ - since height to thickness ratio is less than 15, it can be considered as short wall; Cross-sectional area of form commercial material core $\left(A_{f}\right)=23028 \mathrm{~mm}^{2}$; Cylindrical compressive strength of commercial form material $\left(f_{c}\right)=0.61 \mathrm{MPa}$; Yield strength of steel $\left(f_{\mathrm{sy}}\right)=300 \mathrm{MPa}$; Cross-sectional area of steel sheeting $\left(A_{s}\right)=629.23 \mathrm{~mm}^{2}$ From Neville's equation (Neville 1981), cubical compressive strength (6 inch cube) can be obtained by following Eq. 5.1:

$$
\frac{f_{c}}{f_{c u}}=0.56+\frac{0.697}{\frac{V_{c}}{6 h_{c} d_{c}}+\frac{h_{c}}{d_{c}}}
$$

where, $V_{c}=$ volume of cylinder in cubic inch $=339.29$ inch $^{3} ; h_{c}=$ height of cylinder in inch = 12 inch; $d_{c}=$ diameter of cylinder in inch $=6$ inch;

Hence, cubical compressive strength of form material $\left(f_{c u}\right)=0.75 \mathrm{MPa}$.

According to simplified method, the total axial capacity of the composite wall $(\mathrm{N})$ is the sum of individual axial capacity of steel sheeting and concrete with reduction of $10 \%$ for the possibility of additional compressive bending stress caused by eccentric loading or the imperfection of wall. Thus the total axial load capacity of steel sheeting composite wall (N) as per Eq. 2.1 (described in Chapter 2): 


$$
N=0.6 f_{c u} A_{f}+0.87 f_{s y} A_{s}=0.6 * 0.75 * 23028+0.87 * 300 * 629.23=174.59 \mathrm{kN} .
$$

According to modified method, the equation of axial load capacity by simplified method is modified by introducing modification factor in concrete term for void formed by the profiling on the compressed edge of the wall and in steel term for the buckling of plate in contact with concrete. Axial load capacity of steel sheeting composite wall $(\mathrm{N})$ is can be derived based on Eq. 2.3 (described in Chapter 2):

$$
N=0.4 f_{c u} A_{C} \alpha+0.75 f_{s y} A_{s} \beta
$$

Where

$$
\text { Reduction factor }(\alpha)=1-\frac{D * P-A_{c p}}{2 A_{c p}}=1-\frac{101 * 152-11514}{2 * 11514}=0.83
$$

The ratio of width $(b)$ to thickness $(t)$ of the outer flange plate $=(19 / 0.76)=25$, Hence reduction factor $(\beta)=0.9 \quad$ (from Figure 2.6).

Hence, total axial load capacity (N) of PSSCW with CFM infill

$=0.4 * 0.75 * 23028 * 0.83+0.75 * 300 * 629.23 * 0.9=133.15 \mathrm{kN}$.

\subsubsection{Oriented Strand Board Composite Wall (OSBCW) with CFM Infill}

For these walls, maximum spacing between rows of connector $=420 \mathrm{~mm}$; Minimum thickness of wall = $30+2 * 6.35=42.7 \mathrm{~mm}$; The height to thickness ratio of the wall $=(420 / 42.7)=9.83-$ since height to thickness ratio is less than 15 , it can be considered as short wall.

Axial load capacity of oriented strand board composite wall $(\mathrm{N})$ is calculated based on the sum of individual capacity of oriented strand board and commercial form material using simplified method using $N=0.67 f_{c u} A_{f}+f_{t} A_{o} ;$ Where cross-sectional area of commercial form material core $\left(\mathrm{A}_{\mathrm{f}}\right)=9300 \mathrm{~mm}^{2}$; Cubical compressive strength of form material $\left(f_{c}\right)=0.75 \mathrm{MPa}$; Tensile strength of oriented strand board $\left(f_{t}\right)=9.38 \mathrm{MPa}$; Cross-sectional area of oriented strand board $\left(A_{\circ}\right)=3937 \mathrm{~mm}^{2}$.

Hence axial load capacity $(\mathrm{N})=0.67 f_{c u} A_{f}+f_{t} A_{o}=0.67 * 0.75 * 9300+9.38 * 3937=41.60 \mathrm{kN}$. 
Table 5.1 Comparison of experimental value with analytical value of profiled steel sheet composite wall

\begin{tabular}{|l|c|c|c|c|c|}
\hline \multirow{2}{*}{$\begin{array}{l}\text { Specimen } \\
\text { no }\end{array}$} & \multicolumn{3}{|c|}{ Ultimate load (kN) } & \multicolumn{2}{c|}{ Ultimate load ratio } \\
\cline { 2 - 5 } & Experimental & Simplified & Modified & $\begin{array}{l}\text { Ratio of } \\
\text { experimental } \\
\text { to simplified }\end{array}$ & $\begin{array}{l}\text { Ratio of } \\
\text { experimental } \\
\text { to modified }\end{array}$ \\
\hline Wall 1 & 95 & 174.59 & 133.15 & 0.54 & 0.71 \\
\hline Wall 2 & 78.67 & 174.59 & 133.15 & 0.45 & 0.59 \\
\hline Wall 3 & 72.12 & 174.59 & 133.15 & 0.41 & 0.54 \\
\hline Wall 4 & 71.25 & 174.59 & 133.15 & 0.41 & 0.54 \\
\hline
\end{tabular}

Table 5.2 Comparison of experimental value with analytical value oriented strand board composite wall

\begin{tabular}{|c|c|c|c|}
\hline \multirow[t]{2}{*}{ Specimen no } & \multicolumn{2}{|c|}{ Ultimate Load (kN) } & \multirow{2}{*}{$\begin{array}{c}\text { Ratio of experimental } \\
\text { ultimate load to } \\
\text { theoretical ultimate } \\
\text { load }\end{array}$} \\
\hline & Experimental & Theoretical & \\
\hline Wall 5 & 58.5 & 41.60 & 1.41 \\
\hline Wall 6 & 40.17 & 41.60 & 0.97 \\
\hline Wall 7 & 33.84 & 41.60 & 0.81 \\
\hline Wall 8 & 31.75 & 41.60 & 0.76 \\
\hline
\end{tabular}

\subsection{Analysis of Theoretical and Experimental Axial Load Capacity of Composite Wall}

Tables 5.1 and 5.2 compares the axial capacities of PSSCW and OSBCW with CFM infill derived from experiments and analytical equations. It should be remembered that the theoretical capacity of composite walls are derived based short wall assumption and hence, theoretical equations over predicted axial load capacity and over prediction increased with the increase of slenderness (height to width ratio) and connector spacing to wall height ratio from wall 1 to wall 4 (PSSCW) and wall 5 to wall 8 (OSBCW) as presented in Figures 5.1 and 5.2. Modified method produced lower axial strength for PSSCW walls compared to simplified method and hence reduced over prediction.

As explained before, the theoretical axial load capacity of the wall is based on the short wall with full interaction assuming compression failure rather than buckling. However the axial load capacity of the wall is affected by height to width ratio and connector spacing to height ratio which was seen from experimental axial load capacity of the walls. It was observed from the experimental test that the axial load capacity decreases with increase of height to width ratio and connector spacing to height ratio. The use of commercial form material significantly increased the interaction factor. Experimental load 
capacity of PSS composite walls is lesser than the theoretical capacity due to the local buckling and that of oriented strand board composite walls due to overall buckling. The performance of the theoretical models depends on the failure modes which are affected by height to width ratio and connector spacing to width ratio.
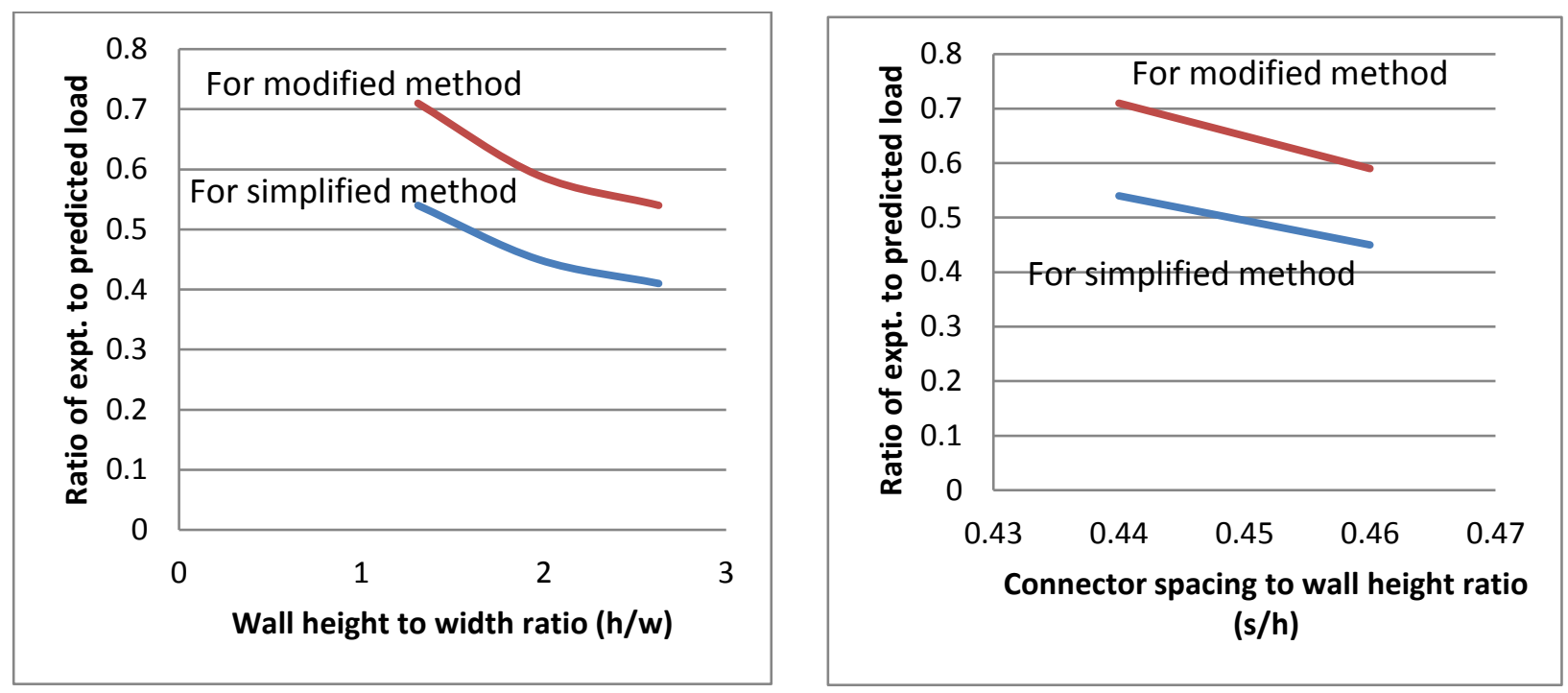

Figure 5.1- Ratio of expt. to predicted load for profiled steel sheet wall with commercial form material infill
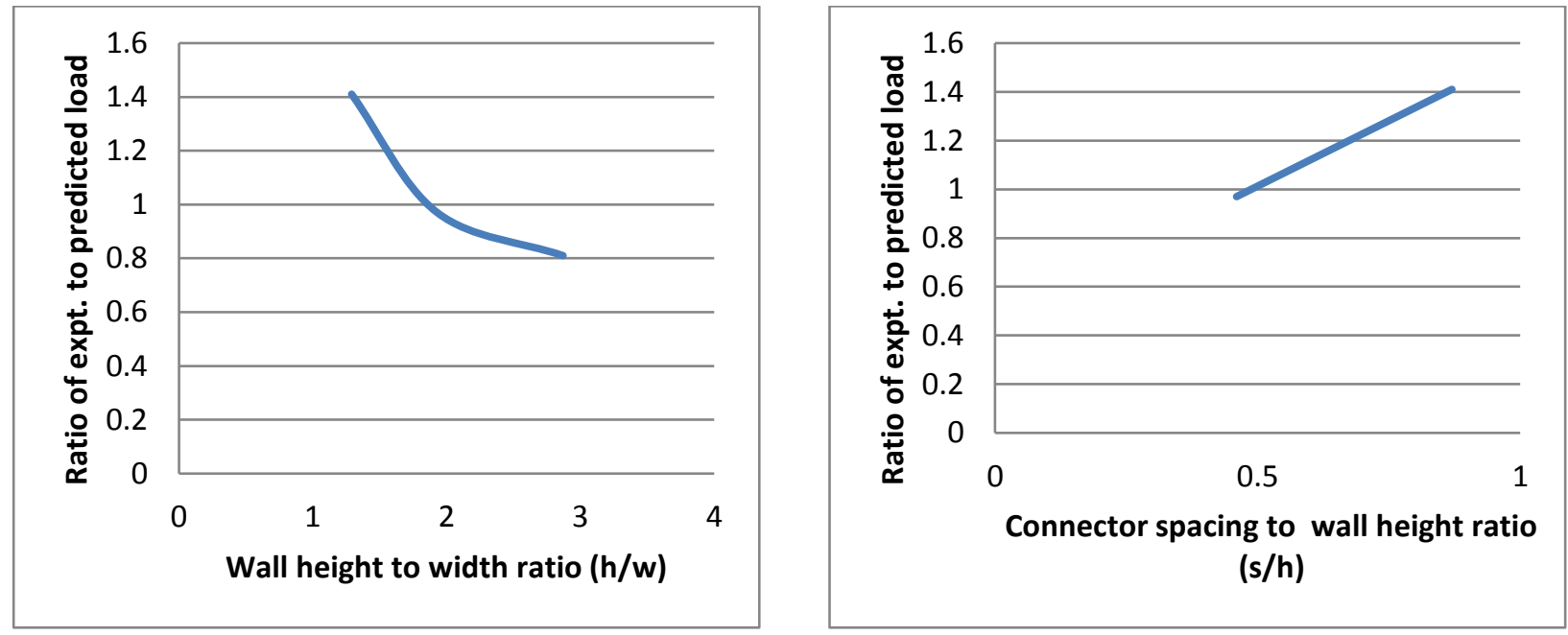

Figure 5.2- Ratio of expt. to predicted load for oriented strand board wall with commercial form material infill 


\section{CHAPTER 6}

\section{CONCLUSIONS AND RECOMMENDATIONS}

\subsection{Conclusions}

This experimental and theoretical research involved two sets of sandwich composite walling system made of two outer skins of profiled steel sheet (PSS) or oriented strand board (OSB) with a lightweight fast setting commercial form material (CFM) infill connected by mechanical connectors. This research mainly focused on the axial load behaviour of profiled steel sheet composite wall (PSSCW) and oriented strand board composite wall (OSBCW) with CFM. In addition, flexural behaviour of OSBCWs and thermal behaviour of both OSBCWs and PSSCWSs with CFM had also been investigated. Axial and flexure behaviour of such walls were studied based on strength, load displacement response, load-strain response and failure modes in addition to understand the influence of height to width ratio and spacing of rows of connectors to height ratio (controlling interaction of between PSS or OSB and CFM). Axial strength of composite walls derived from experiments is compared with those obtained from exiting analytical equations. The following conclusions are drawn from the study:

- The experimental axial load capacity of PSSCWs was affected by local buckling and steel-CFM interface bond while overall buckling and OSB-CFM interface bond seemed to influence OSBCWs. Interface bond between CFM and profiled steel sheeting or oriented strand board was unable to distribute the axial load throughout the height of the wall.

- Compressive axial strain was found to increase from top to bottom in for wall with low slenderness (height to width ratio) and low connector spacing indicating adequate load transfer in such walls. Axial load transfer capacity decreased with the increase of height of the wall or height to width ratio and connector spacing to height ratio.

- The presence of CFM infill significantly increased the axial load carrying capacity of both PSSCWs and OSBCWs. The axial load caring capacity of wall with CFM infill increased by $946 \%$ to $1714 \%$ compared walls without in-fill. This increase was attributed to the presence of infill CFM that enhanced stiffness/confined strength of CFM, buckling capacity of OSB/PSS and overall stiffness/strength of composite system.

- The axial load carrying capacity of composite walls decreased with the increase of height to width ratio and connector spacing to height ratio. The axial load carrying capacity of PSSCW 
decreased by $17.2 \%$ when height to width ratio was increased from 1.32 to 1.97 . On the other hand, the axial load capacity of OSBCW decreased by $15.76 \%$ when height to width ratio was increased from 1.93 to 2.87 .

- The experimental axial strengths of both PSSCWs and OSBCWs were lower compared to those obtained based on existing theoretical equations. Theoretical equations over predicted axial load capacity and over prediction increased with the increase of slenderness (height to width ratio) and connector spacing to wall height ratio.

- Temperature-time development across the depth suggested that OSBCW with CFM infill was less thermal conductive than its PSSCW counterparts.

- Flexural load-deformation response of OSBCW with CFM infill showed linear behaviour up to peak load. Post-peak response was characterized by sudden drop in load followed by a gradual drop till failure.

- Composite walls with CFM infill have potential to meet the modern building construction demands, particularly when lightweight, heat insulation, economical and faster constructions are considered as priorities. However, such walls use as load bearing wall elements depends on the magnitude of load transferred to the wall in the building system.

\subsection{Recommendations for Future Studies}

The following recommendations are suggested for the future research works:

- The analytical models in this research were based on the models developed for composite wall with concrete infill. However commercial form material (CFM) may behave differently than concrete. So it is important to conduct further research to develop analytical models for composite walls incorporating commercial form material as infill.

- Further investigations are to be conducted on thermal and insulating properties of commercial form material itself and composite walls to study energy saving prospective in modern building construction.

- Investigations can be made on short and long-term behaviour of composite walls with commercial form material infill subjected to various environmental loading conditions followed by axial and bending loading conditions. 
- Axial and bending behaviour of composite walls with different connector spacing for different types of profiled sheet and oriented strand board are to be investigated.

- The interaction of commercial form material with different kind of profiled sheet and oriented strand board is to be investigated.

- Research should be conducted to establish the code based design procedure for composite wall with commercial form material infill. 


\section{REFERENCES}

Akram M. (2014), "Behaviour of Composite Framed Shear Wall System”, M.Sc. Thesis, Civil Engineering Dept., Ryerson University, 129p.

ASTM C39 (2012), "Standard Test Method for Compressive Strength of Cylindrical Concrete Specimens", Annual Book of ASTM Standards, West Conshohocken, Pennsylvania, U.S.

ASTM E8 (2011), "Standard Test Method for Tension Testing of Metallic Materials", Annual Book of ASTM Standards, West Conshohocken, Pennsylvania, U.S.

Badaruzzaman W.H., Ahmed E. and Rashid A.K. (1996), "Behaviour of Profiled Steel Sheet Dry Board System", CIB W89 International Conference, 21-24 October, Beijing, China.

Benayoune A.G. and Wan Badaruzzaman W.H. (2000), "Limit State Behaviour of Profiled Steel Sheeting Dry/Board Wall Panel", Proceeding of the $4^{\text {th }}$ Asia-Pacific Structural Engineering \& Construction Conference (APSEC), Malaysia, p. 39-46.

Bradford M.A., Wright H.D. and Uy B. (1998), "Short and Long Term Behaviour of Axially Loaded Composite Walls", Journal of Structures and Buildings, ICE, Vol. 128, No. 1, p. 26-37.

Hossain K.M.A. (2000), “Axial Load Behaviour of Pierced Profiled Composite Walls", IPENZ Transactions, Vol. 27, No 1/civ., p. 1-7.

Hossain K.M.A., Mol L.K. and Anwar M.S. (2015), "Axial Load Behaviour of Pierced Profiled Composite Walls with Strength Enhancement Devices", Journal of Constructional Steel Research, Vol. 110, No. 1, p. 48-64.

Hossain K.M.A. and Wright H.D. (2003), "Experimental and Theoretical Behaviour of Composite Walling under In-plane Shear", Journal of Constructional Steel Research, Vol. 60, No. 1, p. 59-83.

Hossain K.M.A. and Wright H.D. (2004), "Performance of Double Skin Profiled Composite Shear WallsExperiments and Design Equations", Canadian Journal of Civil Engineering, Vol. 31, No. 2, p. 204-217.

Hossain K.M.A. and Wright H.D. (1998), "Performance of Profiled Concrete Shear Panel", Journal of Structural Engineering, Vol. 124, No. 4, p. 368-381. 
Hossain K.M.A., Rafiei S., Lachemi M., Behdinan K. and Anwar M.S. (2013), "Finite Element Modeling of Double Skin Profiled Composite Shear Wall System Under In-plane Loadings", Engineering Structures, Vol. 56, No. 1, p. 46-47.

Hossain K.M.A., Rafiei S., Lachemi M. and Behdinan K. (2016), "Structural Performance of Profiled Composite Wall under In-plane Cyclic Loading", Engineering structures, Vol. 110, No. 1, p. 88-104.

Mydin M.A.O. and Wang Y.C. (2011), "Structural Performance of Lightweight Steel-foamed Concretesteel Composite Walling System under Compression", Thin-Walled Structures, Vol. 49, No. 1, p. 6676.

Neville A. M. (1981), “Properties of concrete”, London: Pitman, Third edition, p. 529-604.

Salma S. (2012), "Axial Load Behaviour of Profiled Steel Sheet Dry Board (PSSDB) Walling System”, MEng Project, Civil Engineering Dept., Ryerson University, 65 p.

Taormina A. (2012), "Axial Load Behaviour of Double Skin Composite Walls Subjected to Elevated Temperatures", M.Sc. Thesis, Civil Engineering Dept., Ryerson University, 159 p.

Wright H. (1998), "The Axial Load Behaviour of Composite Walling", Journal of Constructional Steel Research, Vol. 45, No. 3, p. 353-375.

Wright H. (1998), "Axial and Bending Behaviour of Composite Walls", Journal of Structural Engineering, Vol. 124, No. 7, p. 758-764.

Wright H.D., Gallocher S.C. (1995), "The Behaviour of Composite Walling under Construction and Service Loading", Journal of Constructional Steel Research, Vol. 35, No. 3, p. 257-273. 